\title{
Magma Genesis, Plate Tectonics, and Chemical Differentiation of the Earth
}

\author{
Peter J. Wyllie
}

Division of Geological and Planetary Sciences, California Institute of Technology, Pasadena

\begin{abstract}
Magma genesis, migration, and eruption have played prominent roles in the chemical differentiation of the Earth. Plate tectonics has provided the framework of tectonic environments for different suites of igneous rocks and the dynamic mechanisms for moving masses of rock into melting regions. Petrology is rooted in geophysics. Petrological and geophysical processes are calibrated by the phase equilibria of the materials. The geochemistry of basalts and mantle xenoliths demonstrates that the mantle is heterogeneous. The geochemical reservoirs are related to mantle convection, with interpretation of a mantle layered or stratified or peppered with blobs. Seismic tomography is beginning to reveal the density distribution of the mantle in three dimensions, and together with fluid mechanical models and interpretation of the geoid, closer limits are being placed on mantle convection. Petrological cross sections constructed for various tectonic environments by transferring phase boundaries for source rocks onto assumed thermal structures provide physical frameworks for consideration of magmatic and metasomatic events, with examples being given for basalts, andesites, and granites at ocean-continent convergent plate boundaries, basalts and nephelinites from a thermal plume beneath Hawaii, kimberlites in cratons, nephelinites from continental rifts, and anorogenic granites. The fluid dynamics of rock-melt-vapor systems exerts strong control on igneous processes and chemical differentiation. Unravelling the processes during subduction remains one of the major problems for understanding mantle heterogeneities and the evolution of continents.
\end{abstract}

\section{INTRODUCTION}

The Union Lecture on which this review is based was presented on behalf of the International Association for Volcanology and the Chemistry of the Earth's Interior (IAVCEI). It was an over-illustrated, somewhat superficial ramble through the whole Earth emphasizing volcanic activity, the more dramatic aspects of the Earth's chemical differentiation. I have been charged by President Lal of the International Union of Geodesy and Geophysics (IUGG) to prepare the review more or less along the lines of the lecture, without writing the book and compiling the enormous list of references required to do formal justice to all these topics. The list of references cited is admirably supplemented by the comprehensive bibliographies provided in the U.S. National Report to the IUGG for 1983-1986, published in Reviews of Geophyics (volume 25, numbers 2, 3, 5, and 6, 1987).

Volcanoes have played a significant role in the development of geology since Abraham Werner at the beginning of the last century concluded that all rocks were formed by precipitation from an ocean, with volcanoes being simply local phenomena caused by burning coal seams. The challenge by James Hutton, who concluded that magmas were formed by the internal heat of the Earth, began the study of volcanoes as the overflow edifices for plutonic magma reaching the surface. Most people who have stood and listened and sniffed at the rim of Aetna or any other active volcano can easily be persuaded that the sounds and smells emanate from the bowels of the Earth and that volcanism is the outward and visible sign of deep internal processes, of mantle convection, and of the chemical differentiation of the Earth.

Volcanoes are beautiful structures, but ephemeral in geological time, and the progressive exposure of the deep-seated plutons feeding volcanoes provides a more detailed history of

Copyright 1988 by the American Geophysical Union.

Paper number 8R0242.

8755-1209/88/008R-0242\$05.00 the magmatic processes occurring nearer the source of magma generation. There remains a gap between volcanoes, their plutonic roots, and the magma sources which has to be filled by indirect studies including geophysics, geochemistry, and fluid dynamics. Lavas reach the surface through volcanoes, and lavas can provide information about the source rocks from which they were derived if the materials and processes can be suitably calibrated in the laboratory. The calibration involves the geochemistry of major, minor, and trace element distributions (including isotopes) between minerals and melts and the conditions for melting of the various source materials under various conditions. Some lavas also bring to the surface samples of the host rocks from which they were derived by partial melting or of the rocks through which they rose. The lavas release gases to the atmosphere and hydrosphere which also provide clues about the nature of the source material at depth.

The theme common to the different parts of this review relates to the conditions for melting, transfer, storage, and eruption of melts. The approach is as follows. Plate tectonics provides a framework of tectonic environments and internal processes, which can be calibrated by laboratory experiments at high pressures. Within this framework I next outline the development of ideas on mantle convection and the contributions from geochemistry that identify the separate chemical reservoirs yielding basalts. This approach is complemented by seismic tomography, which is beginning to provide threedimensional pictures of motions in the mantle. The subduction process and the role of volatile components lead to further differentiation of the Earth and to the formation of continents associated with a variety of igneous rocks. Constraints for the conditions of melting are provided by thermal structures and the calibrations from experimental petrology. After reviewing some critical phase relationships of magmas and source rocks and recapitulating models of mantle convection, $I$ then consider magmatic processes in selected plate tectonic environments: basalts at divergent plate boundaries, andesites and batholiths 


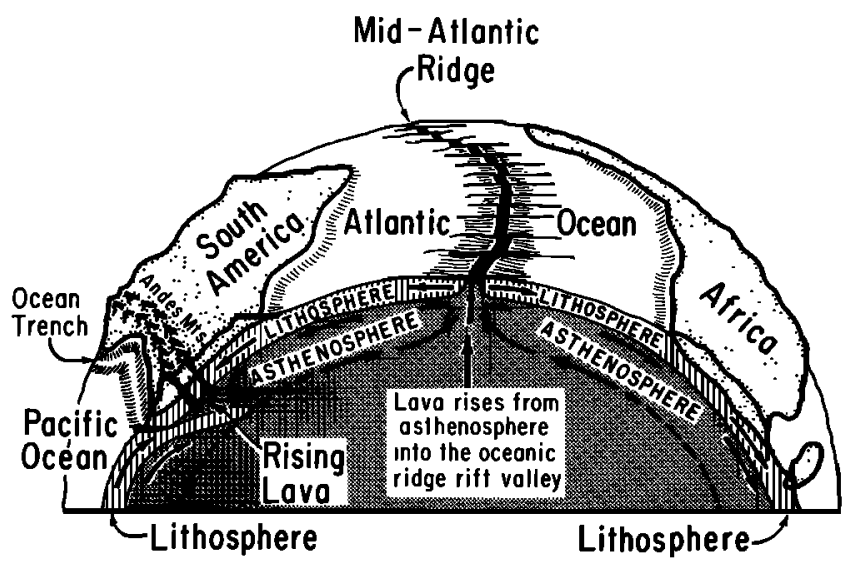

Fig. 1. Outline of plate tectonics, vintage late 1960 s.

at subduction zones, ocean island lavas and anorogenic granitoides associated with mantle plumes, and the subsilicic kimberlites that puncture continental plates. Unravelling the processes during subduction remains one of the major problems for understanding both the origin and evolution of the continents and the heterogeneities in mantle reservoirs.

\section{Magma Genesis and Plate Tectonics}

The main variables to be considered in magma genesis are (1) the compositions of materials, including both the sources of magmas and the magmatic products (the mineralogy is dependent on the other variables), (2) the pressure or equivalent depth, and (3) the temperature. These variables can be controlled in laboratory experiments, providing a static framework of phase boundaries for the Earth materials. The Earth is a dynamic system, and changes through time exert a strong influence on processes. Magmas are generated (1) when bodies of rock are transported across the depth-temperature limits of melting curves by physical convection, (2) through temperature increase arising from tectonic conditions, or (3) by depression of melting boundaries to lower temperatures by influx of volatile components or by change in oxidation state of volatile components with subsequent lowering of the solidus. Physical processes such as mantle convection transport masses of material across phase boundaries and cause chemical transformations. The flow of fluids through rocks transports heat and material and changes bulk composition, causing chemical differentiations. Temperature changes as a function of process occurring, and therefore as a function of time. Time available for reactions also influences the extent to which equilibrium is attained in reacting systems of rockmagma-vapor.

Figure 1 is a simple version of the theory of plate tectonics as it was presented in the late 1960 's. There are large, rigid lithosphere plates migrating across the surface of the Earth, separated along boundaries where adjacent plates are in motion relative to each other. Uprise of mantle is associated with midoceanic ridges, and sinking of lithosphere and mantle is associated with convergent plate boundaries. Convection within the mantle is implied. We can add to this thermal plumes bringing deep material upward to the plates. Deeper down, we have the interactions that must occur between core and mantle providing other heat and material exchanges, and probably initiating vertical processes within the mantle. Plate tectonics has provided an excellent framework for studying magma generation and volcanoes, and the framework has changed the way we consider magmatic processes. Among the more significant change are the following: (1) it provides a framework of tectonic environments within which different suites of igneous rocks can be located, a framework long sought by petrologists; (2) it provides a dynamic mechanism for moving masses of rock up and down within the Earth, changing pressure and temperature, causing partial melting, and therefore initiating magmatism; (3) it provides a broader view of igneous petrology in terms of the chemical differentiation of the Earth instead of the preoccupation with the diversity of igneous rocks; (4) it has changed the subject from descriptive petrography and philosophical petrogenesis to a study of processes and products firmly rooted in geophysics; (5) it involves processes that can be calibrated in part by laboratory experiments at high pressures and temperature; and (6) it provides a mechanism for recycling crustal rocks and volatile components back into the mantle, thus generating volatile fluxes that redistribute elements at depth.

\section{Tectonic Environments and Petrographic Associations}

Figure 1 shows the main tectonic environments: (1) divergent plate boundaries, (2) convergent plate boundaries, (3) oceanic plates, and (4) continental plates. These may be subdivided. Divergent plate boundaries include (1 A) oceanic ridges and (1B) continental rift systems. Convergent plate boundaries include (2A) ocean-ocean, (2B) ocean-continent, and (2C) continent-continent boundaries. Oceanic plates may be (3A) stable or (3B) flowing across a hot spot. Continental plates include, in addition to rift zones, (4A) stable platform or crations, (4B) continents moving across a hot spot, and (4C) passive margins.

There are many different kinds of igneous rocks and petrographic associations, but in this review we will consider only a selection, the basalts occurring in environments 1 and $3 \mathrm{~B}$; the andesites, rhyolites, and granitoid batholiths characteristic of environments $2 B, 2 C$, and $4 B$; the kimberlites of environment $4 A$; nepheline-normative basic lavas of environments $1 B$ and 3B; and carbonatites of environment $1 \mathrm{~B}$.

\section{Chemical Differentiation of the Earth}

The first chapter of Bowen's [1928] book was entitled "The Problem of the Diversity of Igneous Rocks." This was considered to be the primary task of igneous petrology. Bowen accepted as a fundamental thesis the parental nature of basalt and the derivation of other igneous rock types from basalt by fractional crystallization. He found "the most likely source of basaltic magma in the selective fusion of a portion of the peridotite layer." These statements are acceptable today, but they are not sufficient. Sources other than mantle peridotite can yield magmas, and processes other than fractional crystallization of basalt are influential in the derivation of some igneous rocks. Petrologists today are more concerned with the complementary relationship between magmas and source rocks, viewing igneous petrogenesis as one approach to the interpretation of the chemical differentiation of the Earth. Differentiation of magma occurs after it is separated from its source, and the chemical and mineralogical changes following this separation construct screens between observed magmatic product and inferred source rock. Geochemists, petrologists, and experimental petrologists work to unravel the paths in order to see through those screens. 
The Earth is differentiated into core, mantle, crust, hydrosphere, and atmosphere, with the biosphere concentrated in the boundary layers between crust and the fluid envelopes. The major differentiation was accomplished through magmatic processes. Figure 2 compares estimated average compositions for the core, mantle, and crust. The iron-nickel core contains light elements, with sulfur or oxygen being the main candidates. More than $90 \%$ by weight of the mantle is represented by the components $\mathrm{MgO}-\mathrm{FeO}-\mathrm{SiO}_{2}$. The crust is enriched in $\mathrm{Si}, \mathrm{Al}, \mathrm{Ca}, \mathrm{Na}$, and $\mathrm{K}$, with $\mathrm{Mg}$ being left behind in the solid mantle when partial melting occurs. The mantle and crust are both heterogeneous. Heterogeneities are produced in mantle peridotite by partial melting and extraction of melt, passage, or emplacement of melt through or in mantle regions removed from the melt source, by the action of metasomatizing fluids, and by the recycling of crustal materials through convergent plate boundaries. Magmatic processes during the growth of the Earth may have have accompanied by the formation of a magma ocean causing differentiation of the average composition of Figure 2 into two distinct rock types, peridotite and piclogite (see Figure $4 c$ ).

Magmatic processes are also responsible for the diversity of igneous rock types within the crust. The extreme chemical differentiation occurring within the thin veneer of sediments that blankets the solid surface was accomplished by weathering and transportation and redeposition of material by interaction between the fluid envelopes and the solid surface. Water and other fluid components also played an important role in the extreme geochemical concentrations associated with the formation of ore deposits, either with igneous rocks or within sedimentary bodies. Igneous petrology thus involves the chemical differentiation of the Earth, and the mantle is thus an essential part of igneous petrology. There is growing evidence that physical and chemical interactions between solids and fluids (melts and vapors) are important in deep crust and mantle, as well as in the more obvious convection cells associated with plutons, and within the oceanic crust.

\section{Geophysical Roots of Volcanism}

Petrology is rooted in geophysics. The mantle is the source of all good things. It is the dynamics of the mantle that moves lithosphere plates causing plate interactions associated with specific petrographic associations, initiating magma generation within the mantle or within subducted oceanic crust or within the continental crust through upward transfer of heat and material. It is the thermal evolution of the Earth and the consequent movement of material that controls petrological processes.

Seismology has been the major source of information about the Earth's interior, and fruitful developments have been achieved by cross fertilization between seismology, experimental petrology and phase equilibria, and mineral physics. Increasingly precise seismic data are producing more information about the structure of the mantle. High-resolution velocity profiles have been determined for various tectonic provinces. The lithosphere overlies a low-velocity zone commonly correlated rather loosely with the asthenosphere. There are discontinuities at depths of about 200,400 , and $650 \mathrm{~km}$. There is some evidence suggesting that between ocean basins and continental shields, thermal or compositional differences or both persist to depths of at least $400 \mathrm{~km}$. Travel times of $S$ waves from deep-focus earthquakes to oceanic islands are about $5 \mathrm{~s}$ later than the times to continental stations, suggest-

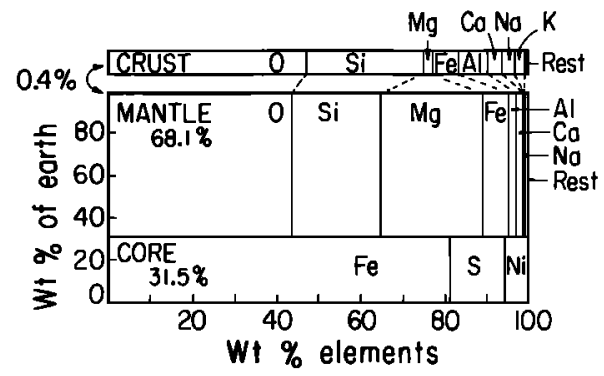

Fig. 2. Average chemical compositions of core, mantle, and crust. See $W$ yllie [1981] for data sources. Oxygen is now a candidate for the light element in the core.

ing that the lithosphere plates that transport drifting continents may be $400 \mathrm{~km}$ thick beneath the continental shields. Other seismologists conclude that systematic continent-ocean differences do not appear to extend below 200-km depth. The low-velocity layer beneath the East Pacific Rise, however, does extend as deep as $400 \mathrm{~km}$. The ratio $V_{p} / V_{s}$ cannot be explained by changes in chemistry or temperature alone, and at least in the upper $200 \mathrm{~km}$ partial melting is believed to be involved; the difference in properties extending to $400-\mathrm{km}$ depth may be caused by material rising to generate the mid-ocean ridge basalts.

The velocity gradients between 400 and $650 \mathrm{~km}$ are higher than expected for a homogeneous self-compressed region. The $650-\mathrm{km}$ discontinuity is a good reflector of seismic energy, requiring that its width be less than $4 \mathrm{~km}$. Another significant observation is that no earthquake foci occur deeper than 700 $\mathbf{k m}$. The changes in physical properties located by seismology must be explained in terms of either chemical composition or phase changes, solid-solid transformations, or melting reactions.

We are on the verge of dramatic increase in our understanding of the Earth's interior, based on improved seismic techniques, improved computers, and the deployment of new digital seismic arrays. Three-dimensional mapping of the interior is progressing rapidly with techniques similar to medical tomography being used for imaging with seismic body waves and surface waves. This represents a dramatic breakthrough in solid Earth physics and chemistry, as discussed in more detail below.

\section{Calibration at High Pressures} and Temperatures

The classical approach to petrology is to study rocks at the surface, analyze them in detail, and develop hypotheses about what happened down below. A basic tool is the geological hammer, and the petrologist attacks mountains of rock with a small piece of steel. This approach is now supplemented by the experimental approach, calibrating at high pressures in the laboratory the reactions expected to occur at depth. In the experimental approach the petrologist takes a small sample of mineral or rock and crushes it together with a furnace in a massive steel press. For even higher pressures, a more delicate approach is adopted using even smaller samples squeezed between two minute diamond anvils, heated by laser. If these approaches fail to achieve the required conditions, the more drastic approach of shock-wave experiments is adopted and the sample is blasted, yielding its secrets only during the last hot nanoseconds of its existence [e.g., Williams et al., 1987].

With the calibrations of laboratory experiments on suitable 


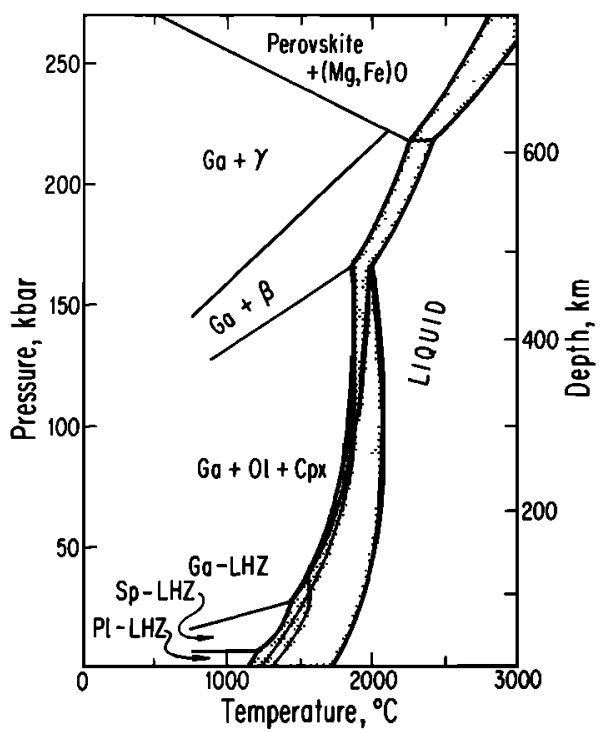

Fig. 3. Experimentally determined phase diagram for peridotite [Takahashi, 1986]. Abbreviations: LHZ, lherzolite; Pl, plagioclase; $\mathrm{Sp}$, spinel; $\mathrm{Ga}$, garnet; Ol, olivine; $\mathrm{Cpx}$, clinopyroxene; $\boldsymbol{\beta}$ and $\gamma$ are high-pressure polymorphs of olivine. The stippled band is the melting interval.

materials at high pressures and temperatures, we hope to produce a static picture of the structure of the mantle, with composition and mineralogy matching the measured physical properties. The interesting geophysical and petrological processes, however, involve a dynamic mantle, and knowledge of the structure is incomplete without information on mantle convection. Inferences about convection are related to the distinct chemical reservoirs required by interpretation of the geochemistry of basalts, and the general problem is further compounded by the invocation of mantle metasomatism to adjust mantle geochemistry to fit the observations in lavas. There is a large variety of igneous rocks representing a variety of processes occurring within the upper mantle and crust. These too are calibrated by experimental studies on suitable materials under appropriate conditions.

The phase relationships of mantle peridotite are reviewed below, but Figure 3 is presented here as an example of the experimental calibration of the mantle or of that part of it composed of peridotite, specifically lherzolite. There are subsolidus phase changes involving increases in density with increasing pressure, and at pressures corresponding to a depth of about $650 \mathrm{~km}$, where there is a seismic discontinuity, it appears that most mantle components find a comfortable home in the mineral structure of perovskite. The solidus curve for the beginning of melting is the most important phase boundary in connection with chemical differentiation of the Earth. The composition of the melt produced within the melting interval above the solidus varies as a function of pressure and temperature. A basic knowledge of the phase equilibria of mantle and crustal rocks is required in order to trace the generation of melts and their chemical differentiation as they move from high- to lower-pressure regimes.

One of the main features of this review is to present a sampling of the phase diagrams used to calibrate geophysical and petrological processes. Many of these diagrams are quite old and are generalized to cover general processes such as the partial melting of mantle or crust. Many of the more recent phase diagrams have been determined to place constraints on the origin of a particular rock, thus dealing with specific, more localized petrological problems. A recent report from the $\mathrm{Na}$ tional Academy of Sciences [Committee on Physics and Chemistry of Earth Materials, 1987] noted that the base of phase equilibrium data remains inadequate. Many of the phase equilibrium data in use to $30-40 \mathrm{kbar}$ are based on results obtained 10-20 years ago, when experimental difficulties were being discovered and sorted out and when microbeam instruments for analysis of products were inferior in comparison with those of today. Critical data on element distribution among phases are still fragmentary. On page 75 the report states: "The great tragedy of the present situation is that there is a general perception that such information is already well known." In fact, the lack of quantitative information "severely cripples all attempts to model accurately the chemical evolution of magmas during ascent." A glance ahead to Figure $33 a$ shows the range of results reported for the solidus of peridotite.

Figure 3 expands the data available for peridotite from 60 to $200 \mathrm{kbar}$, and recent work with the diamond anvil cell has provided information about melting in the lower mantle at pressures greater than $200 \mathrm{kbar}$ [Heinz and Jeanloz, 1987]. These represent significant advances for high-pressure calibration of mantle processes, but the authors of these new results will surely not be offended by the suggestion that in due course, these pioneering results will also need revision as the experimental problems are identified and corrected.

\section{Source Materials, Mantle Reservoirs, AND CONVECTION}

The bulk compositions of Earth, mantle, and crust provide important limits on petrological processes. More important are the compositions and mineralogies of the specific rocks constituting the mantle and crust. There are three major sources for igneous rocks, which constitute separate magmatic hearths: (1) the mantle, (2) subducted oceanic crust, and (3) continental crust. Each hearth is heterogeneous containing several rock reservoirs, but each has its distinctive geochemical characteristics. In fact, more than one source is commonly involved in magmatic processes, and the mantle also contains components recycled from sources (2) and (3). A great deal of attention has been directed toward distinguishing what proportions of a magma are derived from each of these sources and reservoirs, as part of the problem of working out the transfer of chemical elements from one reservoir to another, and the history of crustal growth [Allegre, 1987].

\section{Mantle Sources}

Cosmochemistry is an important approach to mantle composition giving information about the composition of the whole mantle, a somewhat fictitious average, primordial mantle [Wasserburg, 1987]. The approach is model dependent, requiring assumptions about the origin of the solar system. There are currently two significantly different interpretations of mantle mineralogy, involving the distribution of material within the mantle, with several variants.

Until the late 1970s, most models for the mantle were based on an average composition corresponding to peridotite, with chondritic trace elements [Ringwood, 1975]. The main exercise was to fit the major and minor elements into a suitable sequence of phase transitions to satisfy the seismic data on properties and discontinuities, although there were some 
challenges to the concept of a fairly uniform composition from core to crust, with proposals that the lower mantle has higher $\mathrm{Si} / \mathrm{Mg}$ ratio than the upper mantle. Interpretation of the rock compositions in terms of mantle compositions involves either mixing models involving basalt and residual peridotite to reconstitute pyrolite or attribution of the composition of the "most primitive, undepleted peridotite" to the composition of the whole mantle. Results in terms of major elements (Figure 2) are broadly consistent with the cosmochemical approach.

A new approach by Anderson [1983] is independent of the assumptions made in other petrological and cosmochemical approaches. He estimated the composition of the primitive mantle by mass balance calculations that do not make assumptions about basalt/peridotite ratios (pyrolite model) or the large ion lithophile (LIL) components of these components. Nor does the approach assume that $\mathrm{Rb} / \mathrm{Sr}, \mathrm{K} / \mathrm{U}$, and other ratios must be the same in crust as in mantle. Anderson treated the primitive upper mantle as a four-component system, involving crust, peridotite, LIL-depleted basalt midocean ridge basalt (MORB), and a LIL-enriched component. In order not to prejudge the major element chemistry of the mantle, two ultramafic components with different olivine/orthopyroxene are needed. Basalt is decomposed into a depleted component, MORB, and an enriched component with composition KIMB, an average kimberlite. The compositions of many basalts can be approximated by mixing the two components MORB and KIMB.

The equations solved by Anderson defined the weight fractions of each of the five components that yields chondritic ratios of the 18 refractory oxyphile elements. Element concentrations normalized to carbonaceous chondrite abundances show good agreement with the cosmochemical abundances. The results show extensively differentiated Earth and efficient upward concentration of the incompatible trace elements into the crust. Anderson [1983] therefore concluded that the whole mantle has contributed to upper mantle and crustal elemental abundances and that the lower mantle is depleted in the incompatible elements, including $\mathrm{K}, \mathrm{U}$, and Th. If this depletion occurred during the early differentiation of the Earth, it need not imply present-day communication between upper and lower mantle.

The observed or derived seismic and elastic properties for the Earth should be matched by the aggregate properties of the mineral assemblage at each depth. According to Anderson and Bass [1986], an olivine-rich mantle can be ruled out between $450-$ and $650-\mathrm{km}$ depth, whereas an eclogite mantle is permitted by the data. Both pyrolite and eclogite mineral assemblages satisfy the seismic properties between 200 - and $400-\mathrm{km}$ depth. The lower mantle has seismic properties consistent with $(\mathrm{Mg}, \mathrm{Fe}) \mathrm{SiO}_{3}$ in the perovskite structure.

\section{Geochemical Reservoirs}

Basalts and other magmas are derived from the mantle, and variations in trace elements and in particular the variations in isotopic compositions of $\mathrm{Nd}, \mathrm{Sr}, \mathrm{Pb}$, and rare gases indicate that there are distinct sources or reservoirs in the mantle that have remained geochemically distinct and therefore physically separate from each other. It has been demonstrated by geochemical studies that pervasive, long-lived chemical heterogeneities have persisted in the mantle on time scales of a billion years, and the exercise of mapping the heterogeneities in space and time remains a major objective of geochemistry, corre- lating with the geophysical efforts to map convection in the mantle.

Simple petrogenetic schemes related to the derivation of basalt by partial melting of peridotite fail to explain the abundances of trace elements associated with the major elements. The geochemistry of trace elements in many basalts appears to be decoupled from that of major elements. Basalts are said to be depleted, undepleted, or enriched in trace element concentration patterns, trace element ratios, or isotopic ratio signatures. No single definition of these terms can encompass all of the usages. For example, a low $\mathrm{Nd}$ isotope signature may accompany an enriched rare Earth element (REE) pattern. These descriptive geochemical terms are also assigned to the source regions of the basalts with a view to mapping mantle reservoirs. The term "depleted" is also used for major and minor elements or their ratios. A peridotite is said to be depleted in basaltic components by the extraction of basalt, giving the peridotite a higher $\mathrm{Mg} / \mathrm{Fe}$ raio. Peridotites from the mantle give us direct measurements of the chemistry of potential source rocks. Peridotite xenoliths in alkali basalts and kimberlites are described as depleted (or "barren" or "infertile," or "refractory") and "fertile," depending on their concentrations of basaltic components. They are also described as depleted or enriched according to their trace element and isotopic characteristics. A peridotite may be depleted in basaltic components yet enriched in some incompatible trace elements which should have been carried away by the basalt fraction.

The lack of correlation between isotopic composition and incompatible elements in many volcanic rocks is now commonly explained by metasomatic alteration of parts of the upper mantle. The mantle is said to have been metasomatized to the extent necessary to explain the geochemistry of the lava or nodule. Metasomatic fluids rich in LIL elements are assumed to have percolated upward through the mantle, enriching the peridotite by altering the clinopyroxene composition or by crystallizing new hydrous minerals and other minerals. The nature of the fluids is rarely defined, but recently the distinction between silicate melt and hydrous solution has been more consistently made. The effects of metasomatism in the mantle can be examined in samples from peridotite massifs and peridotite xenoliths. These include refractory rocks which nevertheless contain concentrations of compatible elements and light REE/heavy REE ratios greater than chondritic. The evidence for depletion of elements assigned to partial melting, followed by enrichment in trace elements in a subsequent metasomatic event, is well displayed.

Recent discoveries of significant variations in geochemistry and petrology of basalts on local scales support the concept of a mantle heterogeneous on a small scale. These topics were reviewed by Allère [1987], Carlson [1987], McCallum [1987], and Marsh [1987]. The geochemistry of basalts from an individual oceanic island may be distinguishable from that of basalts from other islands. Recent detailed bathymetric maps of the ocean ridge system have revealed tectonic and constructional features on the scale of a few meters, including a series of segmented ridge sections, each with a topographic high probably representing a volcanic center, with overlapping ridge axes, propagating ridge tips, and transform faults. There are significant geochemical and petrological differences among basalts associated with these local tectonic parts of the oceanic ridges, as well as along the ridges. The evidence suggests that mantle heterogeneities may persist on the scale of tens of ki- 


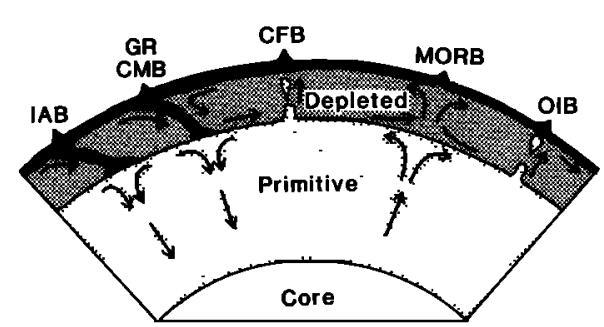

A. 2-LAYER CONVECTION

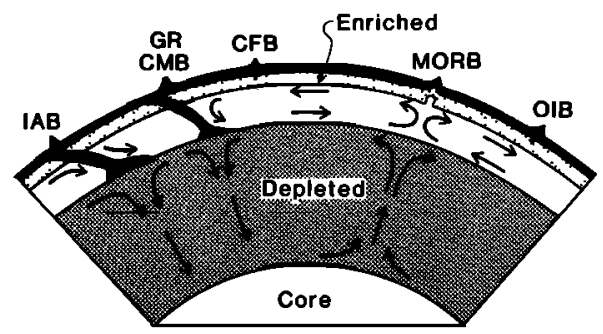

C. PICLOGITE LAYER

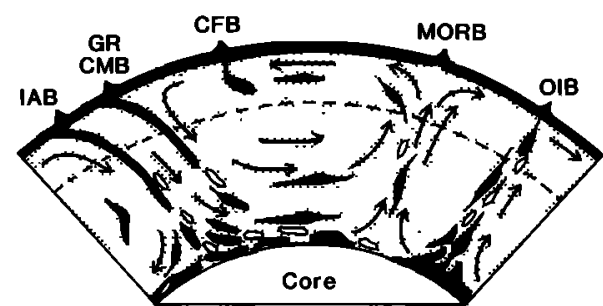

B. 1-LAYER CONVECTION

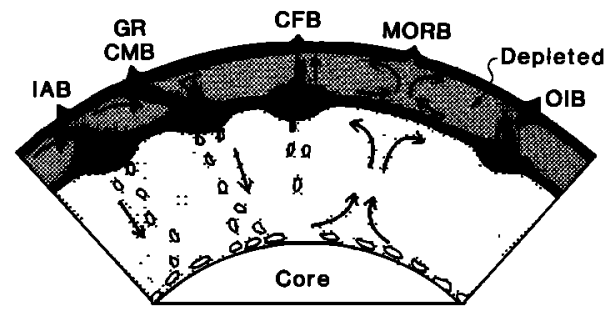

D. HARZBURGITE MEGALITHS

Fig. 4. Four contrasting models for mantle convection proposed mainly on the basis of geochemistry. See text for sources.

lometers beneath the ridges, and there is some evidence of metasomatically enriched regions under the ridges.

Allègre [1987] has presented a comprehensive treatment of the Earth as a system divided into several reservoirs, considering the Earth's behavior to be described as a set of distributions of chemical elements constantly modified by a set of operators which characterize the principal geological functions. Allègre has identified five distinct reservoirs on the basis of multi-isotope studies: (1) depleted and outgassed mantle, the source of MORB's; (2) metasomatized continental lithosphere, the source of continental flood basalts; (3) a mixed reservoir, the source of oceanic island basalts, containing portions of 1 and 2 above and subducted oceanic slab with crust and lithosphere; (4) undepleted, nonoutgassed part of the mantle; and (5) the segmented, enriched continental crust into which elements incompatible in the mantle have been concentrated.

\section{Mantle Convection}

Figure 1 shows a simple interpretation of plate tectonics, emphasizing the tectonic environments demarcated by moving plates with plate boundaries as the loci of major geological activity. The concepts of sea floor spreading and subduction of oceanic plates involve uprise of hot mantle material and sinking of cold plates, which leads smoothly into the formulation of models for mantle convection. The formulations were not uniformly acclaimed. Powerful arguments were produced by authoritative scientists during the 1960 s objecting to the idea of convection in the viscous, solid mantle. Sullivan [1974, p. 84] referred to a rejection slip from a scientific journal citing a referee who said, "This is another in a number of papers by Runcorn on convection in the mantle and I hope it will be the last." The objections faded as geochemical studies of the mantle and crust provided firm evidence for the existence of distinct reservoirs of magma source material that had retained their separate identities for a billion years or more, which was explained in terms of different convecting regions within the mantle. Carlson [1987], in his review of the geochemical evolution of the crust and mantle for the period 1983-1986, noted that "two component compositional models for the mantle expanded to 3, 4, and 5 components as the number of isotopic systems used simultaneously expanded from $\mathrm{Sr}$ and $\mathrm{Nd}$ to include $\mathrm{Pb}, \mathrm{Hf}, \mathrm{He}$, and Xe." The mantle is chemically heterogeneous, different source components have been distinguished, and the exercise of relating these reservoirs to physical layers, strata, or blobs within the mantle has led to a proliferation of convection models. The blank interior of Figure 1 has been replaced by a variety of possibilities, some of which are summarized in Figure 4.

Figure $4 a$ represents the two-layer mantle proposed by $D e-$ Paolo and Wasserburg [1976, 1979] and developed by Jacobsen and Wasserburg [1981], who presented a cartoon of the mechanism for crustal growth according to their model $\mathbf{I}$. Figure $4 a$ shows the continental crust and a thick layer of depleted mantle overlying undepleted primitive mantle, from which the two overlying reservoirs had been derived by magmatic processes and differentiation. The major mantle reservoir, the source of mid-oceanic ridge basalts, is depleted in incompatible elements. According to the model of Jacobsen and Wasserburg [1981], the depleted reservoir has grown downward through time at the expense of primitive, undepleted mantle. The boundary between the two reservoirs at present approximates the depth of the $650-\mathrm{km}$-deep seismic discontinuity, as well as the depth at which the mantle minerals are transformed to perovskite (Figure 3). Ocean island basalts (OIB) and continental flood basalts (CFB) are enriched in incompatible trace elements compared with MORB. Jacobsen and Wasserburg [1981] proposed that these basalts were derived from blobs of undepleted, primitive mantle rising from the deeper layer. Island arc basalts (IAB) are more complicated because of the subduction of oceanic crust, and more than one source is involved. The question arises as to what extent the enriched characteristics of the IAB are due to subducted sources, to mantle source reservoirs, or to contamination of the lavas by lithosphere or crust.

Figure $4 b$ represents an opposing interpretation without separate convecting layers but with mantlewide convection. Hofmann and White [1982] proposed that subducted slab material sank to the mantle-core boundary where it was stored until a thermal plume lifted it to higher levels where chemical 
heterogeneities were transferred to the magmas generated. Several studies have reported seismic anomalies extending into the lower mantle deeper than the seismic zones considered to delineate the subducted lithosphere [e.g., Creager and Jordan, 1984]. If the subducted slabs penetrate deep into the mantle as indicated in Figure $4 b$, two-layer convection is prohibited, and mantlewide motions are required. Carlson [1987] summarized arguments from geochemistry and geophysics against the two-layer mantle, as well as problems facing mantlewide convection. The physical interpretation of Figure $4 b$ involves increasing viscosity as a function of depth [Davies, 1984; Hager, 1984]. The effect of the viscosity increase is to reduce the rates of flow and mixing in the deeper mantle, so that despite the mantlewide convection the upper and lower mantle tend to remain separate from each other through long periods.

In Figure $4 b$ the mantle is composed of peridotite, with phase change to perovskite at the $650-\mathrm{km}$ level, as indicated by the dashed lines. The flows pass through the phase transition region. Distributed through the mantle are blobs and stringers or layers of other material, carried into the mantle at convergent plate boundaries. These heterogeneities vary with respect to their contents of incompatible and radiogenic elements. Basalts are generated by partial melting of the convecting mantle, or of isolated heterogeneities, or of a mixture of host mantle with some enclosed heterogeneity. The more radiogenic masses enriched in subducted crustal material may become heated after a billion years or so and deliver mantle plumes [Hofmann and White, 1982]. These plumes are assumed to be the sources of OIB and CFB. Partial melting to produce MORB is much more extensive, and the contributions of trace element and isotopic signatures from heterogeneous enclosures is correspondingly diluted.

Figure $4 c$ illustrates Anderson's [1982] more complex model for the recycling of oceanic crust, based on the geochemistry of basalts, kimberlites, and peridotites and consistent with seismic data. He suggested that extensive partial melting of primitive mantle during accretion of the Earth was followed by formation of a cumulate layer (unshaded) of olivine eclogite (piclogite), with an overlying peridotite layer (stippled) enriched by residual kimberlite fluids from below. The depleted peridotite from which the basaltic melt was removed constitutes the lower mantle, precisely the opposite of the model in Figure $4 a$. The upper mantle of peridotite composition contains a density-balanced layer of piclogite perched between 220 and $670 \mathrm{~km}$. The low-velocity zone is attributed to incipient melting. The piclogite layer is a depleted reservoir, the source of MORB, and the upper peridotite layer is the reservoir enriched by kimberlite fluids giving it the geochemical requirements of the source of OIB and CFB. Convection within the eclogite layer deforms the upper boundary, raising it above its solidus temperature. Partial melting produces a buoyant diapir with adiabatic ascent leading to extensive melting and eruption at mid-ocean ridges. The eclogite layer is continuously replenished by subduction of the oceanic crust derived directly from the layer some millions of years earlier.

Ringwood [1982] proposed a more elaborate two-layer mantle illustrated in Figure $4 d$, with an additional reservoir occurring as megaliths that flowed to form a layer separating the two convecting layers (solid shading) and with eclogite (no shading) playing a special role. The extraction of MORB at mid-ocean ridges generates a depleted lithosphere of harzburgite and lherzolite. Ringwood suggested that the depleted lher- zolite of the lower lithosphere is stripped off during subduction and resorbed into the upper mantle, which is thus regenerated as the depleted source reservoir for MORB (heavy stippling). The depleted, cool, subducted lithosphere forms a second reservoir of megaliths composed of harzburgite enclosing eclogite from oceanic crust, density-balanced at about 650-km depth between peridotite above and perovskitite below. The megaliths float like icebergs at this level, gradually flowing to produce a continuous layer. The megaliths reach thermal equilibrium with surrounding mantle on a time scale of 1-2 billion years, and at this stage the harzburgite rises buoyantly forming mantle plumes. The depleted harzburgite has been rendered newly fertile by liquids generated by partial melting of the entrained eclogite. The plumes provide the sources for OIB an CFB, and incorporation of the enriched harzburgite into the lithosphere yields the alkaline basaltic suite by small degrees of partial melting. Eclogite in the megaliths may become converted to perovskitite, and sink down through the lower mantle.

In a mantle with layers convecting separately, it has been suggested that motions are related through the boundary layer (Figures $4 a, 4 c$, and $4 d$ ). The cool subducted lithosphere reaching the $650-\mathrm{km}$ level, for example, could initiate downwelling in the layer below, and the upwelling associated with midoceanic ridges might be initiated by plumes rising from the core-mantle boundary in the layer below. This kind of coupling implies opposing flows above and below the boundary layer in such locations, with the development of shear.

Allegre's [1987] interpretation contains elements of the models in Figures $4 a$ and $4 d$, but his scheme was determined on the basis of multi-isotope studies. The Earth's evolution is treated as a transfer matrix made of transfer functions that describe the transfer of mass among reservoirs. The upper mantle, the source of MORBs, is depleted, 99\% outgassed, and well mixed by convection, and it may extend down to the 670-km seismic discontinuity, a convenient, known horizon, coinciding with a large density change associated with the phase transition to perovskite (Figure 3). The limit of the outgassed mantle does not coincide exactly with the limit of the depleted mantle. The lower mantle has been outgassed to about $17 \%$ and is thus more primitive [Allègre et al., 1987]; it is probably convecting. In these respects, Allègre's model corresponds to the "standard model" of Figure $4 a$, but there are additional complexities. The source of continental flood basalts is identified as metasomatized continental lithosphere, which was probably formed early at the same time as the continents and has remained below the continents as the plates have migrated. The enormous dispersion of chemical data for the ocean island basalts involves a mixture of MORB source and at least four different end-members. Allègre places this mixed source in a mesosphere boundary layer between the upper and lower mantle, resembling Figure $4 d$ in geometry. The layer, fed by depleted material from the subducted oceanic crust and by delaminated continental lithosphere, is warmed by conduction from the lower mantle and then mixed back into the upper mantle by convection, producing a "marble cake" mantle with the mixed material deformed by elongation. Large blobs from boundary layer instabilities rise through the convecting upper mantle and yield the ocean island basalts. The largest of these blobs may entrain lower mantle sources, as suggested by the rare gas analyses from Loihi seamount [Allegre et al., 1987]. The formation of continental crust follows scavenging of subducted oceanic litho- 
sphere for incompatible elements by dehydration and partial melting. Each new crustal segment is a mixture between material newly extracted from the mantle and recycled old continental material. Continental collisions destroy continental masses by doubling the crust and exposing it to erosion. The behavior of volatile components is important in processes of crust formation.

\section{Mantle Tomography and the Geoid}

Recent developments in tomography are beginning to yield a three-dimensional picture of density variations attributable to temperature differences and related directly to mantle flow and convection patterns. These results, correlated with fluid mechanical models and geoid calculations, promise rapid advancement in our understanding of mantle structure and convection and in interpretation of mantle geochemistry. The geochemistry, when correlated with present mantle convection patterns, may be applied more readily to ancient mantle dynamics.

Surface waves from large earthquakes circle the Earth many times, and different wavelengths of the surface waves sample different depths. Average velocities along many paths are converted to three-dimensional images of the seismic velocity structure, in specific depth intervals down to $900 \mathrm{~km}$. Present data are sparse and resolving power is limited, but characteristic lengths are relevant for plate tectonics. Global maps have been prepared showing lateral heterogeneities, anisotropy related to horizontal flow directions, and anisotropy related to vertical flow directions [Woodhouse and Dziewonski, 1984; Anderson, 1987; Tanimoto, 1987]. The seismic velocities to depths of more than $100 \mathrm{~km}$ remain closely correlated with major tectonic features of the surface. Correlation with continental shields indicates that continents have roots of 200-300 $\mathrm{km}$ that have drifted with the continents. Slow material beneath oceanic ridges is distinguished to $400 \mathrm{~km}$. Fast material beneath island arcs representing cold subducted lithosphere begins to lose its close correspondence with surface features at depths greater than $250 \mathrm{~km}$. There is a dramatic change at about $450 \mathrm{~km}$ compared with the pattern of shallower depths.

Two methods have been used to invert $P$ wave travel time residual data sets to obtain the velocity structure of the lower mantle. Dziewonski [1984] has expressed velocity perturbations in terms of smooth functions. R. W. Clayton and R. P. Comer (in the work of Hager and Clayton [1987]) adopted a tomographic method with iterative back projections of travel time residuals along ray paths. The advantages and disadvantages of each inversion method were reviewed by Hager et al. [1985] and Hager and Clayton [1987]. There is encouraging agreement between the two methods in many cases. Hager and Clayton [1987] reviewed the velocity variations displayed in a series of mantle cross sections and maps for specific depths, correlating them with surface tectonic features as far as possible. One of the most striking characteristics in the context of mantle convection is the radial variation in velocity structure. Coherent structures commonly have shallow dips.

Hager [1984] and Hager and Clayton [1987] have worked with the long-wavelength nonhydrostatic geoid which provides a fundamental observational constraint on mantle convection, and they demonstrated that most of the variations are ultimately caused by density contrasts in the lower mantle. The tomographic results were used to infer a density field and to calculate geoid anomalies. The calculated geoid was opposite in sign from the measured geoid, which indicated the need to take into account the flow that the density variations induce in the mantle. Fluid mechanical models were used to compute the dynamic topography caused by mantle convection at the Earth's surface and the core-mantle boundary. The dynamically maintained relief at these two levels represent large mass anomalies which contribute to the geoid. These anomalies overwhelm the effects of the internal density contrast driving the flow and thus determine the sign of the geoid. Hager and Clayton [1987] considered in addition the effects of subducted slabs and viscosity variations. From many calculations, they concluded that the best fit was obtained with a nonlayered mantle with an increase in effective viscosity from the asthenosphere to the lower mantle by a factor of 300 . A layered mantle like the mantles in Figures $4 a, 4 b$, and $4 d$ does not satisfy the data. A mantle with such a change in viscosity with depth, however, could lead to a compositionally stratified mantle. Rates of flow would be much higher in the upper mantle than in the lower mantle, and elements or geochemical reservoirs would have a much longer residence time in the lower mantle than in the upper mantle. Figure $4 b$ represents the kind of mantle favored by the tomography and geoid studies, and Hager and Clayton [1987] refer to a lower mantle with the structure of "ribbon candy" rather than that of the more familiar convection experiments. Allegre [1987] similarly refers to a "marble cake" mantle. Another prediction from the new investigations of the geoid is that there is about $5-\mathrm{km}$ relief at the core-mantle boundary, which has implications for the Earth's magnetic field, magnetic reversals, and the orientation of the Earth's spin axis.

Density inhomogeneities in the mantle grow and subside, depending on the location of continents and subduction zones. The resulting geoid highs change slowly. Anderson [1984] has speculated that continental stability leads to the development of thermal and geoid anomalies, followed by a shift of the Earth's axis of rotation relative to the mantle. The geoid would evolve stably and slowly, while the lithosphere would break up and drift away from the thermal anomalies that the continents had caused. The continents would drift toward the colder parts of the mantle, toward the geoid lows, and they would make the mantle cold as they overrode the oceanic lithosphere. These speculations have implications for mantle and igneous petrology.

\section{Oceanic Crust, Continental Crust, and Volatile Components}

The crust, the atmosphere, and the oceans are reservoirs unmixed from the mantle and core. The reincorporation of oceanic crust into mantle reservoirs has been outlined in connection with Figure 4. During the process of subduction, however, the oceanic crust composed of basalt/gabbro/eclogite, at least partly hydrated to amphibolite and enclosing bodies of serpentinite and with some sediment attached, is a separate magmatic hearth, a distinct chemical reservoir. It is subjected to dehydration, decarbonation, and partial melting reactions, with the volcanic island arcs or continental margin volcanic arcs being the most obvious products.

The deep continental crust, composed largely of gabbro, tonalite, and granite with some sediments (together with their metamorphosed equivalents) with average composition close to that of andesite, is another magmatic hearth yielding more silicic partial melts with distinctive geochemical signatures. Armstrong [1968] has concluded on the basis of isotope studies that continental crust is regularly recycled through the 

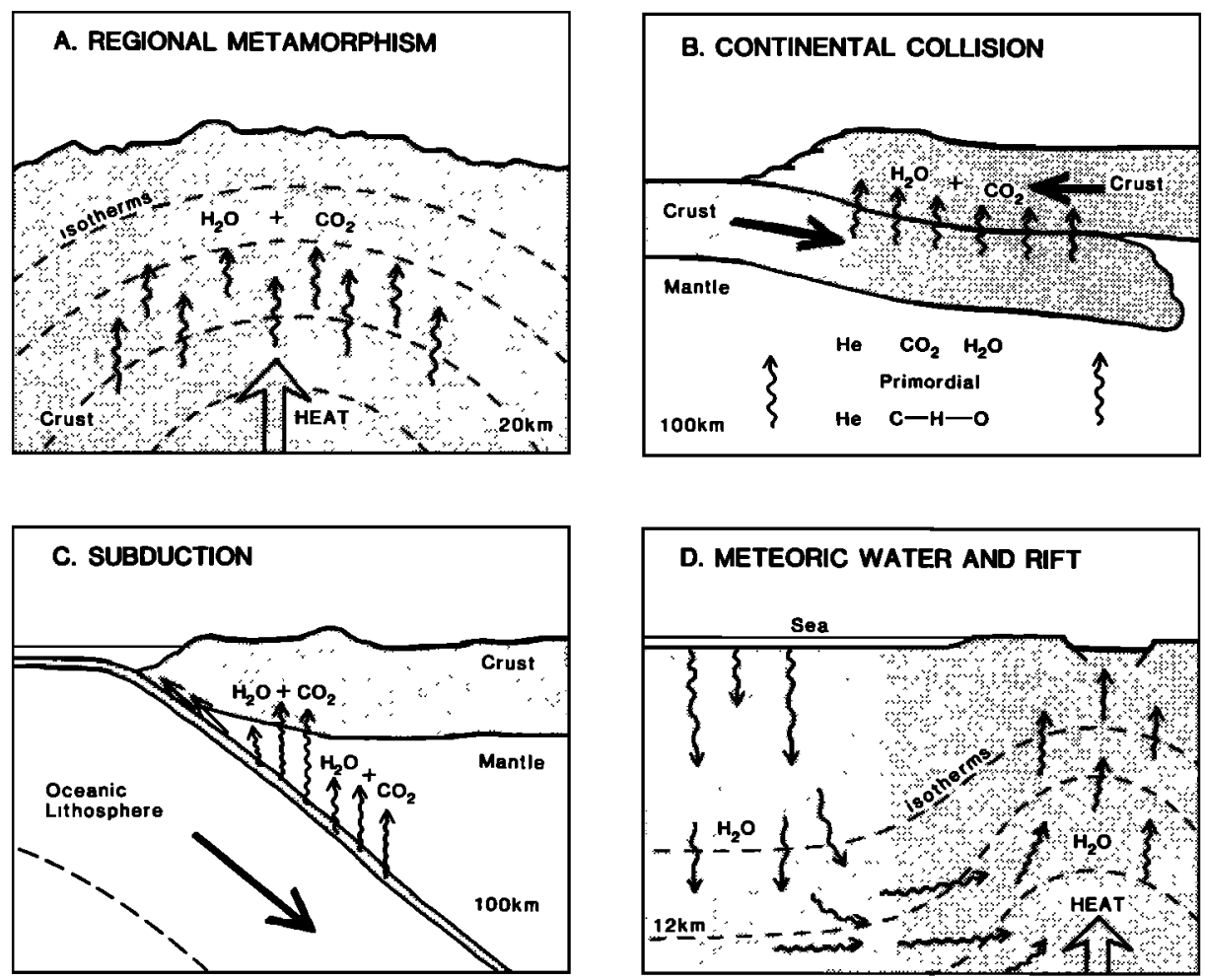

Fig. 5. Four different tectonic environments involving migrations of large volumes of volatile components.

mantle at convergent plate boundaries. Schreyer et al. [1987] have described pyrope-coesite rocks in the Western Alps indicating that continental sedimentary rocks were subducted to depths of about $100 \mathrm{~km}$ at $700^{\circ}-800^{\circ} \mathrm{C}$. These examples were elevated to the surface again, but an alternative fate is dispersal through the convecting mantle.

It has been established that some CFB has been contaminated by its passage through continental crust, and the geochemical effects are similar to those that have been attributed to metasomatism of a mantle source rock. There remains uncertainty about interpreting the trace element and isotope variations observed in basaltic lavas in terms of the relative contributions of mantle metasomatism, crustal contamination, or recycling of crustal material through the mantle.

The distribution and effects of volatile components are particularly significant in magma genesis associated with subducted oceanic crust and the continental crust, but they are also assigned significance in mantle metasomatism. The migration of volatile components as vapors or solutions transfers elements from one source reservoir to another, changing their geochemical signatures. $\mathrm{H}_{2} \mathrm{O}$ is the most abundant volatile component in crustal processes, but $\mathrm{CO}_{2}$ is also plentiful, and other components such as halogens and sulfur, although present in much smaller proportions, may be very influential. Figure 5 summarizes some of the ways in which volatile components are made available for participation in magmatic processes.

Figure $5 a$ represents the occurrence of dissociation reactions releasing mainly $\mathrm{H}_{2} \mathrm{O}$ and $\mathrm{CO}_{2}$ from sedimentary rocks as they are buried and as isotherms rise during regional metamorphism. Similar reactions occur in other environments when physical conditions change so as to bring rocks across phase boundaries. The occurrence of helium in basalts is taken as evidence that not all volatile components were expunged from the Earth's mantle during its early history, and Figure $5 b$ shows primordial volatile components rising from the deep mantle. The major components are probably C-H-O, but their molecular form is controversial, depending on conclusions about the oxygen fugacity in the mantle as discussed in a later section. Allègre et al. [1987] concluded from rare gas systematics that about half of the mantle is $99 \%$ outgassed and that a very early intense stage of degassing was followed by a slow process which continues to the present.

Continental collisions or subduction of oceanic crust at convergent plate boundaries are associated with the release of abundant fluids. Figure $5 b$ represents the dissociation reactions associated with continental overlap like that occurring beneath the Himalaya at present. The overlying continental crust is flushed by large quantities of $\mathrm{H}_{2} \mathrm{O}$ and $\mathrm{CO}_{2}$ released from the sedimentary cover of the subducted continental crust. This is related to the processes described by Schreyer et al. [1987], who emphasized that magma generation in continent/continent collision zones is influenced or even governed by the fluid and melt production within slabs of continental crust that may be subducted to considerable depths within the mantle.

Figure $5 c$ illustrates the general location of vapors released from subducted oceanic crust. Many of the volatile components make their way back to shallower levels along the boundary zone between subducted slab and overlying mantle or crust, and this effect is surely dominant at shallower levels, but it is generally assumed that at deeper levels there is significant migration of volatile components into the overlying mantle. This assumption may require modification if the recent research by Watson and Brenan [1987] on the wetting characteristics of $\mathrm{CO}_{2}-\mathrm{H}_{2} \mathrm{O}$ fluids leads to a firm conclusion that such fluids in the upper mantle are incapable of migration except by hydrofracture. 


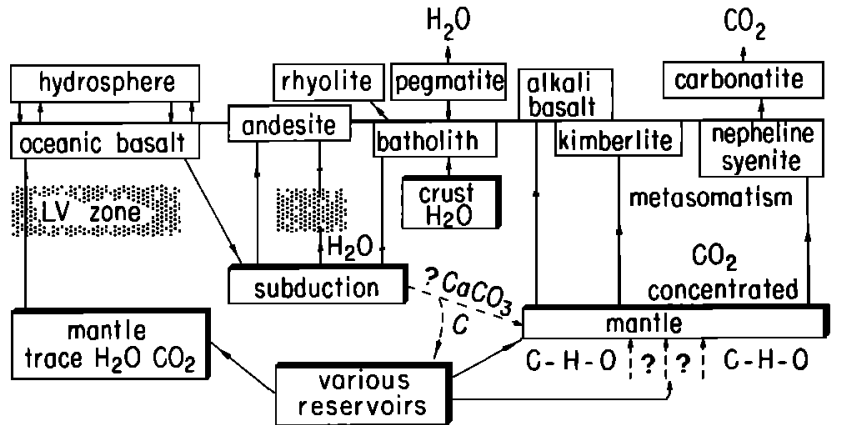

Fig. 6. Schematic diagram illustrating magmatic sources and selected products at divergent plate boundaries, convergent plate boundaries, and continental plates.

Ocean water penetrates deeply into oceanic crust near the midocean ridges, causing important chemical changes in the compositions of both crust and water. The emerging hot water forms spectacular chimneys with their black and white smokers, depositing concentrations of minerals, including sulfide ore deposits. Wickham and Taylor [1987] have concluded on the basis of detailed petrological and oxygen isotope study of a sequence of metamorphic rocks and granites in the Pyrenees that the granitic magmas were derived by partial melting induced in the metamorphic rocks by the flux of meteoric water penetrating as deep as $12 \mathrm{~km}$. They suggested, as illustrated in Figure $5 d$, that crustal rifting was responsible both for the fractures that permitted deep penetration of water from a shallow sea and for the uprise of isotherms associated with the metamorphism and partial melting.

\section{Review}

We have progressed in plate tectonics from the concept of a dynamic Earth activated by unspecified internal convective motions, as indicated in Figure 1, to a situation where we have several varieties of convection to choose from, as indicated by Figure 4. These varieties are based on geochemical data, petrology, and seismology. Figure 6 outlines some of the sources and magmatic products that are products of the mantle convection. These are related to the tectonic environments of plate tectonics (Figures 1 and 4) and to the fluxes of volatile components in some environments (Figure 5).

Starting at the left-hand side of the figure at divergent plate boundaries and in oceanic plates, basalts (MORB and OIB) with small amounts of dissolved $\mathrm{H}_{2} \mathrm{O}$ and $\mathrm{CO}_{2}$ are certainly derived from the mantle. The submarine basalts react with seawater with the formation of carbonates and hydrated minerals which are carried into the mantle in subduction zones. The oceanic crust when subducted may also carry with it pelagic sediments, including limestones (in recent geological times). During subduction it appears that most of the water in subducted oceanic crust is released to participate in convergent boundary processes [Wyllie, 1979]. Allègre et al. [1987] concluded from rare gas systematics that subduction volcanism is a barrier preventing volatile components from deeper return into the mantle. Some of the carbonate may escape these processes and be carried deeper into the mantle for long-term storage of carbon [Huang et al., 1980]. Carbonate in contact with peridotite will be converted to dolomite then to magnesite, or it will be reduced to graphite or diamond depending on redox conditions (see Figures 20 and 21). Basalts (IAB) and andesites are erupted at convergent plate boundaries with a sequence of processes initiated in the subducted slab (by dehydration or partial melting), and at oceancontinent plate boundaries these magmas are joined by rhyolites escaping from granitoid batholiths (GR). Kimberlites rise from volatile-enriched mantle near the asthenospherelithosphere boundary beneath cratons. Various nephelinitic magmas are associated with rift zones in continental platforms, and carbonatites may be formed by their diflerentiation. We aim to determine the petrological and geophysical processes linking the observed magmatic products and the inferred mantle and crustal reservoirs, stripping off the effects of mixing or contamination, and differentiation of magmas.

The interpretation of geochemical data with respect to mantle convection continues to be discussed, as outlined by Carlson [1987]. The situation remains about the same as summarized by Davies [1984, p. 6017], except that there are now even more data to be interpreted:

With the current proliferation of isotopic systems and data being applied to the problem of the structure and evolution of the mantle, any attempt to synthesize a model consistent with a large variety of geophysical and geochemical data risks being rapidly outdated. However, it seems not to be widely appreciated that as some models of the recent past have been elaborated to accommodate new data, some of their basic assumptions have been progressively undermined by the same data. Furthermore, many of the geophysical and geochemical constraints are in apparent conflict, and there has been, as a result, a proliferation of mutually exclusive models [e.g., Wasserburg and DePaolo, 1979; Allègre et al., 1980; Davies, 1981; Anderson, 1982b; Hofmann and White, 1982]. The natural tendency to ignore inconvenient constraints is reinforced by the breadth of material relevant to this subject, while a preference for one model can easily blind one to alternative interpretations of data.

Davies [1984] went on to discuss assumptions and overinterpretations that have been made in both geochemical and geophysical approaches to the problems represented in Figure 4 and presented a structure for a heterogeneous mantle with increasing viscosity as a function of depth, corresponding to Figure 4b. Allegre's [1987] global synthesis of the geochemical data transcends most previous models, and his conclusion is that the lower mantle has remained physically separate from the upper mantle, except for intermittent entrainment of lower mantle in blobs rising from the mesosphere boundary layer. Whole mantle convection is precluded by the rare gas data [Allegre et al., 1987]. This conclusion contradicts that of Hager and Clayton [1987], who find whole mantle convection (Figure $4 b$ ) to be more in accord with the geophysical evidence.

The models for mantle structure and dynamics must satisfy not only the data of geochemistry and seismology [Allègre, 1987; Hager and Clayton, 1987], but also the constraints imposed by thermal structures and phase boundaries, particularly solidus curves. These two topics are considered in the following sections and used to test the models in Figure 4. At present, they provide constraints but not definitions. These topics become more definitive for the shallower processes associated with subduction and the lithosphere.

\section{Thermal Structures}

Magmas are generated because from place to place and from time to time, the Earth's internal temperature exceeds that for the beginning of melting of some source rock at depth. The thermal history of the Earth is thus a fundamental factor. 
The present temperature distribution depends upon the Earth's temperature when formed, heat added during its early growth and history, the amount of heat generated as a function of depth and time, and the rate of outward flow of heat. Processes for the outward flow of heat include (1) conduction, (2) radiation, (3) convection, and (4) migration of fluids through the lithosphere. Geotherms have been calculated assigning different significance to these processes.

It is now evident that the mantle convection associated with plate tectonics is the major process of heat transfer from the Earth's interior to the surface. Despite this understanding, a history of revisions of what scientists have believed to be the thermal state of the Earth's interior should generate a certain skepticism about current estimates. Lord Kelvin's authoritative estimate of the Earth's youthful age because of his calculated cooling time from a molten state did not include the unknown effect of radioactivity. The concept of cold accretion of planets was reversed following the study of lunar rocks and development of the idea of a magma ocean. It is now believed that the Earth became hot during accretion and that magma genesis was probably an integral part of the growth history, rather than a process that began only when the Earth had heated sufficiently. Even during the past decade estimates of geotherms for the mantle have varied considerably, with the uncertainties increasing as a function of depth.

\section{Geotherms}

A variety of geotherms calculated with assignment of different values to conduction, radiation, and convection of heat was compared by Wyllie [1971, Figure 3-12]. Figure 7 compares a more recent selection. Ringwood's [1975] calculated geotherm (a-a) is based on conduction and radiative heat transfer. Jeanloz and Richter [1979] presented an improved geotherm $b-b$ for a conducting lithosphere (layer 1 about 120 km thick) overlying a convecting mantle. Richter and $\mathrm{Mc}$ Kenzie [1981] added the third layer 3, convecting independently of layer 2 , based on the two-layer convection model of Figure $4 a$. They determined from laboratory and numerical experiments that there is a marked increase in temperature between the two discrete convecting layers as shown by geotherm c-c. There is a conductive geotherm in layer 1 , the lithosphere lid; there are two steep adiabatic gradients in the two convecting layers; there is a double thermal boundary layer between the convecting layers 2 and 3, resulting in an average temperature increase of about $500^{\circ} \mathrm{C}$ near $700-\mathrm{km}$ depth if the lower mantle is isolated from the upper layer. If the deep layer 3 is assumed to have been depleted of its radioactive elements through magmatic processes early in Earth history, as proposed by Anderson [1982] in Figure 4c, the geotherm would not exhibit a step, but would remain near b-b. We need to know the Earth's thermal structure in order to understand magma genesis, but we also need to know the Earth's magmatic history in order to determine the present geotherm. In regions of active upward mantle movement, as associated with mid-oceanic ridges and mantle plumes, the lithosphere is thinned, and the adiabatic part of the geotherm corresponding to layer 2 in Figure 7 is extended upward, as shown for geotherms d-d and e-e, respectively. The estimated positions of the changes in slope of the geotherms are based on independent evidence or assumptions about lithosphere thickness or melting temperatures (see below).

From the geothermometry and geobarometry of mantle nodules we have a geotherm for cratons (f- $f$ ) consistent with

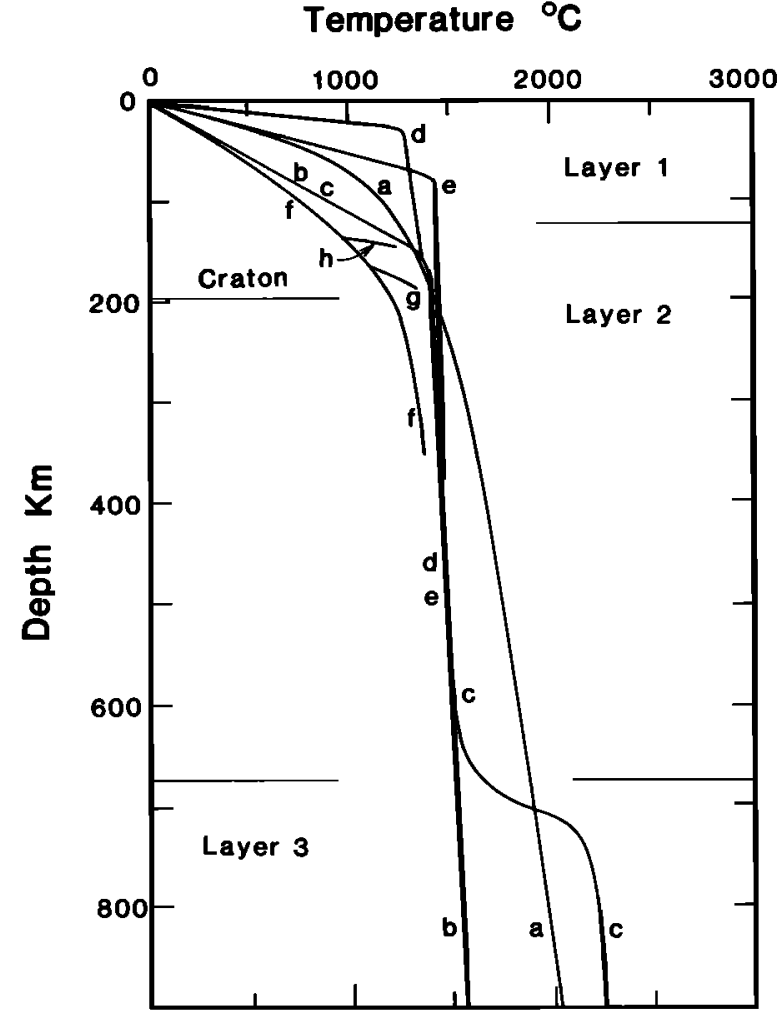

Fig. 7. Geotherms for different tectonic environments; see text for locations and sources.

that calculated from heat loss [Boyd and Gurney, 1986]. The geotherm for many kimberlites is inflected to higher temperatures at a depth of about $175 \mathrm{~km}(\mathrm{f}-\mathrm{g})$, somewhat deeper than the graphite to diamond transition. The inflection occurs at shallower levels ( $\mathrm{f}-\mathrm{h}$ ) in mobile belts. As reported by Boyd and Gurney [1986], the inflection has been interpreted in terms of uprise of mantle diapirs associated with the generation of kimberlites or in terms of local magma chambers. Nickel and Green [1985] refined empirical garnet-orthopyroxene geobarometry and presented a distinctive pattern for South African xenoliths where the high-temperature xenoliths give nearisobaric estimates, corresponding to a depth of $150-160 \mathrm{~km}$, at $900^{\circ}-1400^{\circ} \mathrm{C}$.

Recent measurements of the melting curve for iron at high pressures using shock wave methods and diamond anvil apparatus have improved the constraint on the geotherm at the core-mantle boundary, $2900 \mathrm{~km}$ down, and at the Earth's center [Williams et al., 1987]. Temperature estimates at the core-mantle boundary are in the range $3000^{\circ}-3500^{\circ} \mathrm{C}$, with a distinct thermal boundary layer.

\section{Isotherms}

The perturbations caused by uprising mantle material, or by sinking lithosphere in subduction zones, cannot be represented completely by geotherms. We need to see the thermal structure as depicted by isotherms. The thickness of the lithosphere is an important variable because of the change in rheology occurring through the asthenosphere-lithosphere boundary layer, which is assumed to be near the $1200^{\circ} \mathrm{C}$ isotherm in the following diagrams. This layer is depicted as a line near 200-km depth beneath a continental craton in Figures 8 and 10 and near $90-\mathrm{km}$ depth beneath an ocean in Figure 9 .

Figure 8 illustrates the regular distribution of isotherms as- 


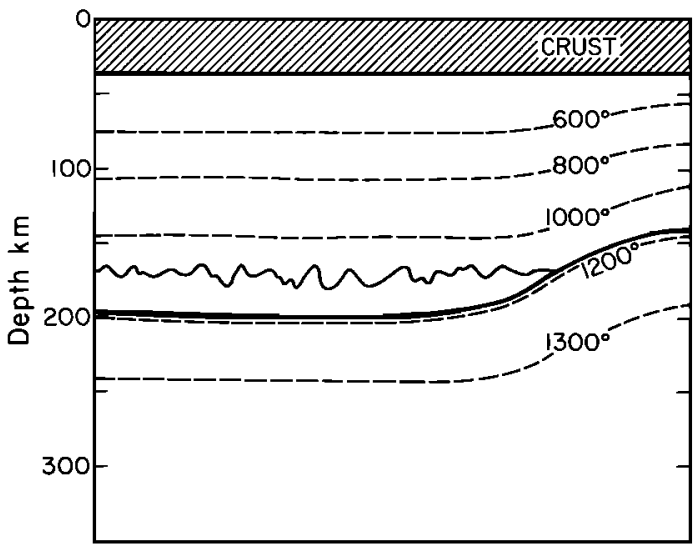

Fig. 8. The craton with isotherms superimposed according to the uninflected geotherm (f-f) in Figure 7.

sociated with a thick craton and a somewhat thinner lithosphere. If a thermal plume rises below the lithosphere, the asthenosphere-lithosphere boundary rises to shallower levels, causing thinning of the lithosphere, as indicated by the $1200^{\circ} \mathrm{C}$ point on the inflected geotherm (f-g) of Figure 7 . In a different environment the effect of a plume on the isotherms is depicted in Figure 9, which represents an oceanic plate moving from right to left. The asymmetry of the plume and of lithosphere thinning is caused by movement of the plate. The geotherm in the center of the plume corresponds to e-e in Figure 7. The lithosphere is heated above the plume, and associated with the rise in isotherms is thinning of the lithosphere. A mantle plume rising beneath a static craton changes the isotherms as shown in Figures 8 and 10. There is evidence that beneath major continental rifts the lithosphere is thinned. The continued heat flux permits uprise of the asthenosphere [Gliko et al., 1985]. This is represented by the isotherms in Figure 11.

There have been so many different calculated thermal structures published for subduction zones that we may conclude either that the thermal structures are not yet known in detail or that there is considerable variation. The subducted oceanic crust may be relatively warm or significantly cooled by endothermic dehydration reactions [Anderson et al., 1978, 1980].

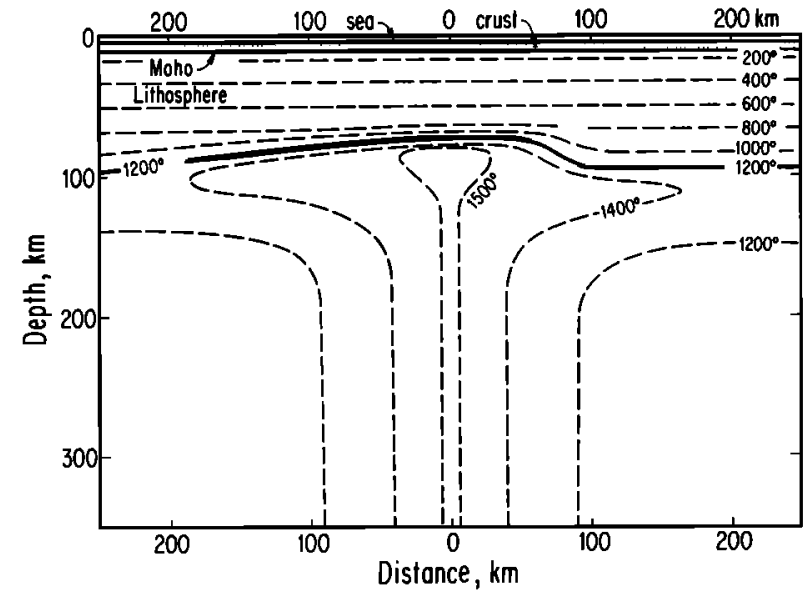

Fig. 9. Schematic isotherms for mantle plume based on plumes of Courtney and White [1986], the requirement for melting at $M$ in Figure 21, and with asymmetry caused by motion of lithosphere plate above the plume. The change in rheology associated with the asthenosphere-lithosphere boundary layer is arbitrarily represented by the heavy line for the $1200^{\circ} \mathrm{C}$ isotherm.

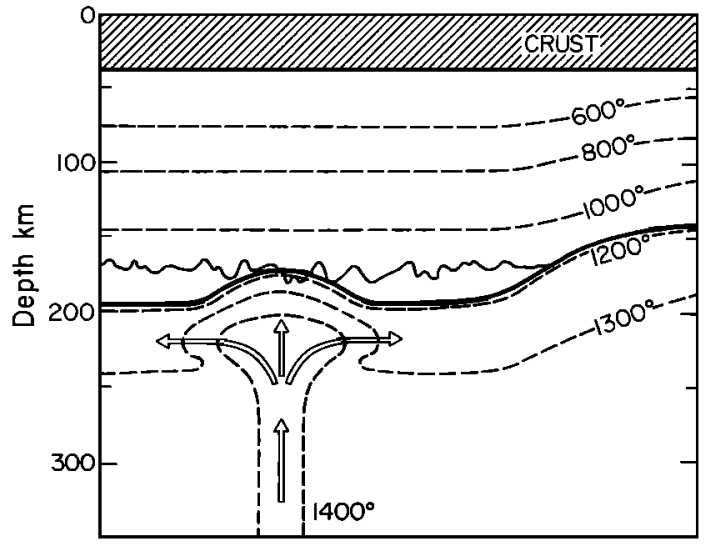

Fig. 10. The lithosphere section corresponding to Figure 8, with isotherms perturbed by a plume rising from the deep mantle and diverging within the asthenosphere beneath the lithosphereasthenosphere boundary layer.

The mantle wedge may be relatively cool, chilled by the subducted slab, or it may be heated by induced convection [Toksöz and Hsui, 1978]. Schematic isotherms for these two mantle conditions are illustrated in Figure 12. Combinations of these four conditions provide four limiting cases. An important fifth condition must be included. Marsh, [1979] and Maaloe and Petersen [1981] have appealed to extreme induced convection cells in the mantle wedge, raising the temperature of the subducted oceanic crust at $100-\mathrm{km}$ depth to $1250^{\circ} \mathrm{C}$ or $1450^{\circ} \mathrm{C}$.

\section{Experimental Calibrations: Source Rocks and Magmas}

Figure 13 outlines some of the ways that phase diagrams for minerals and rocks may help to decipher the processes occurring between the partial melting of the inferred source rocks and the observed magmatic products. Wyllie et al. [1981] discussed the use of experimental petrology in forward and inverse approaches to the problem of source-magma relations and reviewed in detail the inverse approach for basalts. Interpretation of geochemical analysis of magmatic products in terms of the chemistry of source rocks is an inverse approach. Forward and inverse approaches supplement each other as illustrated in Figure 13. This is followed by a series of phase diagrams providing limits and calibrations for processes involving the major materials of source reservoirs in mantle and crust.

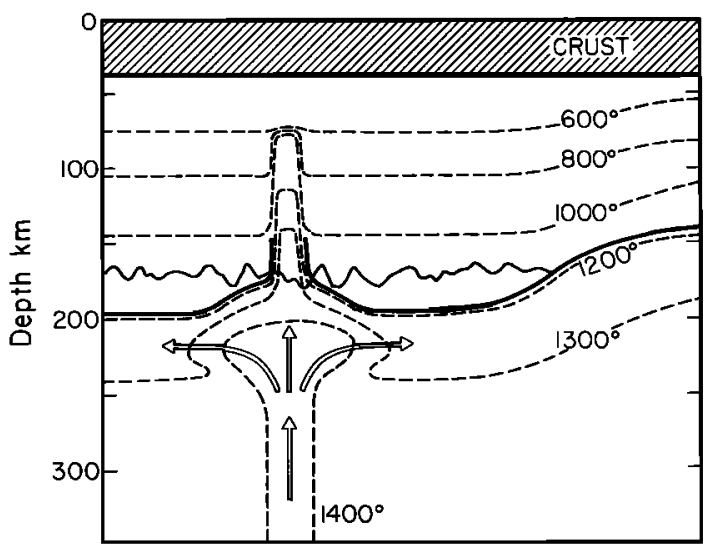

Fig. 11. Schematic isotherms in craton as in Figure 10, with additional thinning of the lithosphere beneath a rift zone. 

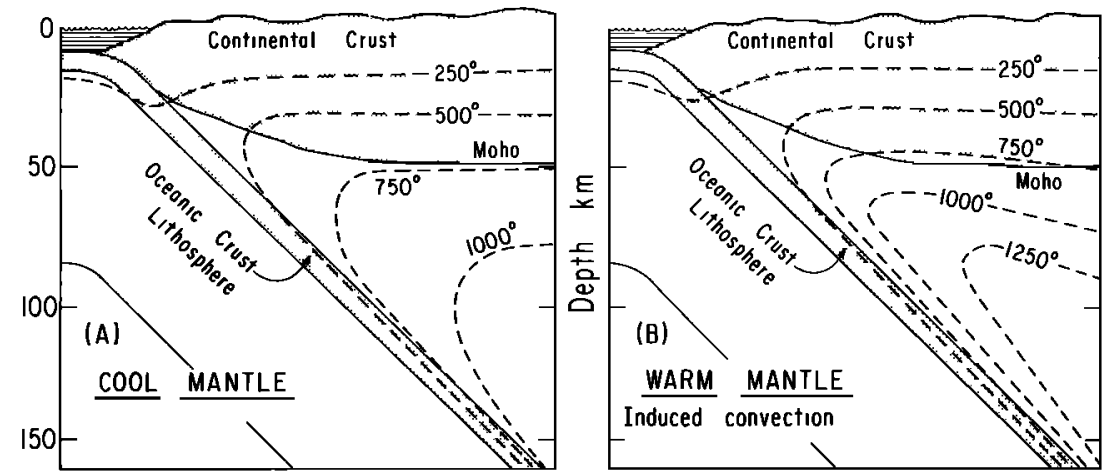

Fig. 12. Distribution of isotherms in mantle wedge (between the two stippled crusts) for $(a)$ a relatively cool mantle wedge and $(b)$ a mantle wedge warmed by induced convection.

\section{Phase Diagrams and Their Interpretation}

The main variables for representing the phase relationships are pressure, temperature, and parameters for composition. The simplest, most convenient geometrical framework for experimental data, considering the variables that can be measured and controlled in the laboratory, is $P-T-X\left(\mathrm{SiO}_{2}\right)-X\left(\mathrm{H}_{2} \mathrm{O}\right)[W$ yllie, 1977, 1979]. For an individual rock, $X\left(\mathrm{SiO}_{2}\right)$ is constant, and the framework is reduced to the three-dimensional model $P-T-X\left(\mathrm{H}_{2} \mathrm{O}\right)$ illustrated in Figure $14 a$. This is too complicated for convenient viewing, and results are commonly presented in sections through the model. Figure $14 b$ is an isobaric $T-X\left(\mathrm{H}_{2} \mathrm{O}\right)$ section. Note the three different solidus temperatures, one for excess vapor, one for a rock with all $\mathrm{H}_{2} \mathrm{O}$ stored in a hydrous mineral, and one for the completely anhydrous rock without any hydrous minerals. Note also the large area for $\mathrm{H}_{2} \mathrm{O}$-undersaturated liquid with crystals.

Isoplethal sections through the model in Figure 14a provide four types of $P-T$ diagrams corresponding to different ranges of $\mathrm{H}_{2} \mathrm{O}$ contents. Each of these is correlated in Figure 14 to the isobaric section, Figure $14 b$. Figures $14 c$ and $14 f$ represent the familiar extremes for the melting interval of a rock either completely anhydrous or with excess $\mathrm{H}_{2} \mathrm{O}$. Figure $14 d$ represents a rock without pore fluid, but with some $\mathrm{H}_{2} \mathrm{O}$ stored in

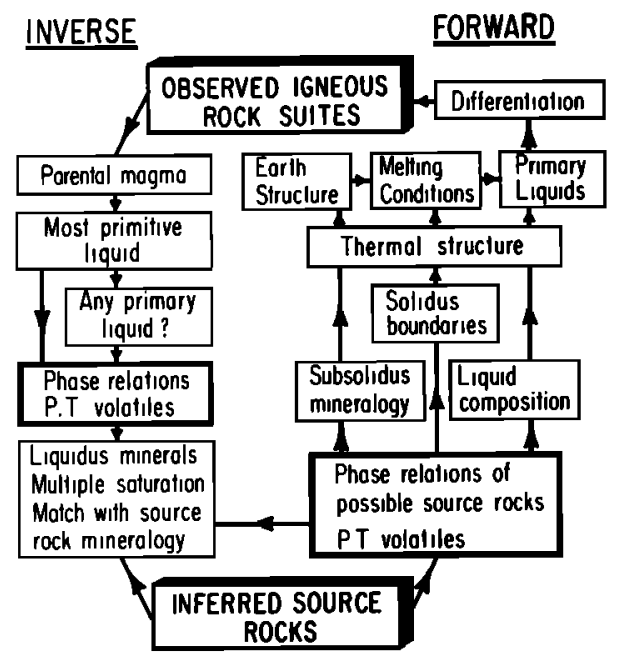

Fig. 13. The inverse and forward approaches for testing the relations between observed igneous rocks and inferred source rocks as depth, using phase equilibrium results from experimental petrology (simplified from Wyllie et al. [1981, Figure 3.1.4]). hydrous minerals. The solidus curve at low pressures is the same as that for Figure $14 f$. At higher pressures, however, the solidus corresponds to the reaction where the hydrous mineral breaks down, providing $\mathrm{H}_{2} \mathrm{O}$ for solution in $\mathrm{H}_{2} \mathrm{O}$-undersaturated liquid. Figure $14 e$ represents a rock system with hydrous minerals and subsolidus vapor but with insufficient $\mathrm{H}_{2} \mathrm{O}$ to saturate the liquid. The solidus is the same as that in Figure $14 f$, but the melting interval includes a large area of crystals plus $\mathrm{H}_{2} \mathrm{O}$-undersaturated liquid. Similar diagrams can be constructed for silicate- $\mathrm{CO}_{2}$ systems including carbonate minerals.

In order to trace geological processes for a given rock, we should follow polybaric-polythermal paths through the phase volumes in Figure 14a, which is graphically difficult. However, the types of processes can be illustrated in isobaric or isothermal diagrams.

The phase equilibrium data for rocks and magmas provide a set of constraints that can be used in the following ways as outlined in Figure 13: (1) to define the mineralogy of possible source rocks as a function of depth; (2) to define the compositions of liquids produced from possible source materials; (3) to define polybaric polythermal paths of crystallization or differentiation; (4) to determine, in conjunction with geochemical data, which composition in an igneous suite represents the

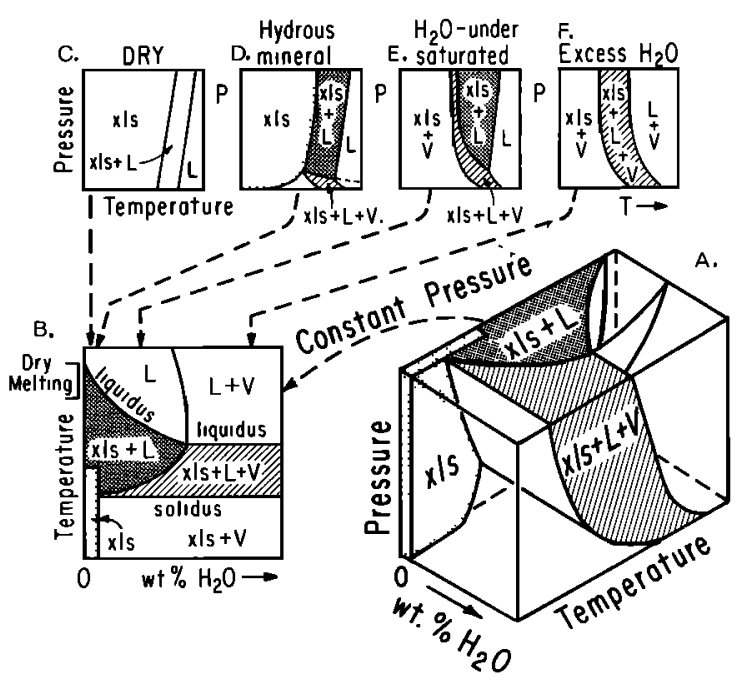

Fig. 14. Phase relationships for a single rock represented within a $P-T-X\left(\mathrm{H}_{2} \mathrm{O}\right)$ model and illustrated by isobaric and isoplethal sections through the model. 


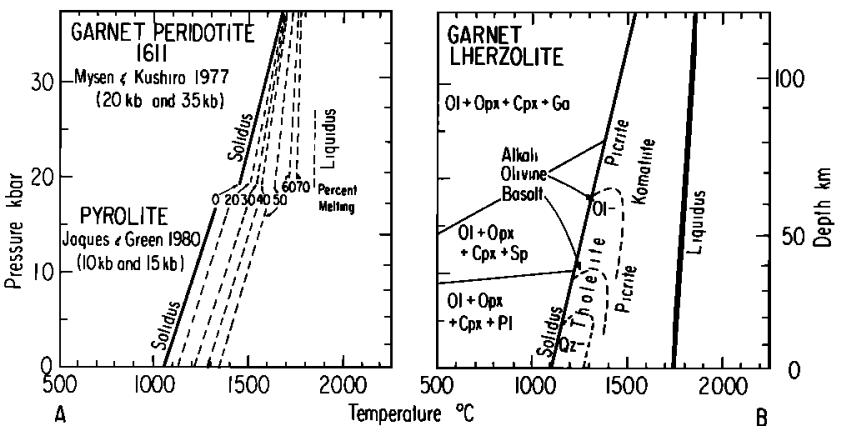

Fig. 15. Phase relations for peridotites. (a) Limited data for percentage of liquid within melting interval above solidus, after $M$ ysen and Kushiro [1977] and Jaques and Green [1980]. (b) Compositions of liquids generated within melting interval, after Jaques and Green [1980].

primary or most primitive liquid; and (5) to determine the conditions under which specific liquid compositions could coexist with residual minerals in a source rock. These approaches, in combination with the thermal structure within the Earth, provide a means to test geophysical and petrological models in different tectonic environments.

The mantle, subducted oceanic crust, and continental crust contain several different source rock types that may contribute to magmas. In a forward approach, we should know for each rock: (1) the subsolidus phase relations at least to the depths of magma generation, (2) the solidus curve, which defines the conditions for beginning of melting, (3) the percentage of melting as a function of temperature above the solidus, and (4) the changing composition of the liquid within the melting interval as a function of pressure. For some environments, we should know (5) the effect of volatile components such as $\mathrm{H}_{2} \mathrm{O}$ and $\mathrm{CO}_{2}$ on the previous items and (6) the effect of oxygen fugacity in changing vapor phase composition and solidus. In order to translate these chemical parameters into magmatic processes, we need to know in addition (7) the physical characteristics of the partially molten rocks and their variation with pressure, temperature, percentage of melting, and liquid-mineral compositions. This information is required to establish the range of conditions through which a partly molten source may rise as a unit, the conditions through which a liquid may percolate upward through the crystalline mush, maintaining equilibrium with its host, and the condition where the liquid may escape from its host and rise as an independent body of magma in a crack or diapir. Dense melts formed at depth may sink [Rigden et al., 1984].

A primary magma is a liquid whose composition has not changed since it was generated by partial melting in the source region. Figure 13 outlines the procedures in the inverse approach of deducing source rock chemistry and mineralogy from the phase relationships of primary magmas. Wyllie et al. [1981] gave detailed accounts of the procedures, of a search for possible primary magmas, and of a case study for oceanic tholeiites. They concluded that primary magmas were rare, most magmas having experienced low-pressure crystal-liquid fractionation. One critical test is to match multiple-mineral saturation on the liquidus of a primitive magma with the residual minerals of a multimineral source rock at the same pressure-temperature conditions. Although an internally consistent solution may be constructed for source-magma relations, this is not necessarily unique. The approach may be more useful in demonstrating that a proposed petrogenetic scheme is wrong because it violates the constraints of experimental petrology.

\section{Lherzolite}

There have been many experimental studies on various aspects of the phase relationships of mantle peridotite, lherzolite, and harzburgite, with most pressures limited to about $40 \mathrm{kbar}$. The persistence and ingenuity of Japanese scientists with the development of massive presses and relatively large volume high-pressure experiments have been rewarded recently with Takahashi's [1986] most extensive phase diagram for lherzolite as illustrated in Figure 3. The diagram shows phase relationships determined for a lherzolite up to pressures of 200 kbar, with distinctive cusps associated with subsolidus phase changes, where the aluminous minerals change from plagioclase at low pressure, to spinel, and to garnet at pressures corresponding to depths of about $75 \mathrm{~km}$. Some indication of experimental problems is given by the variety of results published for solidus curves. Figure $33 a$ shows the solidus curves previously published for different peridotites [Wyllie, 1984, Figure 2]. A linear extrapolation along c-d provides very high solidus temperatures at depth. The calculated Simon-type fit along c-e [Griggs, 1972] is a better approximation to the recent high-pressure measurement (Figure 3). The calculated solidus is paired with an estimated liquidus curve in Figure $33 b$ [Wyllie, 1981].

The results of two attempts to measure the percentage of liquid produced above the solidus of peridotite are compared in Figure 15a. Mysen and Kushiro [1977] reported nearisobaric invariant melting with production of much liquid just above the solidus at $20 \mathrm{kbar}$ and $35 \mathrm{kbar}$ in a garnet peridotite, with distinct change in slope of the melting curve wherever one or more minerals disappeared. According to Jaques and Green [1980], their results for pyrolite demonstrated that the steplike melting characteristic of simple synthetic systems was smoothed out by solid solution effects involving Fe-Mg, $\mathrm{Al}-\mathrm{Si}, \mathrm{Na}-\mathrm{Ca}$, etc., Despite the different solidus curves for the two rock compositions, the melting results appear to converge for about $\mathbf{5 0 \%}$ melting. The reason for the difference between these two sets of results has not been established despite their significance with respect to the partial melting of the mantle. The fact that the solidus curves for the two materials compared in Figure 15a are different may be due to differences in composition, but differences in experimental techniques and sample containers could contribute. When Takahashi and $\mathrm{Ku}$ shiro [1983] redetermined the solidus for a lherzolite measured early by Kushiro et al. [1968], using better experimental techniques, the solidus temperature was lowered by about $70^{\circ}-100^{\circ} \mathrm{C}$ and the solidus curve had the cusps as given in Figure 3, instead of the original linear solidus like those shown in Figure 15. The presence of detectable cusps on the peridotite solidus, corresponding to the subsolidus phase transitions, was first recorded by Presnall et al. [1979] in a synthetic system. More detailed study would probably reveal similar cusps for the solidus curves in Figure 15.

Figure $15 b$ shows the subsolidus phase relations and estimated melting interval for garnet lherzolite, with the $P-T$ ranges for liquids of various compositions within the melting interval. Liquid compositions correspond to those calculated by Jaques and Green [1980], who concluded that "most, perhaps all, previously published partial melt compositions obtained by direct analysis of quenched glasses" are in error, because of iron loss from sample as documented by Nehru and 
Wyllie [1975] and growth of metastable crystals during quench [Green, 1976]. Takahashi and Kushiro [1983] reached conclusions consistent with Figure $15 b$ based on microprobe measurements of glass using a technique designed to overcome the $\mathrm{Fe}$ loss and quench problems.

\section{Lherzolite- $\mathrm{H}_{2} \mathrm{O}$ and Lherzolite- $\mathrm{CO}_{2}$}

The phase relationships for the system lherzolite- $\mathrm{CO}_{2}-\mathrm{H}_{2} \mathrm{O}$, involving the minerals amphibole, phlogopite, dolomite, and magnesite, provide the framework for upper mantle petrology and for evaluation of the phase relations with reduced oxygen fugacity. There remains uncertainty about the position of the solidus, which also varies as a function of composition and oxygen fugacity.

The solidus curve for lherzolite is compared in Figure 16 with some of the important phase boundaries introduced by the addition of $\mathrm{H}_{2} \mathrm{O}$. The solidus curve is lowered considerably by the presence of an aqueous vapor phase, and the hydrous minerals amphibole and phlogopite coexist with the liquid; see $W$ yllie [1978a] and $W y$ ylie et al. [1981] for sources and for different experimentally reported curves for amphibole and the solidus. Note that if there is only enough $\mathrm{H}_{2} \mathrm{O}$ present to form amphibole or phlogopite, with none left over for a separate vapor phase, the solidus curves for phlogopiteperidotite or for amphibole-peridotite would be at somewhat higher temperatures than the phase boundaries for phlogopite and amphibole, respectively, in Figure 16 (compare Figure $14 d$ ). Hydrous minerals talc and serpentine are produced in peridotite at moderate temperatures, and at high pressures dense hydrous magnesian silicates (DHMS) are formed.

Figure 17 shows an interpretation of the phase relationships for peridotite with a small amount of $\mathrm{CO}_{2}$. This remains valid for up to about $5 \% \mathrm{CO}_{2}$, which would be sufficient to complete the carbonation reaction represented by the line TQ where dolomite $(\mathrm{Cd})$ is being generated at the expense of clinopyroxene; as it is, all $\mathrm{CO}_{2}$ is used up in reaction $\mathrm{TQ}$, and no free vapor remains at higher pressures.

The solidus from $P$ to $Q$ is depressed only slightly below the peridotite solidus PS because the solubility of $\mathrm{CO}_{2}$ is so low, in contrast with that for $\mathrm{H}_{2} \mathrm{O}$ (compare solidi in Figures 16 and 17). The formation of dolomite in the peridotite (reaction TQ) changes this situation, and along QR the partial melting of dolomite-lherzolite generates a liquid rich in carbonate, with about $40 \% \mathrm{CO}_{2}$ in solution; this is not a siliciate liquid, but a carbonatitic liquid. With increasing temperature above the solidus, the liquid composition migrates back toward sili-

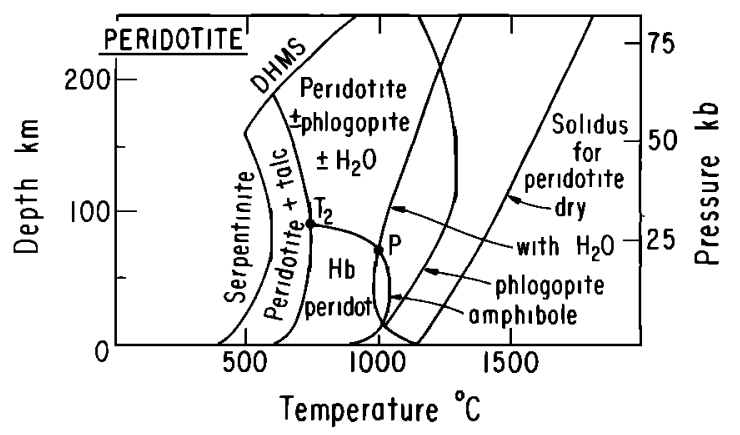

Fig. 16. Selected reactions showing the effect of $\mathrm{H}_{2} \mathrm{O}$ on melting and hydration of peridotite. DHMS, dense hydrous magnesian silicates (see $W y$ llhe [1978a] for sources and reference to other experimentally determined curves for the solidus and for amphibole).

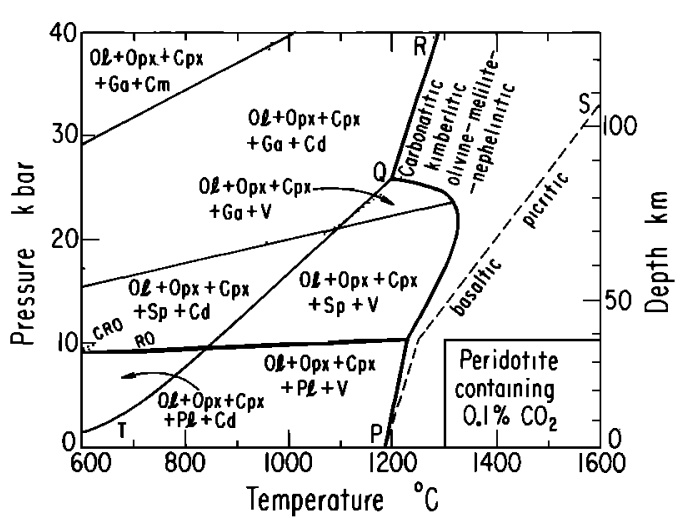

Fig. 17. An interpretation of phase relationships for peridotite- $\mathrm{CO}_{2}$, based on various sources $[W y l l i e, 1978 b]$. The subsolidus exchange reaction with dolomite replaced by magnesite is now known to be at lower pressures (see $W$ yllie et al. [1983] for a review). Abbreviations: Ol, olivine; Opx, orthopyroxene; $\mathrm{Cpx}$, clinopyroxene, $\mathrm{Ga}$, garnet; Sp, spinel; $\mathrm{Pl}$, plagioclase; $\mathrm{Cd}$, dolomite solid solution; $\mathrm{Cm}$, magnesite solid solution; $\mathrm{V}$, vapor. Dotted lines are estimated geotherms. See Figure 7.

cate compositions from the $\mathrm{CO}_{2}$-rich extreme, as indicated by the estimated liquid compositions marked in the diagram. The principle is clear, but there remains some uncertainty about the pressure of $Q$, as shown by the variety of estimates given in Figure 19c. Wyllie and Rutter [1986] have new experimental data placing $Q$ at 22 kbar.

\section{Lherzolite- $\mathrm{H}_{2} \mathrm{O}-\mathrm{CO}_{2}$}

Some aspects of the phase relationships in this system remain controversial [Wyllie, 1987b, c; Eggler, 1987; Taylor and Green, 1987], but we can adopt some diagrams and consider applications without becoming embroiled in the controversies. In the presence of $\mathrm{H}_{2} \mathrm{O}-\mathrm{CO}_{2}$ vapors, the solidus becomes a divariant surface connecting the $\mathrm{H}_{2} \mathrm{O}$ and $\mathrm{CO}_{2}$ solidi in Figures 16 and 17. The reactions for amphibole and dolomite also become divariant, and all three phase surfaces overlap in a broad region. The details of the solidus in this region vary according to the ratio and amounts of $\mathrm{H}_{2} \mathrm{O}$ and $\mathrm{CO}_{2}$ present.

If there is excess vapor, more than enough to make the maximum amounts of dolomite and amphibole within their stability ranges, then the solidus surface is divariant, as shown in Figure 18. Figure 18 reproduces the liquid compositions and solidus for volatile-free peridotite from Figure $15 b$ and shows in addition the solidus curves for peridotite- $\mathrm{H}_{2} \mathrm{O}$, peridotite- $\mathrm{CO}_{2}$, and the divariant solidus surface connecting these curves. Details of the phase relations and the geometry of isoplethal sections are given by $W y l l i e[1978 c, 1979,1980]$. There have been several experimental studies and many controversial reviews concerned with the composition of nearsolidus liquids in this system. Figure 18 is an attempted compromise that illustrates the major trends, with chemical variation shown by the lines representing changes in normative composition of the near-solidus liquids [Wyllie et al., 1981, pp. 553-556]. The amount and composition of liquid developed at the solidus depends on the amount of $\left(\mathrm{CO}_{2}+\mathrm{H}_{2} \mathrm{O}\right)$, on $\mathrm{CO}_{2} / \mathrm{H}_{2} \mathrm{O}$, and on the presence or absence of buffering minerals amphibole, dolomite, and phlogopite. The effect of $\mathrm{H}_{2} \mathrm{O}$ on liquid compositions is to cause enrichment in $\mathrm{SiO}_{2}$, whereas the effect of $\mathrm{CO}_{2}$ is to cause depletion in $\mathrm{SiO}_{2}$. With progressive melting at mantle pressures, the liquids follow 


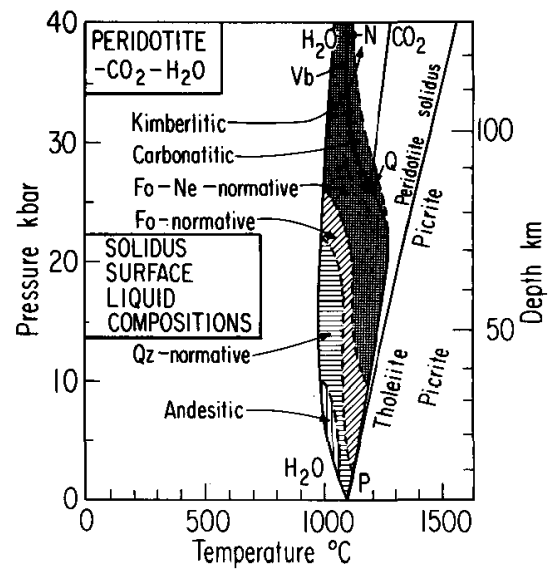

Fig. 18. Projection of the solidus surface for peridotite- $\mathrm{CO}_{2}-\mathrm{H}_{2} \mathrm{O}$, with tentative boundaries showing the changes in composition of the near-solidus, vapor-saturated liquids [Wyllie, 1979]. Solidus with $\mathrm{CO}_{2}$, P-Q-CO buffered vapor $(\mathrm{Vb}), \mathrm{Q}-\mathrm{N}$.

paths through wide temperature intervals toward the basaltic and picritic liquids near the solidus of volatile-free peridotite.

For a particular rock with defined volatile component contents, we need isopleths through the complete phase diagram [Wyllie, 1979]. If the lherzolite contains less than $5 \% \mathrm{CO}_{2}$ and less than $0.4 \% \mathrm{H}_{2} \mathrm{O}$, then the solidus curve involves dolomite, amphibole, or both in buffered melting reactions. For a wide range of conditions, the solidus curve remains univariant in terms of pressure and temperature. The only two experimental studies published on amphibole-dolomite-peridotite indicate that the amphibole stability volume overlaps the solidus with dolomite. There is a difference of several kilobars between the results of Brey et al. [1983] and those from the detailed investigation of Olafsson and Eggler [1983], as shown in Figure 19.

An estimated (but constrained) and extrapolated solidus curve for amphibole-dolomite-peridotite is compared with curves for peridotite dry and with $\mathrm{H}_{2} \mathrm{O}$ in Figure 20. This is modified from a previous version [Wyllie, 1980] incorporating new data [Olafsson and Eggler, 1983; Wyllie, 1987a]. Despite differences in experimental results in Figure 19, the existence of the solidus ledge near $\mathrm{Q}$, where the solidus changes slope and becomes subhorizontal, appears to be established (level 4 in Figure 20). In the following discussion the extrapolated solidus for peridotite- $\mathrm{H}_{2} \mathrm{O}$, which is believed to remain close to that for peridotite- $\mathrm{CO}_{2}-\mathrm{H}_{2} \mathrm{O}$ at pressures greater than about $35 \mathrm{kbar}$, is adopted as the solidus at depth for

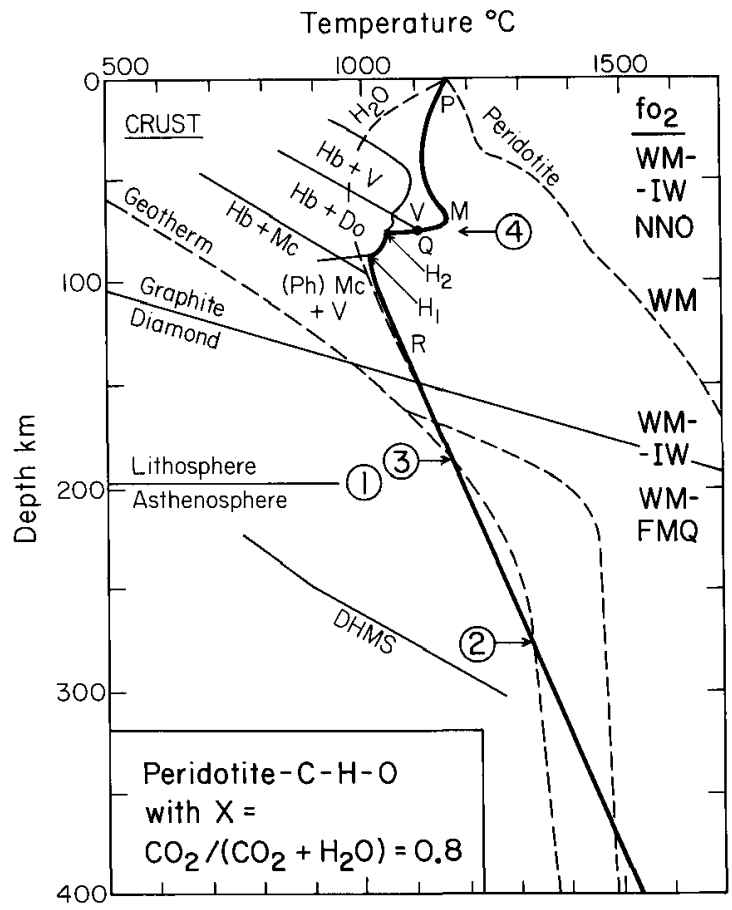

Fig. 20. Solidus curves for peridotite- $\mathrm{H}_{2} \mathrm{O}$ (dashed lines) and for peridotite- $\mathrm{CO}_{2}-\mathrm{H}_{2} \mathrm{O}$ with defined ratio of $\mathrm{CO}_{2} / \mathrm{H}_{2} \mathrm{O}$ (PMQR) extrapolated to high pressures and compared with the cratonic geotherm, with and without inflection (Figure 7). The positions of selected phase boundaries relevant to mantle processes and the origin of kimberlites and nephelinites are given. Possible oxygen fugacities at various levels are indicated by the buffers listed [Haggerty, 1988]. The peridotite solidus is from Figure 3. For DHMS dense hydrated magnesian silicates (DHMS), see Ringwood [1975, p. 295]. Abbreviations: Hb, amphibole; Ph, phlogopite; Do, dolomite; Mc, magnesite; V, vapor.

peridotite-C-H-O for a system with volatile components in the ratio $\mathrm{CO}_{2} /\left(\mathrm{CO}_{2}+\mathrm{H}_{2} \mathrm{O}\right)=0.8$, if oxidized. With variation in this ratio the solidus temperature changes at pressures shallower than point $Q$ at about $75 \mathrm{~km}$ but remains unchanged at higher pressures. Experimental data extend no deeper than about $180 \mathrm{~km}$.

Important levels in the mantle are those where volatile components would be released by activation of a dissociation reaction. One such reaction is represented in Figure 20 by the line DHMS giving the boundary for the reaction of olivine to form dense hydrous magnesian silicates in the presence of $\mathrm{H}_{2} \mathrm{O}$ (Figure 16). The estimated position of the reaction for the conversion of forsterite to brucite and enstatite in
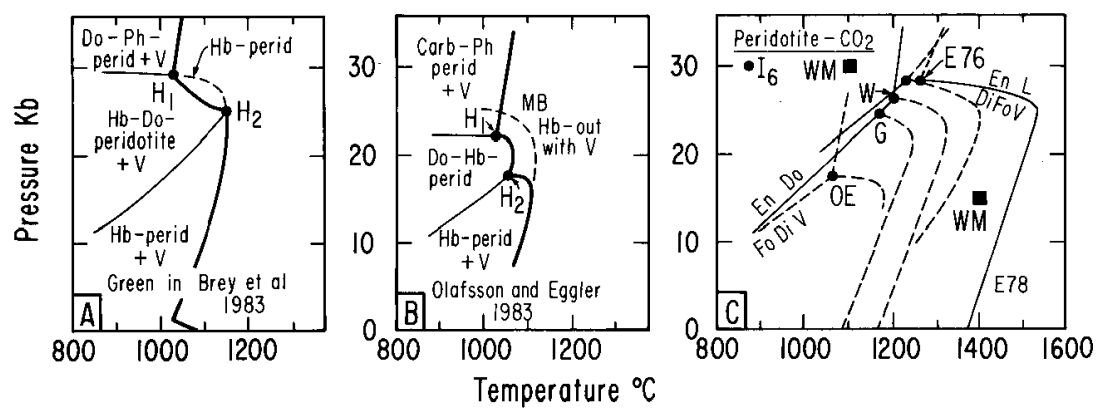

Fig. 19. $(a, b)$. Experimentally determined solidus curves for hornblende-dolomite-peridotite. (c) Locations for the invariant point $\mathrm{I}_{6}$ on the solidus for peridotite- $\mathrm{CO}_{2}$ deduced or estimated from experimental data in other systems. Points $\mathrm{G}$ and $\mathrm{OE}$ are deduced from Figures $19 a$ and $19 b$, respectively [Wyllie, 1987b,c]. 
$\mathrm{MgO}-\mathrm{SiO}_{2}-\mathrm{H}_{2} \mathrm{O}$ (Figure 21) is close to the DHMS curve at $300 \mathrm{~km}$ [Ellis and Wyllie, 1979].

\section{Lherzolite-C-H-O}

The redox state of the deeper mantle appears to be such that the components $\mathrm{C}-\mathrm{H}-\mathrm{O}$ exist as carbon and $\mathrm{H}_{2}$ or $\mathrm{H}_{2} \mathrm{O}$ with $\mathrm{CH}_{4}$, rather than as $\mathrm{CO}_{2}$ and $\mathrm{H}_{2} \mathrm{O}$ [Deines, 1980; Ryabchikov et al., 1981; Green et al., 1987], although this remains controversial. According to D. H. Eggler (personal communication, 1987), "My sources now indicate that it is by no means certain that asthenospheric oxygen fugacity is low enough (well below magnetite-wustite) that volatile components in $\mathrm{C}-\mathrm{H}-\mathrm{O}$ would exist as $\mathrm{H}_{2} \mathrm{O}$ and $\mathrm{CH}_{4}$ rather than as $\mathrm{H}_{2} \mathrm{O}$ and $\mathrm{CO}_{2}$." Figure 20 summarizes Haggerty's [1986, 1988] picture of the possible variations of oxygen fugacity in terms of standard buffers down to $250 \mathrm{~km}$.

With low oxygen fugacities at high pressures, $\mathrm{C}-\mathrm{H}-\mathrm{O}$ exists as $\mathrm{H}_{2} \mathrm{O}$ with $\mathrm{CH}_{4}$ or graphite/diamond. Under these conditions, the peridotite-C-H-O solidus may be raised in temperature compared with the oxidized solidus as indicated by the arrows in Figure 21. According to some investigators, the solidus may remain close to that for peridotite- $\mathrm{H}_{2} \mathrm{O}$, with carbonate ions being generated in the melt when $\mathrm{CH}_{4}$ or graphite/diamond dissolves [Eggler and Baker, 1982; Ryabchikov et al., 1981; Woermann and Rosenhauer, 1985]. According to D. H. Green (personal communication, 1987), however, recent experiments with pyrolite- $\mathrm{CH}_{4}-\mathrm{H}_{2} \mathrm{O}$ at various $\mathrm{H}_{2} \mathrm{O}$ activities with reduced oxygen fugacities do move the solidus to higher temperatures.

The dashed lines in Figure 20 show geotherms from mantle xenoliths in kimberlites (Figure 7, $\mathrm{f}-\mathrm{f}, \mathrm{f}-\mathrm{g}$ ), corresponding to isotherms in Figures 8 and 10. In Figure 21 the solidus is compared with two geotherms associated with a suboceanic mantle plume (Figure 9). The temperatures are higher and the lithosphere is thinner than in Figure 20. Note that the reactions of olivine with water to form DHMS or brucite probably intersect the geotherm somewhere between 300 and $400 \mathrm{~km}$, suggesting that perhaps no $\mathrm{H}_{2} \mathrm{O}$ but only reduced gases $\mathrm{CH}_{4}$ and $\mathrm{H}_{2}$ can exist at deeper levels. These species are not stored in high-pressure minerals as far as we know. The depths 2 and 3 are variable, depending on conditions.

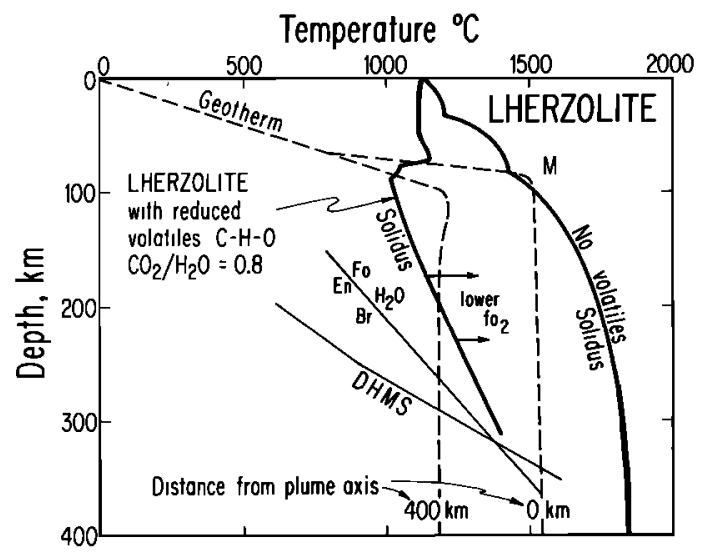

Fig. 21. Solidus curves for lherzolite with and without volatile components and deep dehydration reactions (see Figure 20), compared with geotherms located at center of mantle plume axis and 400 km away (see Figure 9).

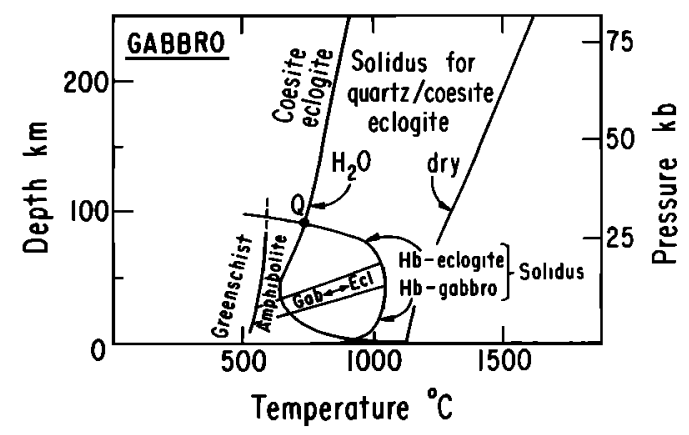

Fig. 22. Selected reactions showing the effect of $\mathrm{H}_{2} \mathrm{O}$ on melting and hydration of basalt (and eclogite). After Wyllie [1978a].

\section{Gabbro-Eclogite}

Basalt, the most abundant magma derived from the mantle, crystallizes as basalt or gabbro at crustal pressures and as eclogite at mantle pressures. Part of this phase transition is shown in Figure 22. There has been extensive debate about whether or not the Moho could be explained by the gabbroeclogite phase transition [Wyllie, 1971, chapter 5], but present evidence favors a chemical change. There have been extensive studies of the liquidus minerals of various basaltic compositions in efforts to relate them through the inverse approach (Figure 13) to peridotite source rocks at various depths. The results and approaches were reviewed in detail by $W$ yllie et al. [1981], with particular attention to MORB's. It is expected, for example, that a basalt liquid derived directly from lherzolite would be in equilibrium with the lherzolite minerals olivine, orthopyroxene, clinopyroxene, and a fourth aluminous mineral, or at least olivine plus orthopyroxene if partial melting had been extensive. The results for the basalt composition given in Figure 23 show olivine on the dry liquidus only to about $20-\mathrm{km}$ depth and without orthopyroxene on the liquidus. One conclusion is that this particular basalt composition was not a primary magma and had experienced differentiation en route to the surface. According to Figure $15 b$, basalt magma can be derived from peridotite only at depths of less than $50-60 \mathrm{~km}$; melts formed deeper than this are richer in magnesium, corresponding to picrites or komatiites. Limits of these kinds are fundamental in checking the validity in detail of the processes represented broadly in diagrams such as those in Figure 4.

\section{Gabbro/Basalt $-\mathrm{H}_{2} \mathrm{O}$}

The main source rock in subducted oceanic crust is basalt or gabbro, metasomatized to uncertain extent by penetration

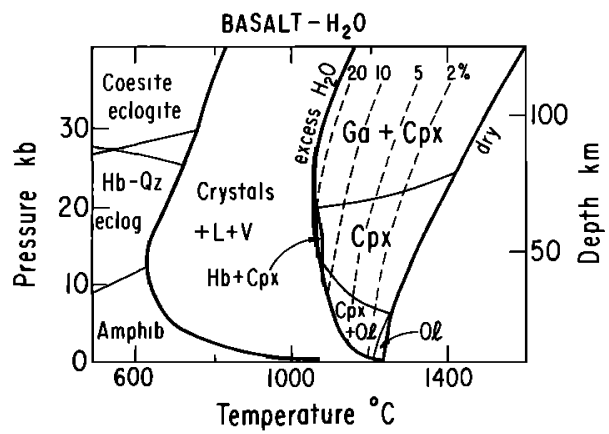

Fig. 23. Phase reactions for basalt- $\mathrm{H}_{2} \mathrm{O}$, modified after Stern et al. [1975] by Wyllie [1979]. 
A

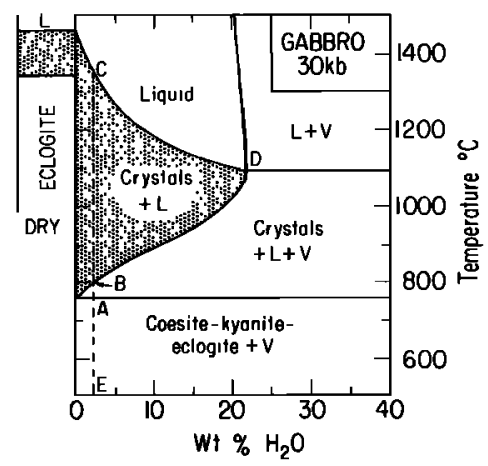

$B$

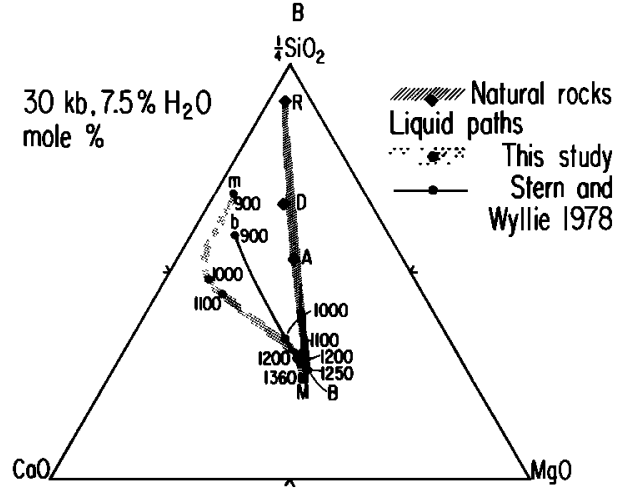

Fig. 24. (a) Isobaric section for gabbro/eclogite- $\mathrm{H}_{2} \mathrm{O}$ at $30 \mathrm{kbar}$, showing path through phase fields for rock or melt with $5 \% / 1 \mathrm{H}_{2} \mathrm{O}$. (b) The calc-alkaline rock sequence B-A-D-R compared with equilibrium paths for liquids generated experimentally in quartz eclogite at 30 kbar with $7.5 \% \mathrm{H}_{2} \mathrm{O}$, using natural basalt (bB [Stern and Wyllie, 1978]) and synthetic basalt in system CaO-MgO- $\mathrm{Al}_{2} \mathrm{O}_{3}-\mathrm{SiO}_{2}-\mathrm{H}_{2} \mathrm{O}(\mathrm{mM})$. "This study" is from Sekine et al. [1981].

of seawater and metamorphosed during subduction through greenschist, amphibolite, and eclogite facies. Amphibolite is also an important source rock in continental crust. Addition of water to gabbro introduces hydrous minerals and lowers the melting temperatures. Figure 22 shows the stability range of the hydrated subsolidus assemblage in the greenschist facies, with dehydration of chlorite at about $600^{\circ} \mathrm{C}$ marking the transition to amphibolite facies. Amphibole stability extends to temperatures above the solidus curve in the presence of $\mathrm{H}_{2} \mathrm{O}$, which is lower by several hundred degrees than the dry solidus for the rock. The greenschist facies assemblage extends to high pressures, whereas the amphibole is limited to pressures of less than $30 \mathrm{kbar}$ because it breaks down to the dense eclogite phase assemblage that is responsible for the change in slope of the solidus with $\mathrm{H}_{2} \mathrm{O}$ at about $15 \mathrm{kbar}$. If the rock contains only enough $\mathrm{H}_{2} \mathrm{O}$ to form amphibole with none left over for free vapor, then the solidus is associated with the breakdown of vapor-absent hornblende-gabbro or hornblende-eclogite, releasing $\mathrm{H}_{2} \mathrm{O}$ for solution in $\mathrm{H}_{2} \mathrm{O}$-undersaturated liquid (Figure $14 d$ ). The phase boundaries in Figure 22 are those used in the forward approach of calibrating what happens to basalt under various conditions. For the reverse approach of considering possible source for this basaltic composition with dissolved $\mathrm{H}_{2} \mathrm{O}$, we need information about the liquidus.

Figure 23 outlines phase relationships for basalt- $\mathrm{H}_{2} \mathrm{O}$ extending from the solidus to the liquidus surface which is contoured in terms of $\mathrm{H}_{2} \mathrm{O}$ content. The solidus is the same as long as there is a free vapor phase, but the liquidus curve for any specific $\mathrm{H}_{2} \mathrm{O}$ content is given by the appropriate contour. This is illustrated in Figure 24a, an outline of the isobaric section for the system (Figure 13) at $\mathbf{3 0} \mathrm{kbar}$, above the stability range of amphibole. Notice the liquidus for $\mathrm{H}_{2} \mathrm{O}$-undersaturated basalt. A gabbro with a lew percent olivine is converted to coesite-eclogite at $30 \mathrm{kbar}$ (Figure 23). The results of two attempts to determine the compositions of liquids produced during progressive fusion of quartz-eclogite in the presence of a few percent of $\mathrm{H}_{2} \mathrm{O}$ are compared in Figure 24b. Stern and Wyllie [1978] plotted liquid compositions ranging through intermediate $\mathrm{SiO}_{2}$ contents, with $\mathrm{Ca} /(\mathrm{Mg}+\mathrm{Fe})$ higher than the average composition trend for calc-alkaline dacite-andesite-basalt. Results of Sekine et al. [1981] for synthetic basalt composition in the system $\mathrm{CaO}-\mathrm{MgO}-\mathrm{Al}_{2} \mathrm{O}_{3}-\mathrm{SiO}_{2}-\mathrm{H}_{2} \mathrm{O}$ reinforced the conclusion.

\section{Tonalite/Andesite $-\mathrm{H}_{2} \mathrm{O}$}

Andesite is the characteristic lava of convergent plate boundaries, and tonalite (with similar composition in terms of major elements) is a major component of many batholiths in the same environments. Tonalitic gneiss is probably an important component of the source rocks in the lower continental crust. Figure 25 is directly analogous to Figure 23, showing the liquidus surface for the magma contoured in terms of $\mathrm{H}_{2} \mathrm{O}$ content and the effect of $\mathrm{H}_{2} \mathrm{O}$ on the liquidus mineralogy, as well as the effect of excess $\mathrm{H}_{2} \mathrm{O}$ on the solidus curve and the subsolidus mineralogy. The liquidus surface provides the key evidence in the inverse approach concerning possible source rocks for an andesite of this composition, if it is considered to be a primary magma. An isobaric section at $15 \mathrm{kbar}$ is shown in Figure 26 [Huang and Wyllie, 1986]. This is analogous to Figure $24 a$ for basalt, with the addition of details of the subliquidus mineralogy. Note that the vapor-absent tonalite begins to melt at a higher temperature than the vapor-present rock, following the example of Figures $14 b$ and 14d. Huang and $W$ yllie [1986] reported the compositions of glasses and minerals in the sequence of runs with $5 \% \mathrm{H}_{2} \mathrm{O}$.

Rutter and Wyllie [1988a] studied the progressive melting of vapor-absent tonalite at $10 \mathrm{kbar}$, representing partial melting of tonalite gneiss in the lower crust in the absence of pore fluids. They measured the percentage of $\mathrm{H}_{2} \mathrm{O}$-undersaturated melt produced as a function of temperature as well as the compositions of glasses and minerals. The results in Figure 27 show that melting begins at about $825^{\circ} \mathrm{C}$ with the breakdown of biotite to produce $\mathrm{H}_{2} \mathrm{O}$-undersaturated liquid; $20 \%$ liquid

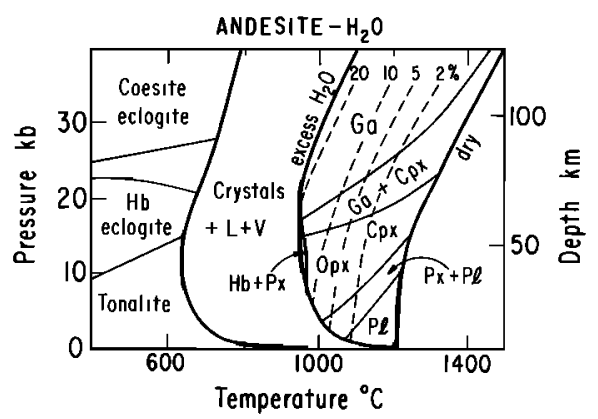

Fig. 25. Phase relationships for andesite- $\mathrm{H}_{2} \mathrm{O}$ modified after Stern et al. [1975]. 


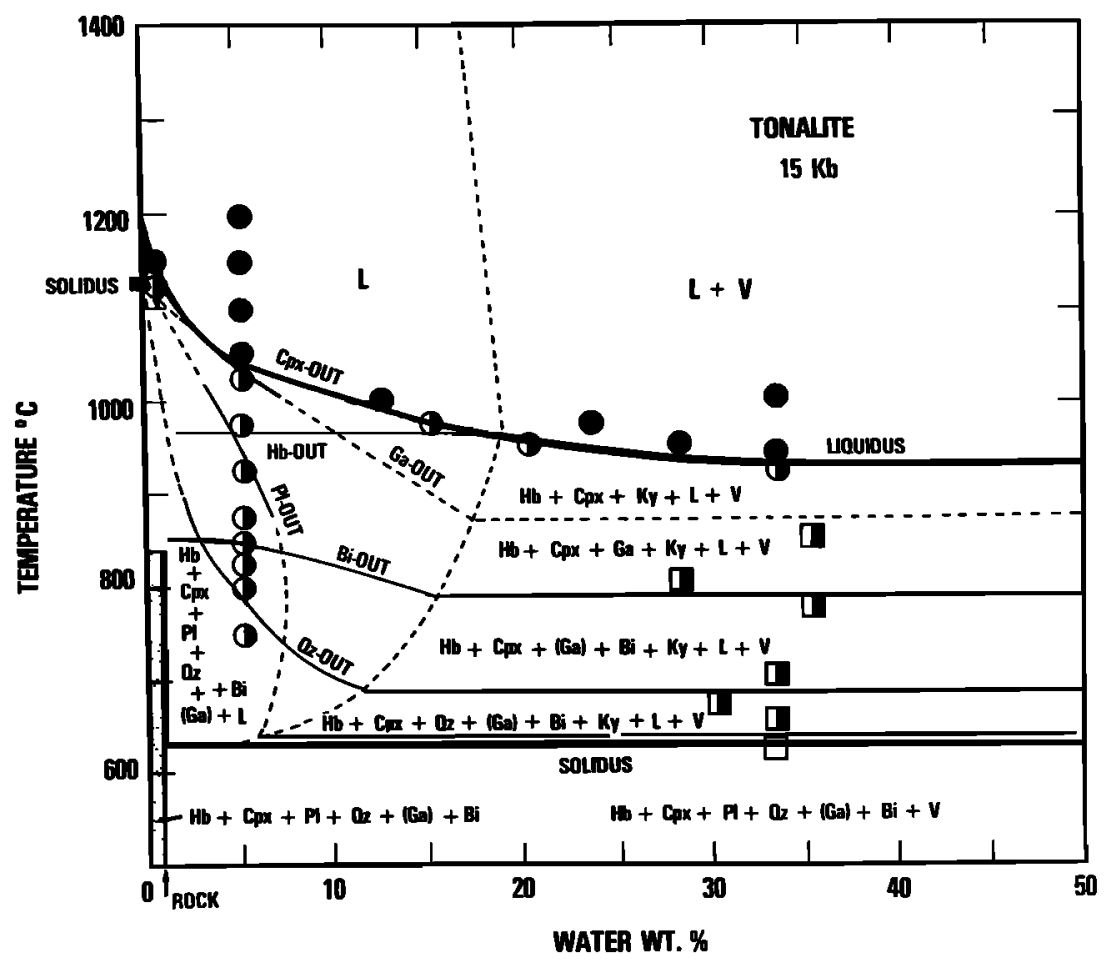

Fig. 26. Isobaric section for tonalite- $\mathrm{H}_{2} \mathrm{O}$ at $15 \mathrm{kbar}$ [Huang and Wyllie, 1986].

is produced during the biotite reaction between $825^{\circ} \mathrm{C}$ and $900^{\circ} \mathrm{C}$. By $1000^{\circ} \mathrm{C}$ the horblende had also melted, producing $35 \%$ liquid containing a calculated 2.3 weight percent $\mathrm{H}_{2} \mathrm{O}$.

The composition of hornblende in granitic intrusions is a function of the magma composition and the conditions of crystallization. An empirical geobarometer has been proposed recently on the basis of total Al content of calcic hornblendes in tonalites and granodiorites for which there was independent

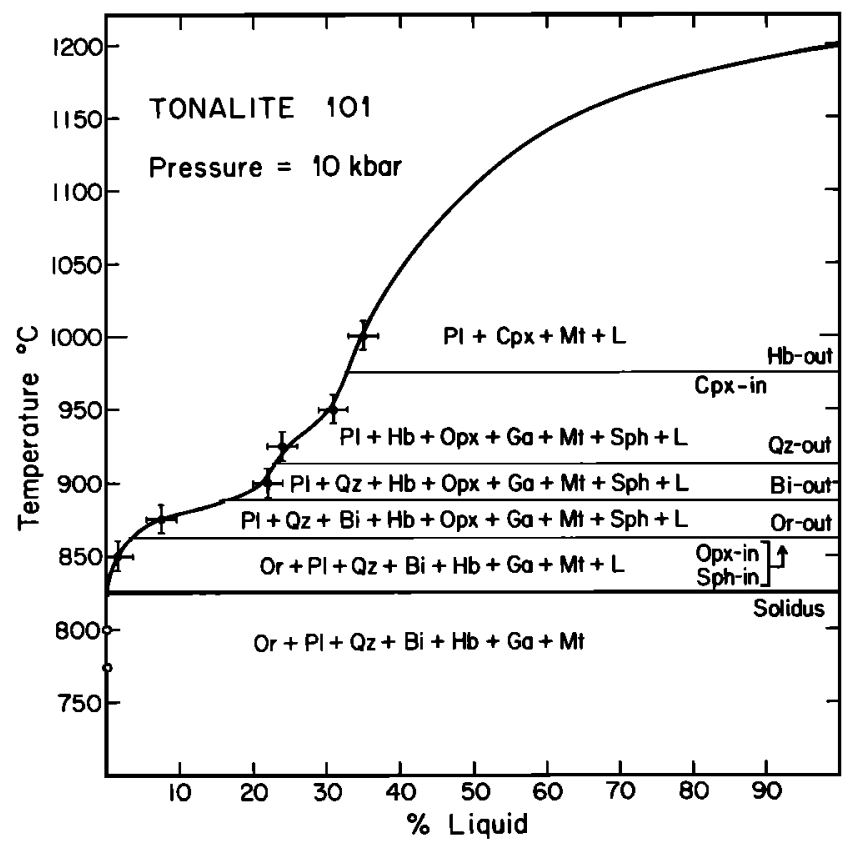

Fig. 27. Dehydration melting of tonalite at $10 \mathrm{kbar}$. Phase boundaries and percentage of liquid through the melting interval [Rutter and Wyllie, 1988a]. evidence for depth of crystallization. The two empirical curves published are reproduced in Figure 28 [Hammarstrom and Zen, 1986; Hollister et al., 1987]. These are applicable only under the specified conditions, because of the large number of variables that can affect the hornblende composition. The experimental results for hornblende composition in partly melted tonalites determined by Rutter and Wyllie [1988b] provide encouraging support for the empirical geobarometer.

\section{Granite/Rhyolite- $\mathrm{H}_{2} \mathrm{O}$}

Figure 29 provides the basis for considering the inverse approach for the origin of rhyolite and granite. The $\mathrm{H}_{2} \mathrm{O}$-undersaturated liquidus surface shows the range of depth-temperature conditions for the formation of a liquid of

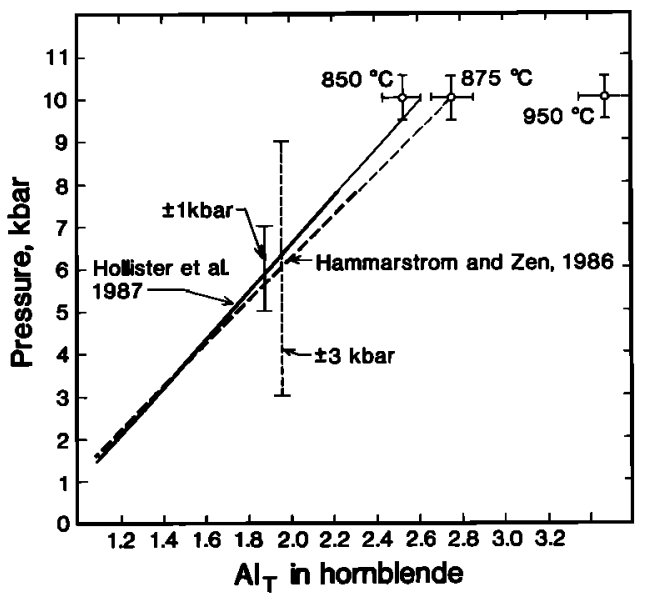

Fig. 28. Empirical curves of total $\mathrm{Al}$ in hornblende versus pressure of crystallization, extrapolated to $10 \mathrm{kbar}$. The crosses are for microprobe analyses of hornblendes in partly melted tonalite experimental products at $10 \mathrm{kbar}$. 


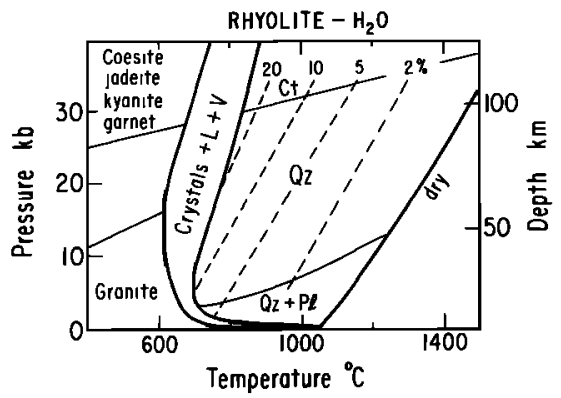

Fig. 29. Phase relationships for rhyolite- $\mathrm{H}_{2} \mathrm{O}$ modified by Wyllie [1979] after Stern et al. [1975].

rhyolite composition with various amounts of dissolved $\mathrm{H}_{2} \mathrm{O}$. If this particular rhyolite (or others with similar compositions) was a primary magma, the residual minerals left behind in the partly melted source rock should include the minerals on the liquidus. At crustal pressures these include quartz and plagioclase. At mantle pressures the liquidus mineral is quartz, and quartz crystallizes alone through a large temperature interval below the liquidus [Stern and Wyllie, 1981]. There is no source rock in the mantle that could leave residual quartz. Rhyolite, therefore, cannot be a primary magma from mantle peridotite or eclogite.

Rhyolite is not generated from mantle source rocks, and granite is a crustal rock. Crustal rocks, however, may be carried to considerable depths during the geologically brief periods when continental thickness is greatly increased by continental collisions, as indicated in Figure 5b. Schreyer et al. [1987] have presented evidence for the recrystallization of granitic rocks beneath the convergent Alps at depths of about $100 \mathrm{~km}$. The isobaric section for granite- $\mathrm{H}_{2} \mathrm{O}$ at $30 \mathrm{kbar}$ illustrated in Figure 30 is, therefore, relevant for interpretation of such processes. Note that the subsolidus mineralogy at $\mathbf{3 0}$ kbar is completely different from that of normal granite. The

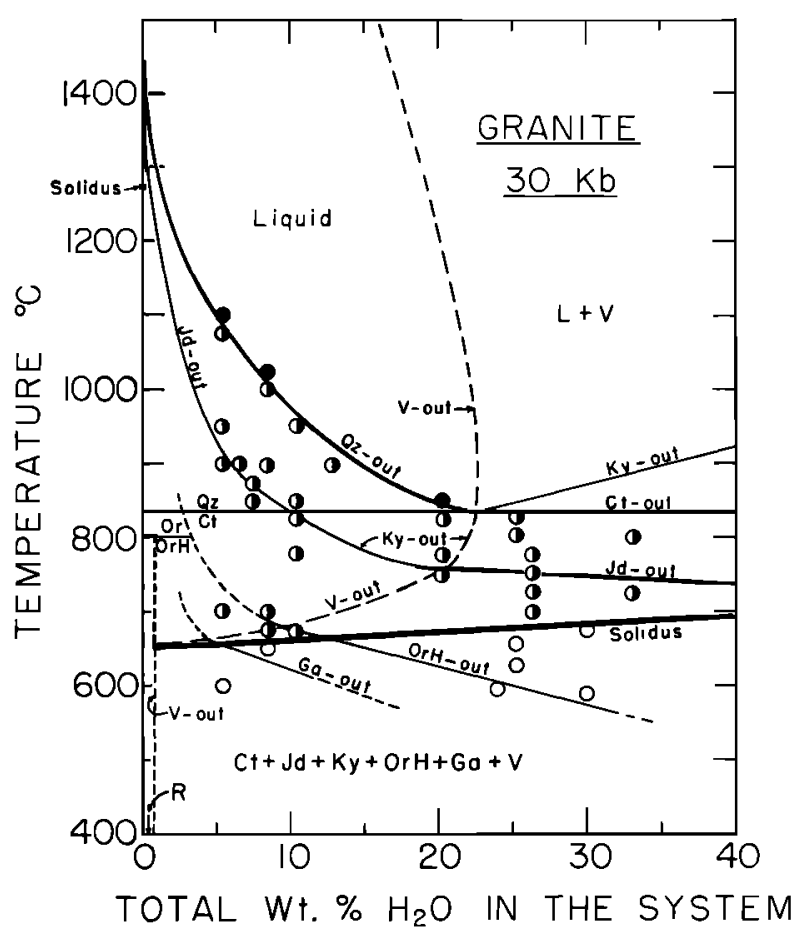

Fig. 30. Isobaric section for granite- $\mathrm{H}_{2} \mathrm{O}$ at $30 \mathrm{kbar}$ [Stern and Wyllie, 1981].

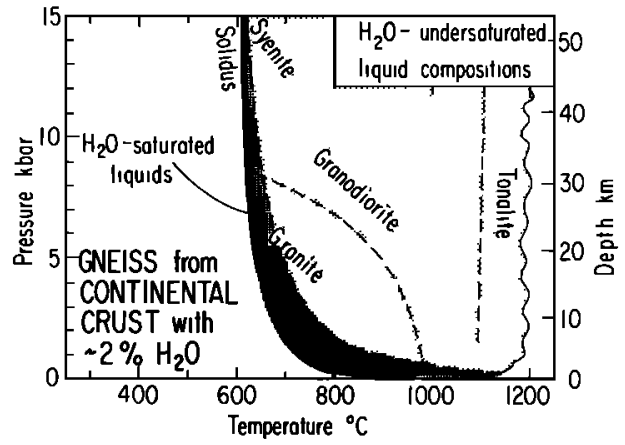

Fig. 31. Compositıons of liquids generated within the melting interval of rocks of continental crust in the presence of $\mathrm{H}_{2} \mathrm{O}$ [after $W y$ llie, $1977]$.

feldspars and quartz have been replaced by eclogitic minerals plus kyanite (in proportions quite different from those in gabbro, of course). Biotite and amphibole are no longer present at $30 \mathrm{kbar}$, but the dense mineral sanidine hydrate has become stable, and muscovite remains in more aluminous granites [Huang and Wyllie, 1981]. The composition of the subsolidus vapor phase has not been determined, but this would be of interest [Schreyer et al., 1987].

\section{Gneiss- $\mathrm{H}_{2} \mathrm{O}$}

The dominant rocks of the deep continental crust consist of the calc-alkaline plutonic rocks and their metamorphic equivalents, together with metamorphosed shales and greywackes. Wyllie [1977] presented a detailed review of experiments related to crustal anatexis for conditions with a pore fluid and for vapor-absent melting of rocks with hydrous minerals muscovite, biotite, or amphibole.

Figure 31 shows the approximate $P-T$ ranges for the generation of liquids of various compositions from continental gneisses, with a generous allowance of $2 \% \mathrm{H}_{2} \mathrm{O}$ in pore fluids. The temperature interval for the persistence of $\mathrm{H}_{2} \mathrm{O}$-saturated granitic liquids is narrow. At lower pressures, $\mathrm{H}_{2} \mathrm{O}$ undersaturated granite (rhyolite) liquid coexists with residual minerals through a wide range of temperatures. Very high temperatures are required to reach liquid compositions corresponding to tonalites (andesites). Increasing pressure produces liquids with lower $\mathrm{SiO}_{2}$, and rhyolite liquid cannot be produced at the base of the normal continental crust. For thick-

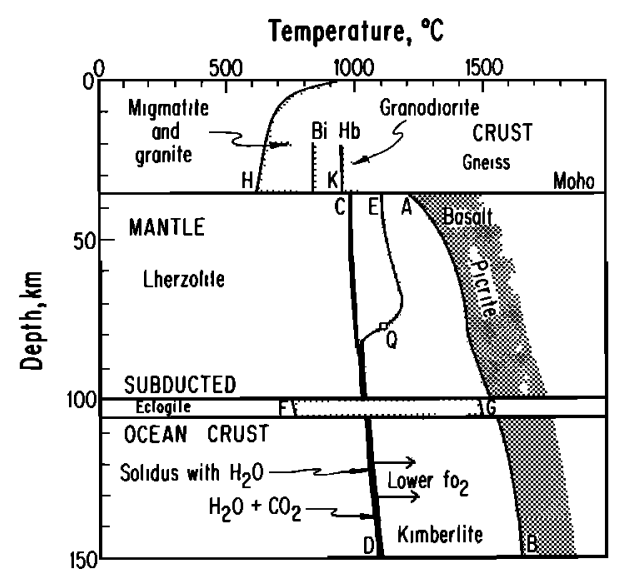

Fig. 32. The major sites of magma generation (stippled) in continental crust, mantle, and subducted oceanic crust (at 100-km depth). Solidus curves are transferred from previous figures, as cited in text. 

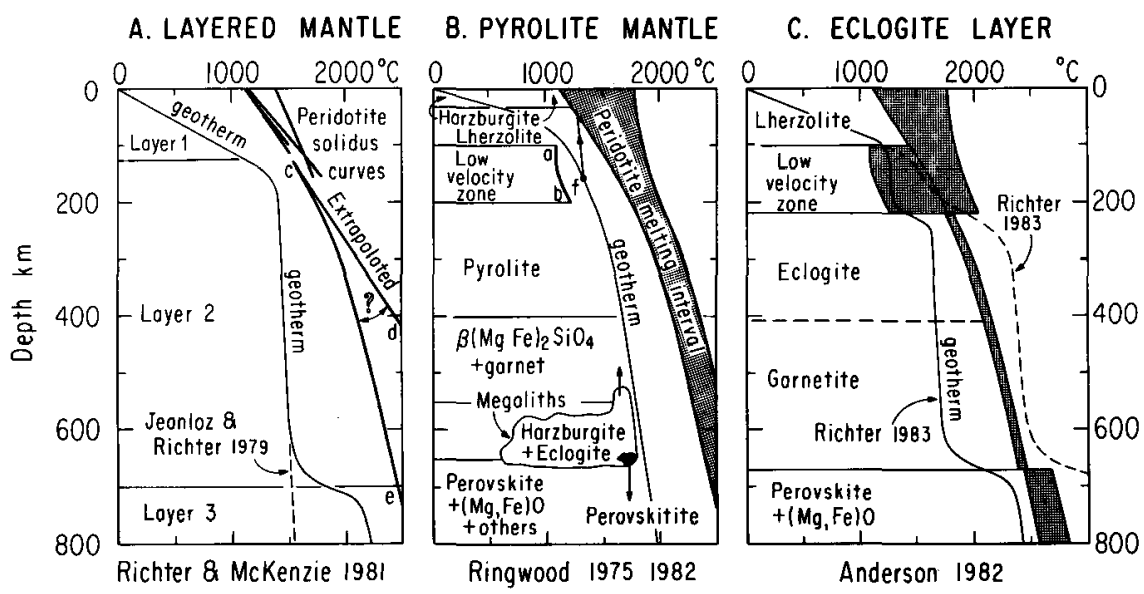

Fig. 33. Proposed mantle structure and geotherms compared with experimentally determined and extrapolated melting conditions for peridotite and eclogite. (a) Experimental peridotite solidus curves extrapolated long either ce or cd. (b) Estimated peridotite melting interval, after $W$ yllie [1981]. The curve ab is the solidus QR with buffered vapor, from Figure 20. (c) Eclogite melting interval extrapolated from $100 \mathrm{~km}$, from $W y l l i e$ [1984, Figure 1]. See text for comparison with Figure 4.

ened crust, the near-solidus liquid approaches syenite composition [Huang and Wyllie, 1981]. The vapor-absent melting of tonalite gneiss at $10 \mathrm{kbar}$ was illustrated and described above (Figures 26, 27, and 28).

\section{Depth-Temperature Framework}

The solidus curves for the various materials reviewed above provide a depth-temperature framework useful for consideration of magmatic sources and magma interactions in various tectonic environments. Figure 32 provides specific depthtemperature limits for some of the magmatic processes summarized in Figure 6. It shows the continental crust overlying the mantle, with a layer of subducted oceanic crust $100 \mathrm{~km}$ below the surface. The sites of possible magma generation in these various magmatic hearths are identified by shading. High-temperature conditions for the generation of basalts and picrites above $\mathrm{AB}$ are from Figure $15 \mathrm{~b}$. The influence of $\mathrm{H}_{2} \mathrm{O}$ or $\mathrm{C}-\mathrm{H}-\mathrm{O}$ species on magma generation in mantle peridotite is given by $\mathrm{CD}$ and EQD from Figures 20 and 21. With the availability of $\mathrm{H}_{2} \mathrm{O}$ in subducted oceanic basalt, melt can be generated in the interval FG (Figure 24). The continental crust begins to melt above $\mathrm{H}$ in the presence of aqueous pore fluids (Figure 31). In the absence of pore fluids, melting begins near $\mathrm{K}$ when biotite or amphibolite breaks down to form $\mathrm{H}_{2} \mathrm{O}$-undersaturated liquid (Figure 27). Figure 32 shows the potential for interaction of rising melts of different compositions and temperatures, considering simply mantle magmas rising into the crust or the more complex situation of magmas from subducted oceanic crust rising into mantle and continental crust.

\section{Convection, Geotherms, and Solidus Curves}

The geotherms and solidus curves in Figure 33 provide tests for the different mantle convection models summarized in Figure 4 . The solidus curves plotted for peridotite are older versions that should be compared with the curve in Figure 3 by Takahashi [1986], which is reproduced in Figure 34 along with a geotherm (Figure 7) corresponding to the mantle model in Figure $4 a$.

Figure $33 a$ reproduces the different experimentally determined solidus curves for peridotites. These are extrapolated linearly along c-d. The calculated Simon-type fit along c-e [Griggs, 1972] is probably a better representation of a peridotite solidus, and it matches more closely the recent experimental determination (Figure 34). The peridotite melting interval in Figures $33 b$ and $33 c$ was estimated by $W y$ llie [1981]. The geotherms in Figure 33 are from various sources, and these merit comparison with Figure 7.

Jacobsen and Wasserburg's [1981] mechanism for crustal growth according to their model I was illustrated in Figure $4 a$. This model is represented in "Figure $33 a$ by the layered mantle considered by Richter and McKenzie [1981]. They assumed that the separate reservoirs situated below the lithosphere (layer 1) consisted of superimposed layers 2 and 3 , convecting without significant mass transfer across the boundary between them. Jacobsen and Wasserburg [1981] proposed that blobs of undepleted mantle rise from layer 3 and intersect the solidus at shallower levels. According to the recent determination of the peridotite solidus (Figure 34), material rising from layer 3 with the geotherm of Figures $33 a$ and $33 b$ would begin to melt at depths considerably below the lithosphere.

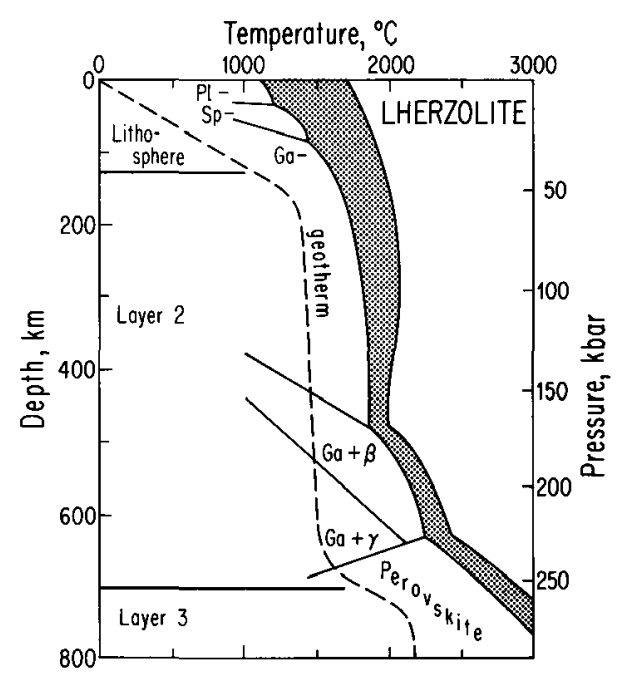

Fig. 34. Phase diagram for lherzolite from Figure 3 [Takahashi, 1986], compared with proposed upper mantle structure and geotherm from Figure $33 a$. 
Figure $33 b$ illustrates Ringwood's [1982] modification of the pyrolite-basalt model (see Ringwood [1975] for a summary), as sketched in Figure 4d. The lithosphere is composed of depleted harzburgite and lherzolite overlying pyrolite which resorbs the depleted material stripped off during subduction, thus maintaining a continuous source for MORBs. The seismic low-velocity zone is attributed to incipient melting at temperatures above the solidus, a-b, for peridotite- $\mathrm{H}_{2} \mathrm{O}-\mathrm{CO}_{2}$ (Figure 18). Ringwood [1975] used the calculated geotherm shown in Figure $33 b$, with diapiric uprise of mantle masses tracing adiabatic paths such as that rising from point $f$. The second mantle reservoir composed of megaliths of depleted, subducted, cool lithosphere enclosing eclogite from oceanic crust is density balanced at about $650-\mathrm{km}$ depth. Attainment of thermal equilibrium after 1-2 billion years is followed by uprise of the refertilized harzburgite. The model needs testing and review in terms of new solidus curves and geotherms (Figures 34 and 7).

Anderson's [1982] model of Figure $4 c$ is represented in Figure $33 c$. The low-velocity zone is attributed to incipient melting. The density-balanced eclogite layer perched between $220 \mathrm{~km}$ and $670 \mathrm{~km}$ is the depleted reservoir, and the upper peridotite layer is a reservoir enriched by kimberlite fluids. The schematic, extrapolated melting interval for peridotite of Figure $33 b$ is replaced between $220 \mathrm{~km}$ and $670 \mathrm{~km}$ by an estimate of the melting interval for eclogite. The extrapolation preserves the narrow melting interval known to occur through $30 \mathrm{kbar}$ and the proximity of the solidus for quartz-free eclogite with that for peridotite [Wyllie, 1984, Figure 1]. Anderson's [1982] mantle in Figure $33 c$ has an additional convecting layer, compared with the model of Richter and McKenzie [1981] in Figure 33a. This introduces another step into the geotherm. The solid line in Figure $33 c$ is a conservative estimate for the geotherm with this mantle model, but the dashed line is a more realistic estimate of what the additional convecting layer would do to the geotherm according to F. M. Richter (personal communication, 1983).

The solidus curves provide constraints on the dimensions of layers in Figures 33a, 33c, and 34, because of the large steplike increases in temperature associated with each boundary. With the results used by Richter and McKenzie [1981] in Figure $33 a$, the temperature at $700 \mathrm{~km}$ is not high enough to cause partial melting of layer 3. They pointed out, however, that if the bottom of layer 2 were shallower than about $500 \mathrm{~km}$, then widespread melting is suggested by their calculation, and the two-layer arrangement would be untenable. Therefore it is not clear how the two-layer convecting mantle (Figure 4a) could have developed into what is presently a stable condition, if layer 2 is the depleted mantle reservoir which has grown downward through time at the expense of undepleted source layer 3, as in model I of Jacobsen and Wasserburg [1981]. The problem is exacerbated if mantle temperatures were even higher in early Earth history.

Consideration of solidus curves and geotherms is essential for testing the validity of mantle models, and as data from experimental petrology and geophysics improve, they may facilitate discrimination among interpretations based on geochemistry. They do provide close constraints on subduction and lithosphere processes.

\section{Magma Generation and Transport}

The combination of isotherms and solidus curves shows possible sites of magma generation, but the mechanism of melting and the process of magma migration are controlled by physical properties. The densities of rocks and melts are important variables in controlling convection and the migration of magmas. Viscous forces which act to impede melt segregation depend critically upon the rheological response of the crystal-liquid system to local conditions.

A magma is defined as a melt-crystal assemblage. There are three ways for magma or melt to migrate in the mantle: (1) the partially molten assemblage may become dynamically unstable and migrate upward as a diapir through its host; (2) the interstitial melt may percolate upward through the crystalline host along grain boundaries; or (3) the melt fraction may segregate from the crystalline host in either example, and rise through a propagating crack. The escaping magma could transport with it some of the host crystals.

The question of how much melt needs to be produced in a partly molten rock before the melt can segregate (the critical melt fraction) is an important topic. Another is how much residual melt is retained within the pore spaces and intergranular boundaries of a rock that has been effectively drained of magma. This has implications for interpretation of the seismic low-velocity zone and the chemistry of the mantle, especially with respect to LIL elements and to mantle metasomatism. Answers to these questions will be different for mantle magmas and for the more viscous crustal magmas.

Maaloe and Scheie [1982] considered the process of partial melting of lherzolite in a rising mantle plume. They defined a partial melting boundary, the level where melting begins, and a permeability boundary at a higher level where the partly molten source became permeable. They demonstrated that once permeable, the mantle would undergo compaction and the melt would be squeezed out, accumulating in the form of horizontal layers. The magma may be tapped from a dispersed source consisting of a multitude of layers and interconnecting veins. With divergent flow as in the topmost part of the plume, the layers come apart and a large magma chamber may be formed [Maaloe, 1981]. Ribe and Smooke [1987] also concluded that layers of segregated melt are likely to form magma chambers above plumes at the base of the lithosphere and that about $60-80 \%$ of the melt generated within the plume is extracted from an area comparable to that of the plume itself. Navon and Stolper [1987] modeled aspects of the chemical interaction between rising melts and the mantle in terms of ion exchange processes with particular attention to trace elements and including specific treatment of melt in a rising plume.

In a review of magmatic processes, Marsh [1987] concluded, "No other quadrennium has contributed so much to advancing our understanding of magmatic processes." $\mathrm{He}$ noted that we are in the midst of an extremely fertile burst of activity with petrologists actively seeking evidence for and against various physical processes and applying the essentials of the mechanics of magmas with quantitative insights. He reviewed developments in understanding the role of compaction in deforming a solid to close the pores in a rock and thus force out interstitial liquid [McKenzie, 1984] and the transport of liquids in solitons, solitary waves of increased percentages of liquid which travel as pulses deforming the rock matrix [Scott and Stevenson, 1986]. These processes may be important in the mantle. In the crust, however, where silicic melt viscosities are much larger, the conditions over which compaction is effective are more limited. Marsh's [1987] review also covers additional physical topics crucial to understanding diapirism, chemical plumbing systems, processes of 
convection and mineral sorting in magma chambers, and the withdrawal and eruption of magmas.

The variation of density of melts as a function of pressure, temperature, and composition is a fundamental parameter in all magmatic processes. The densities of molten silicates up to $230 \mathrm{kbar}$ have been measured for the first time recently using shock wave techniques [Rigden et al., 1984]. Results were obtained for a synthetic model basaltic composition and were compared with density-depth relations for the Earth derived from recent seismological models. Some implications of the results are as follows: (1) melts become denser than host mantle at pressures of $60-100 \mathrm{kbar}(200-300 \mathrm{~km}$ in the Earth), (2) there is a maximum pressure from which basaltic (or picritic) melt can rise within planetary interiors, (3) the slope of silicate melting curves should become very shallow at high pressures (see Figure 3), and (4) enriched reservoirs formed by sinking liquids may exist at depth within the Earth.

These results have important implications for early evolution of the Earth and the origin of komatiites. Komatiite melt formed at depth would be too dense to rise. It would sink, and the olivine with which it could coexist would float to generate a refractory cap. The concept of a magma ocean formed in this way and implications for the thermal and geochemical evolution and stratification of the mantle have been discussed by Nisbet and Walker [1982], Anderson [1982], and Ohtani [1985].

There is another kind of control exerted by density on magma migration. The melt in equilibrium with mantle peridotite changes composition as it rises from picritic (more dense) to basaltic (less dense). Picritic melt, if emplaced into a basaltic magma chamber in the crust, is denser than the basalt melt and may form a separate layer beneath it. This has interesting petrological consequences that have been explored recently. Picritic melt is also denser than continental crust, and lowdensity crustal rocks could act as a density filter preventing the eruption of picritic lavas.

With crystallization of a magnesian melt at any depth, the subtraction of crystals from the melt causes a progressive change in its density. Stolper and Walker [1980] calculated the change in density of such liquids versus fractionation. The densities of residual liquids pass through a minimum when pyroxene and plagioclase join the crystallization sequence and then rise to a maximum corresponding to the stage where ilmenite begins to crystallize. They also demonstrated that oceanic basalt compositions cluster around the composition corresponding to the density minimum for differentiating liquids. Magnesian melts trapped in the crust by their density may evolve by crystallization to melts with densities lower than the overlying crust, which then permits their eruption. The "window of eruptibility" is restricted by the subsequent increase in melt density, and it could be this filter effect which favors the eruption of the observed basalts compared with denser, more or less fractionated liquids.

\section{Divergent Plate Boundaries}

The major chemical differentiation of the Earth is accomplished at mid-ocean ridges by the separation of MORBs from mantle lherzolite or from piclogite or from some mixture of peridotite and eclogite (Figure 4). The lithosphere is thin, and mantle uprise yields an oceanic geotherm approximating $\mathbf{d}-\mathbf{d}$ in Figure 7, crossing the solidus of lherzolite (Figures 2, 33, and 34). The application of phase diagrams to the origin of

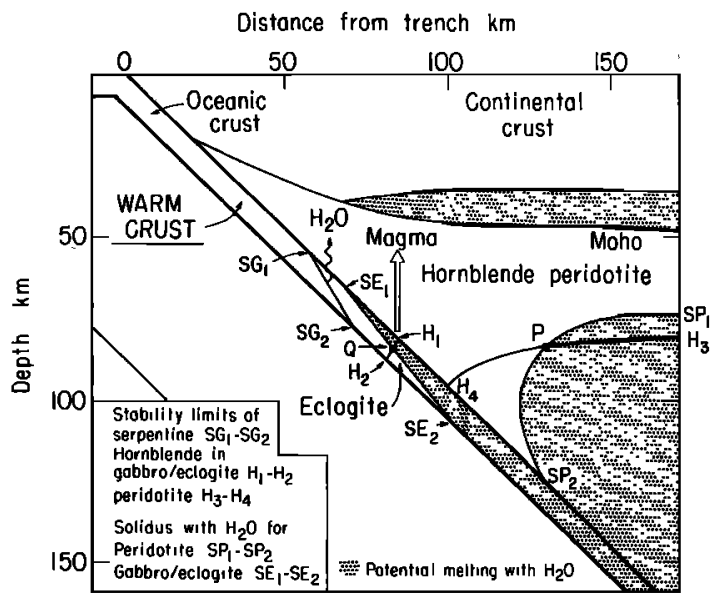

Fig. 35. Cross section of a highly idealized $45^{\circ}$ subduction zone, showing (for a particular set of isotherms) the petrological structure of subducted oceanic crust, the overlying mantle wedge, and the continental crust, with particular reference to the regions of potential melting tf $\mathrm{H}_{2} \mathrm{O}$ is present.

MORB's was reviewed in detail by Wyllie et al. [1981]. The cycle involving piclogite, basalt, and subducted eclogite was developed by Anderson [1982]. It is now evident that many complex processes including magma mixing and differentiation have occurred in shallow level magma chambers beneath the ridges. A recent review by Falloon and Green [1987] presents new experimental data supporting the idea that MORBs are derivative from primary picritic magmas generated at depths greater than $30 \mathrm{~km}$.

\section{Convergent Plate Boundaries}

There are many variables in petrology and geophysics at convergent plate boundaries, but the emergent plutonic and volcanic rocks have common, distinctive chemical characteristics and organized structural geology [Gill, 1981]. These characteristics indicate crustal differentiation modified by dissolved $\mathrm{H}_{2} \mathrm{O}$ [Grove and Kinzler, 1986], but the evidence for multiple source materials is clear [Carlson, 1987]. The sources include subducted oceanic crust, overlying mantle, and continental crust if present. Subducted pelagic sediments may contribute to the magmas. Bodies of serpentinite in the oceanic crust are a source of aqueous solutions. The subduction of volatile components distinguishes this tectonic environment from others, and the influence of these components after thermal dissociation produces magmas of distinctive composition.

\section{Ocean-Continent Boundary}

Applying experimentally determined phase boundaries for the three source regions in the presence of aqueous fluids (Figures 16, 22, 31, and 32) to specific thermal structures (Figure 12) provides a framework locating sites of dehydration and potential melting. Figure 35 shows the boundaries for an idealized $45^{\circ}$ subduction zone, for a relatively warm crust and cool mantle. The points where wet solidus curves cross the amphibole-out curves are located in Figures $16(\mathrm{P})$ and $22(\mathrm{Q})$; these points occur at fixed pressures, but they may move horizontally in Figure 35 as the thermal structure varies. Magmas are developed in the shaded areas only if aqueous vapors pass through them. The locations of the phase boundaries and thus the petrological structure are sensitive to changes in thermal structure. Four examples are shown in Figure 36, correspond- 

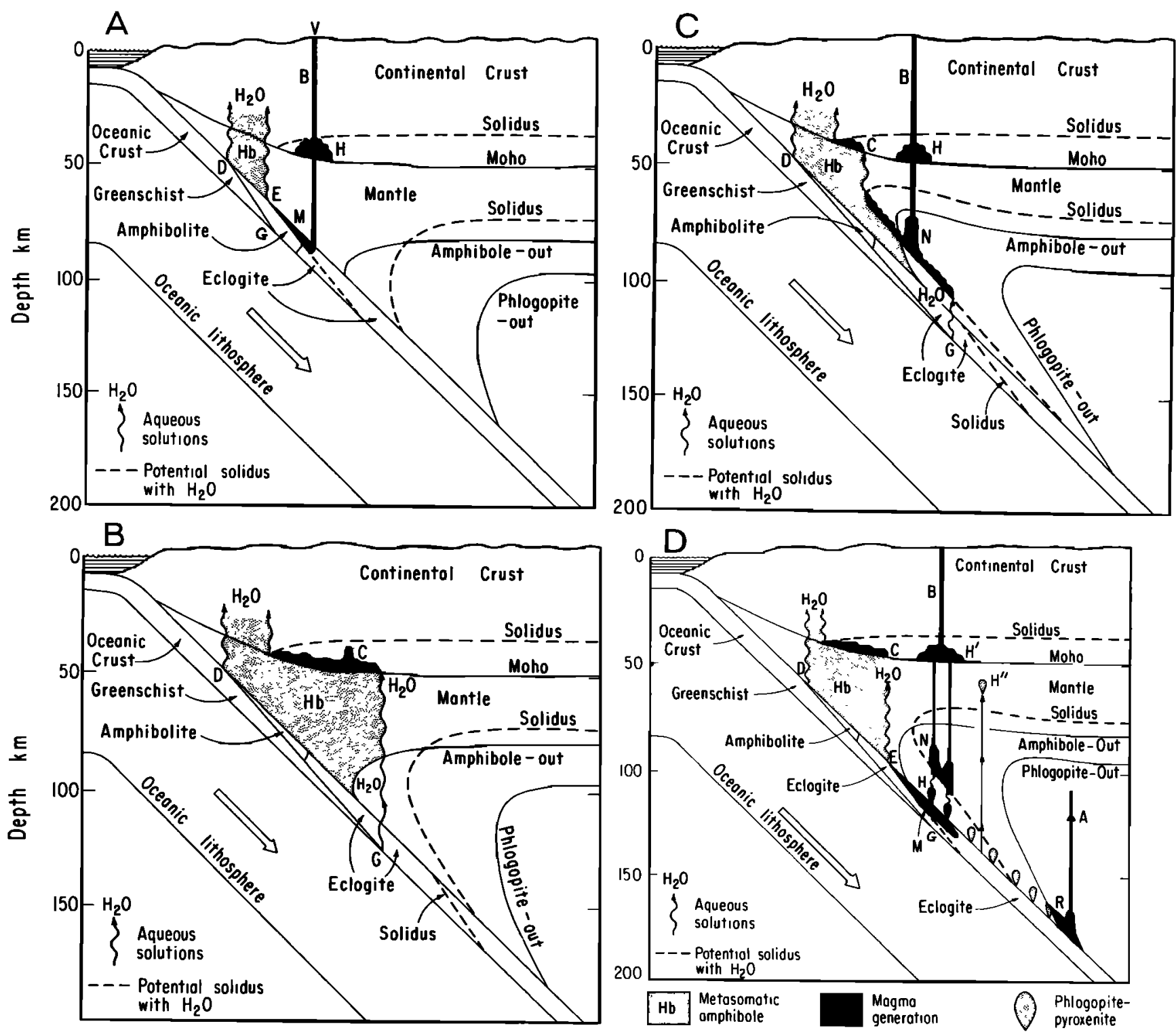

Fig. 36. Locations of dehydration, metasomatism, and melting in subduction zones from results of experimental petrology, according to four thermal structures obtained by combinations of warm or cool (by endothermic dehydration) subducted ocean crust, with cool or warm (by induced convection) mantle. (a) Cool mantle-warm crust. (b) Cool mantlecool crust. (c) Warm mantle-cool crust. (d) Warm mantle-warm crust [Wyllie and Sekine, 1982].

ing to the four combinations of warm and cool mantle and crust discussed in connection with Figure 12. These figures are designed to illustrate the kinds of processes and products that can occur, rather than what actually happens in any particular subduction zone.

Dehydration occurs wherever rock masses are transported across the dehydration boundaries in Figure 36. The dehydration front for serpentinite (D-G) approximates the greenschist facies boundary, and the dehydration front for amphibole separates amphibolite from eclogite in the subducted oceanic crust. Partial melting occurs if $\mathrm{H}_{2} \mathrm{O}$ passes into the regions on the high-temperature sides of the dashed solidus boundaries for rock- $\mathrm{H}_{2} \mathrm{O}$ (shaded areas in Figure 35).

Aqueous solutions rising from the dehydration front D-G may migrate back toward the trench along the dislocation above the slab, but direct upward migration of solutions into the overlying mantle wedge is commonly assumed (Figure 5c). These solutions may precipitate metasomatic amphibole in the large shaded areas of mantle and continental crust and generate magma in the continental crust (C). For a cool mantlewarm crust (Figure 36a), most solutions enter the mantle along D-E, but some generate magma from subducted crust at M. For a cool mantle-cool crust (Figure 36b), the metasomatic solutions do not enter the melting regions of either subducted crust or mantle peridotite. For a warm mantle-cool crust (Figure $36 c$ ), induced convection brings the region for potential melting of the mantle above the dehydration fronts, and metasomatic fluids cause partial melting of peridotite. Note how dehydration of metasomatic mantle amphibole could localize enhanced melting at $\mathrm{N}$, perhaps controlling the position of the volcanic front.

Figure $36 d$ represents an intermediate thermal structure with relatively warm mantle and relatively warm subducted crust. Magmas are generated simultaneously in all three source materials at $\mathrm{M}, \mathrm{N}, \mathrm{C}$, and $\mathrm{H}^{\prime}$ [Anderson et al., 1980]. Nicholls and Ringwood [1973] proposed that hydrous siliceous 
magma from $\mathbf{M}$ would react with overlying mantle, producing hybrid olivine pyroxenite. Wyllie and Sekine [1982] concluded from their experiments [Sekine and Wyllie, 1982, 1983] that a series of discrete or overlapping bodies of hybrid phlogopitepyroxenite would be transported downward with the slab to $R$, where vapor-absent melting defines another possible site of magma generation. Solutions released during hybridization at $\mathrm{H}$ cause metasomatism, followed by partial melting in the shallower mantle at $\mathbf{N}$. Another possibility is that the hydrous magma from $\mathbf{M}$ could enter the region $\mathbf{N}$ for hydrous melting of peridotite.

Release of vapors from deep dissociation fronts in subducted oceanic crust leads to migration of fluids through large volumes of upper mantle. The geometry of the arrangement of metasomatic volumes, and volumes where the fluids dissolve in magmas, is strongly dependent on the geometry of subduction, the thermal history of the plate being subducted, and the thermal structure of the subduction zone. Note in Figure $36 \mathrm{~d}$ the complicated sequence of events that could be experienced by water stored initially in serpentine in the oceanic crust. Figure 14 shows the types of phase fields traversed by the water. It starts in the "vapor-absent rock," then alternates between fields for "rock $+V$ " and "xls $+L$ " (with very short intervals of "xls $+L+V$ " between). Following dehydration at about 100-km depth (Figure 36d), the aqueous vapor would rise through eclogite, cross the solidus, and dissolve in interstitial melt near $\mathbf{M}$. The magma would solidify by hybridization, releasing $\mathrm{H}_{2} \mathrm{O}$ at $\mathrm{N}$, forming vapor that would rise through peridotite until it crossed the mantle solidus near $\mathbf{N}$, generating a second batch of magma. This would rise into the base of the continental crust at $\mathbf{H}^{\prime}$, perhaps escaping in eruption $\mathrm{B}$ but more likely becoming involved in additional reactions between $\mathbf{H}^{\prime}$ and the surface.

The fifth arrangement advocated by Marsh [1979] and Maaloe and Petersen [1981] with convection in the mantle wedge raising the temperature of the subducted oceanic crust at $100-\mathrm{km}$ depth to $1250^{\circ}-1450^{\circ} \mathrm{C}$ is hot enough to generate primary basaltic andesite directly from the subducted crust. Johnston [1986] studied the liquidus phase relationships for a near-primary high-alumina basalt and concluded using an inverse approach (Figure 13) that this composition could be derived as a primary melt from subducted MORB. Brophy and Marsh [1986] considered the partial melting of subducted quartz eclogite (with $\mathrm{H}_{2} \mathrm{O}$ playing a minor role) and concluded that gravitational instability of the entire source region would occur before melt extraction was possible. Uprise of the mush with increasing melting to $50 \%$ liquid would continue through $15-20 \mathrm{~km}$, at which stage the melt could escape from the crystalline host and rise diapirically. The liquid at this stage would have a pattern of REE equal to that observed for island arc magmas. They presented other arguments involving the mechanics of ascent and melt extraction along with phase equilibria to support their conclusion that partial melting of quartz eclogite best satisiles the geochemical constraints of island arc basalts.

\section{Continent-Continent Boundary}

Schreyer et al. [1987] reviewed convincing evidence that metasediments from the Alpine/Mediterranean area had been subducted to depths of at least $100 \mathrm{~km}$. Pyrope-coesite rocks with individual pyrope crystals up to $20 \mathrm{~cm}$ in diameter include varieties with kyanite and jadeite, as well as phengite and talc. The assemblage pyrope-coesite-jadeite-kyanite occurs subsolidus in tonalite and granite at pressures corresponding to a depth of about $100 \mathrm{~km}$ (Figures 26 and 29), confirming the conclusions of Schreyer et al. [1987] based on other phase studies. They estimated temperatures of $700^{\circ}-$ $800^{\circ} \mathrm{C}$ for the metamorphism, which would place the rocks close to or above their solidus curves in the presence of aqueous pore fluid according to Figures 26,29 , and 30 . The possibility that the subducted metasediments released trachytic melts or KMg-rich fluids into overlying mantle was evaluated by the authors, who noted that the trace element signature of lamproites is best explained by contamination of normal mantle with material from continental crust prior to magma formation.

\section{Magma Contamination and Mixing}

The dehydration and partial melting of subducted oceanic and continental crust introduces material for contaminating mantle-derived magmas, and basalts from the mantle have similar potential for contaminating magmas derived in the continental crust. Magma mixing was not a popular process until about a decade ago. In their influential textbook, Carmichael et al. [1974, p. 67] wrote: "Mingling of magmas is no longer considered to be a principal factor in evolution of such continuous magma series," although they did not rule out completely the possible role of magma mixing in volcanic rocks of the orogenic, calc-alkaline series. The frequency with which magma mixing and contamination are now called upon demonstrates that they are once again respectable processes in the petrogenesis of many igneous rocks. Marsh [1987] noted that although magma mixing continues to be a popular process, its nomenclature is in a shambles and the process is not clearly defined. To some the process means homogenization, to others it means simply mingling, and yet others mean merely contamination. Metasomatism may be superimposed for some mantle magmas. Sparks and Marshall [1986] presented a detailed evaluation of thermal and mechanical constraints on mixing between mafic and silicic magmas.

The transfer of melts and vapors from one region of the mantle to another producing a nonequilibrium situation was illustrated in Figures 32 and 36 (see also Figures 42, 43, 44, and 46). In a subduction zone environment, there is an especially high potential for interactions among melts, rocks, and vapors in both mantle and crust, as illustrated in Figure 36. There are five situations involving magmas and rocks of particular interest: (1) the intrusion of hydrous, siliceous magma from the subducted slab into cooler mantle peridotite (H, Figure 36d); (2) the intrusion of the same melt into partly melted, hydrous peridotite at somewhat shallower levels $(\mathbf{N}$, Figure 36d); (3) the intrusion of basic magmas into the deep continental crust; (4) the intrusion of basic magmas into partly melted continental crust or into siliceous magma chambers $(H$ and $\mathrm{H}^{\prime}$, Figures $36 c$ and $36 d$ ); and (5) the intrusion of granitoid magmas into shallow crust. There are few experimental data providing information about the complex processes occurring in these regions of hybridism, contamination, or mixing. Some examples and their relationship to subduction are illustrated in Figure 37.

Hybridism between hydrous siliceous magma and mantle peridotite at $100-\mathrm{km}$ depth, a process proposed by Nicholls and Ringwood [1973], has been explored experimentally by Sekine and $W y l l i e[1982,1983]$ using either mixtures of granite and peridotite with $\mathrm{H}_{2} \mathrm{O}$ or reaction couples of hydrous granitic melt adjacent crystalline peridotite (Figure 37, 


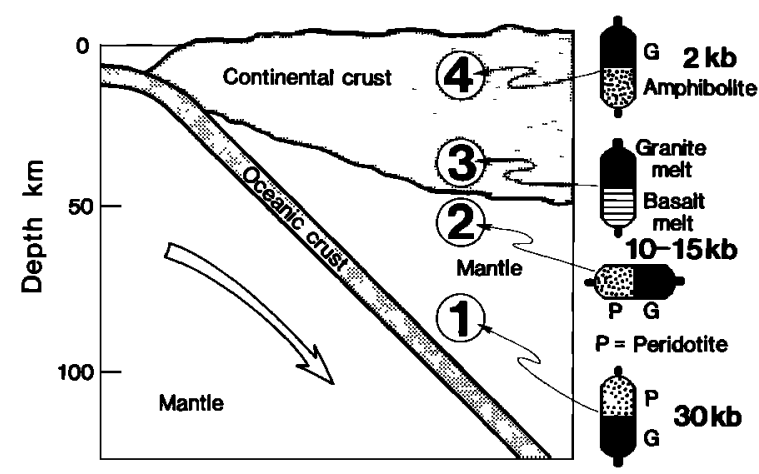

Fig. 37. Locations of four reaction experiments designed to explore interactions between magmas and rocks from subducted slab to shallow crust.

number 1). Figure 38 is a sketch of a polished surface through a typical experimental reaction charge. In the mineral reaction zones produced by hydridization of $\mathrm{H}_{2} \mathrm{O}$-undersaturated granite liquid and the overlying peridotite, orthopyroxene and jadeitic pyroxene are ubiquitous products with compositions different from those in peridotite.

Figure 39 shows Sekine and Wyllie's [1982] framework of liquidus field boundaries at $30 \mathrm{kbar}$ associated with peridotite and the calc-alkaline rock series in the presence of $\mathrm{H}_{2} \mathrm{O}$. Johnston and $W y$ llie [1986a] studied the phase fields intersected by mixtures on the join tonalite-peridotite- $\mathrm{H}_{2} \mathrm{O}$ at $30 \mathrm{kbar}$, and confirmed the position of the boundary between the liquidus fields for garnet and orthopyroxene in Figure 39, on the $\mathrm{MgO}$ side of the calc-alkaline series BAR. Similar experiments conducted by Carroll and Wyllie [1987] at $15 \mathrm{kbar}$, corresponding to the depth of the Moho in orogenic belts where the crust is thickened (Figure 37, number 2), show that the garnetorthopyroxene boundary (with $\mathrm{H}_{2} \mathrm{O}$ ) becomes almost coincident with the calc-alkaline series in this projection.

Watson [1982] studied experimentally the chemical processes resulting from contact of molten basalt with felsic minerals, concluding that selective contamination of the basaltic

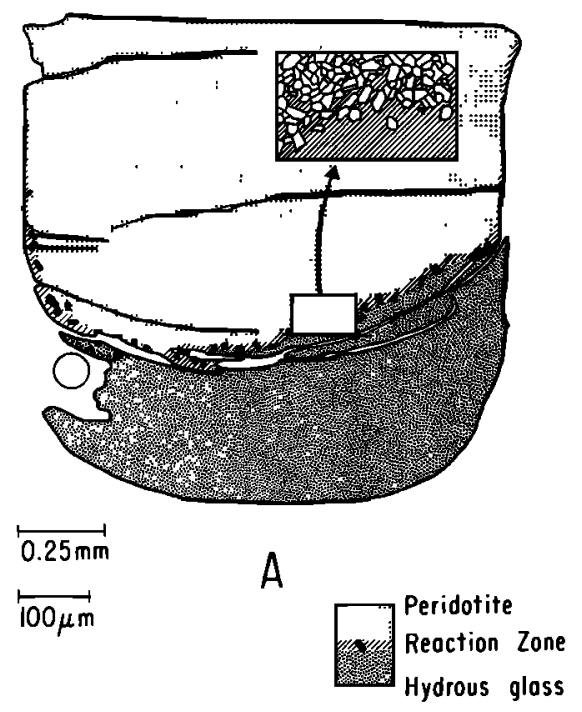

Fig. 38. Sketch of polished section of quenched run products of crystalline peridotite above $\mathrm{H}_{2} \mathrm{O}$-undersaturated granite melt. The run was at $30 \mathrm{kbar}, 1000^{\circ} \mathrm{C}$ for 45 hours. Minerals in the reaction zone are orthopyroxene, jadeitic pyroxene, and quartz [Sekine and Wyllie, 1983]. magma by potassium is likely. He used the results to illustrate quantitatively the principles of selective contamination during basalt/crust interaction. Watson and Jurewicz [1984] described additional experiments aimed specifically at the chemical diffusivity of potassium and the partitioning of sodium. These experiments were conducted with dry materials, and Watson [1981] concluded that diffusion rates in crustal magmas are extremely sensitive to $\mathrm{H}_{2} \mathrm{O}$ content. Johnston and $W y$ llie $[1986 b, 1988]$ reported results of a first set of experiments at 10 kbar designed to explore the properties of coexisting basaltic and rhyolitic magmas and to determine how these properties vary as a function of pressure, temperature, $\mathrm{H}_{2} \mathrm{O}$ content, and other variables (Figure 37, number 3 ). They found that even with $\mathrm{H}_{2} \mathrm{O}$-undersaturated conditions at $920^{\circ} \mathrm{C}, \mathrm{Na}_{2} \mathrm{O}$ and $\mathrm{K}_{2} \mathrm{O}$ were rapidly equalized between the two melts, $\mathrm{CaO}, \mathrm{MgO}$, and $\mathrm{FeO}$ migrated somewhat less rapidly, and the gradient in $\mathrm{SiO}_{2}$ and $\mathrm{Al}_{2} \mathrm{O}_{3}$ persisted for a longer period.

M. R. Carroll and P. J. Wyllie (manuscript in preparation) also conducted experiments with $\mathrm{H}_{2} \mathrm{O}$-undersaturated granite glass adjacent peridotite at $15 \mathrm{kbar}$ designed to study isothermal contamination and element diffusivities. They discovered instead that the granite melt experienced remarkable convective motion, as shown in Figure 40. Unmelted crystals of feldspar and quartz at the far end of the granite melt became entrained in the flow defined by trails of graphite, which formed by reduction of the small amount of carbonate in the granite. Despite the reduction of viscosity by dissolved $\mathrm{H}_{2} \mathrm{O}$ and the relatively high temperature of $920^{\circ} \mathrm{C}$ at $10 \mathrm{kbar}$, convection was not expected in such a small sample. The phenomenon is reproducible and is currently being explored in detail. Similar contamination experiments between $\mathrm{H}_{2} \mathrm{O}$-saturated granite and crystalline amphibolite at $800^{\circ} \mathrm{C}$ and 2 kbar (Figure 37, number 4) produced results as expected: diffusivities in granite melt are very slow under these conditions [Rutter and $W y$ llie, 1986]. Figure 41 is a sketch of a typical experimental sample. Bubbles in the glass are caused by the small amount of $\mathrm{CO}_{2}$ in the granite. Note the bubblefree zone against the contact. This was slightly wider than the zone of element diffusion.

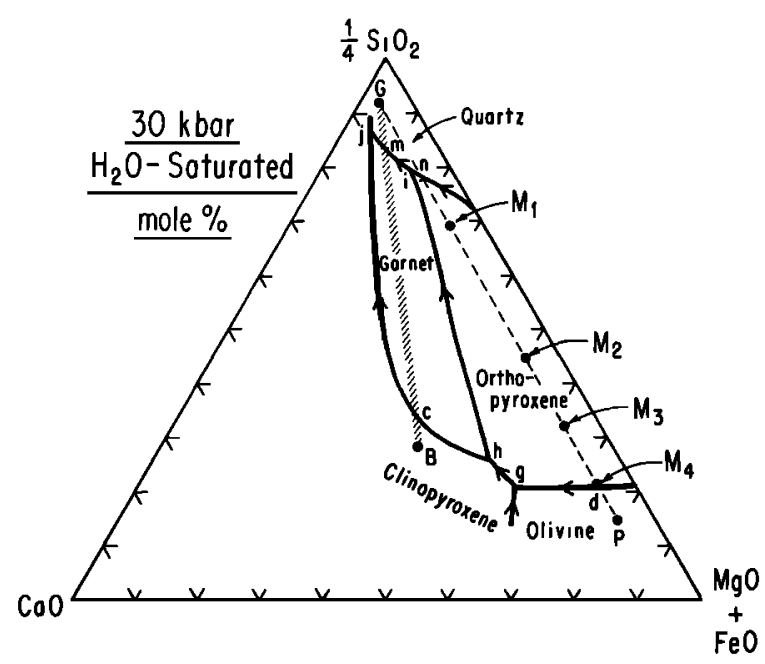

Fig. 39. Pseudoternary liquidus field boundaries at $30 \mathrm{kbar}$ with excess $\mathrm{H}_{2} \mathrm{O}$, separating areas for the primary crystallization of minerals, based on experiments with calc-alkaline rock series, BG, and with mixtures between peridotite and granite, PG [Stern and Wyllie, 1978; Sekine and Wyllie, 1982]. 


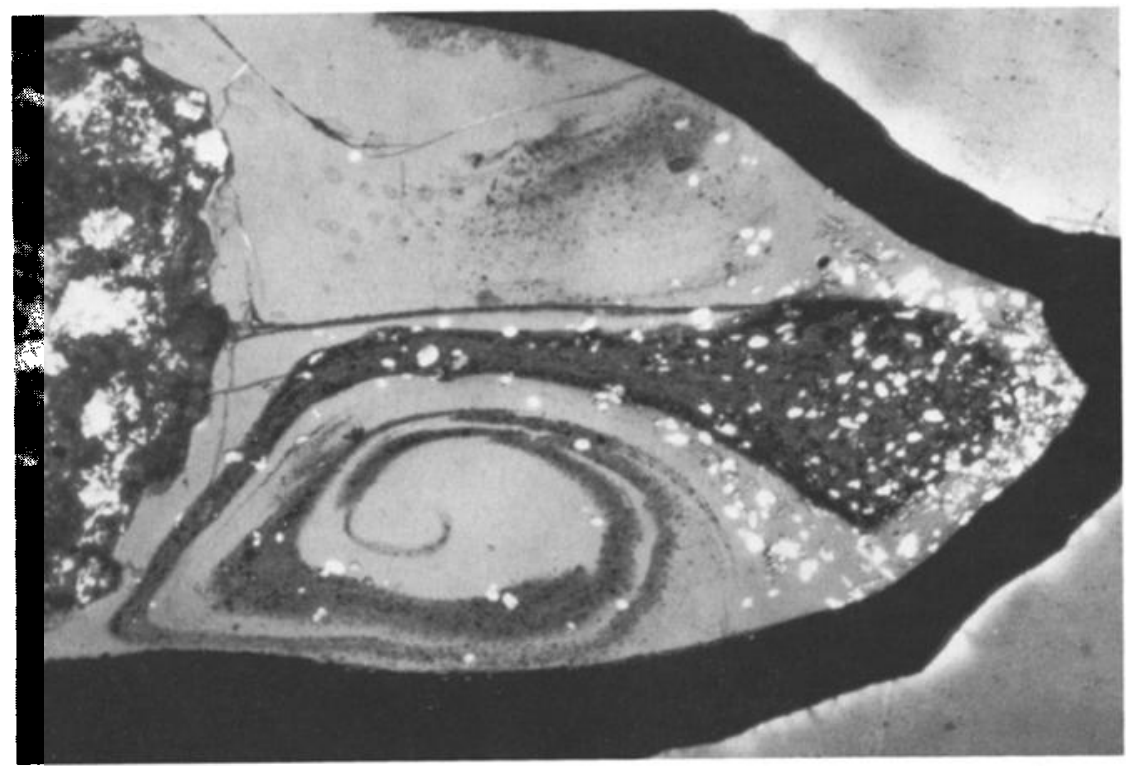

Fig. 40. Thin section (transmitted light, nicols partly crossed) of reaction experiment between largely molten hydrous granite and solid peridotite (left side) at $15 \mathrm{kbar}$ and $1050^{\circ} \mathrm{C}$. Vertical field of view is $0.2 \mathrm{~mm}$. Position number 2 in Figure 37. Convection is shown by trails of graphite (from trace of reduced carbonate) emanating from cluster of unmelted quartz plus feldspar crystals at left of charge. From M. R. Carroll and P. J. Wyllie (manuscript in preparation).

The proposal that hydrous siliceous magmas rising from subducted oceanic crust react with overlying mantle peridotite [Nicholls and Ringwood, 1973] can be evaluated in terms of Figure 39. The liquids generated in subducted crust follow paths on the $\mathrm{CaO}$ side of the calc-alkaline series (j-c). Johnston and $W y$ llie [1986a] demonstrated that the liquids changed to the $\mathrm{MgO}$ side of the volcanic line if they reacted with peridotite at 30-kbar pressure (line i-k). Carroll and Wyllie [1987]

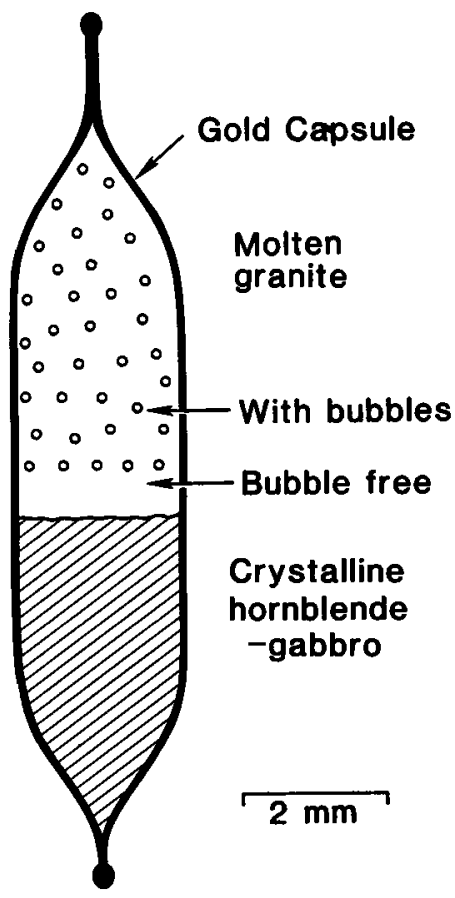

Fig. 41. Sketch of sample run in gold capsule to study reaction between solid amphibolite (below) and hydrous granite liquid (above). Position number 4 in Figure 35. Bubbles are from trace of $\mathrm{CO}_{2}$ in granite; note the bubble-free zone adjacent to the amphibolite [Rutter and $W$ yllie, 1986]. found that the position of this reaction line moved very close to the calc-alkaline series at $15 \mathrm{kbar}$. Thus if melts from the subducted slab experienced continued reaction with the host mantle as they rose through the mantle, their compositions might be directed toward the calc-alkaline compositions as they approached the mantle-crust boundary. For a relatively warm mantle capable of yielding basalts, however, the slabderived melts would have to traverse a region of partially melted peridotite (Figure 36d).

\section{Ocean Plate}

The hot spots generating the enriched OIB's in Figure 4 are commonly assumed to involve thermal plumes, although other processes involving propagating fractures and shear melting have been proposed. The concept of plumes may include source material rising from the core-mantle boundary (Figure $4 b$ ), from a primitive layer below $650 \mathrm{~km}$ (Figure $4 a$ ), from a megalith or mesosphere boundary layer at the $650-\mathrm{km}$ level (Figure $4 d$ ), from a shallow enriched layer below the lithosphere (Figure $4 d$ ), or from large-volume isolated blobs within the mantle (Figure $4 b$ ).

\section{Hawaiian Islands}

The Hawaiian Islands are the most intensively studied OIB's, but according to Frey and Roden [1987, p. 434], "There is no consensus on a general petrogenetic model for Hawaiian volcanism." This leaves considerable latitude in setting up a thermal and petrological framework, an exercise I attempted elsewhere [Wyllie, 1988a] and will summarize here. The physical framework is developed by superposing isotherms and phase boundaries and considering the flow lines transporting material. Some of the starting points are controversial, but similar frameworks can be constructed with alternative assumptions. The key phase relationships were summarized in Figure 21, and the temperatures are given in Figure 9. The thermal structure is based on theoretical models constructed by Courtney and White [1986], with asymmetry estimated, 


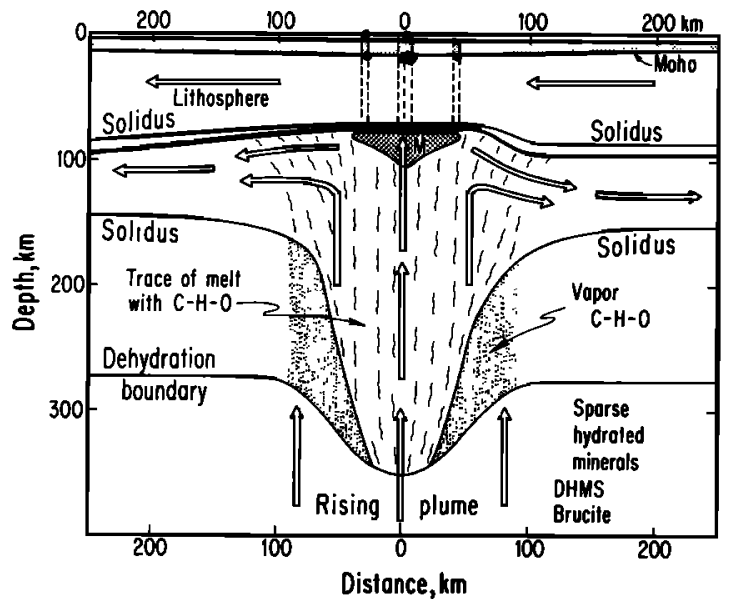

Fig. 42. Petrological structure beneath Hawaii based on the isotherms in Figure 9 and the phase boundaries in Figures 20 and 21. Material following flow lines crosses the phase boundaries, causing the distribution of vapor and melt in rising plume as shown. Major plume melting occurs at $\mathbf{M}$, with magma chambers forming at various levels. Figure 43 shows more details in the region of the asthenosphere-lithosphere boundary layer (heavy line).

and with the constraint that Hawaiian lavas were derived from a source rock containing garnet (still controversial) requiring that melting occurred at pressures greater than the solidus cusp for garnet (Figure 3), that is in the region $M$ in Figure 21. With this constraint, temperatures in the center of the plume must exceed $1500^{\circ} \mathrm{C}$. If the lithosphere plate moves faster than the plume, the plume may be bent over to one side or sheared off [Presnall and Helsley, 1982].

The relationship of geotherms to the phase boundaries for lherzolite-C-H-O is shown in Figure 21. Mapping the phase boundaries from Figure 21 in terms of the pressuretemperature points of Figure 9 yields the petrological structure in Figure 42, with an expanded view of the asthenosphere-lithosphere relations in Figure 43. These phase

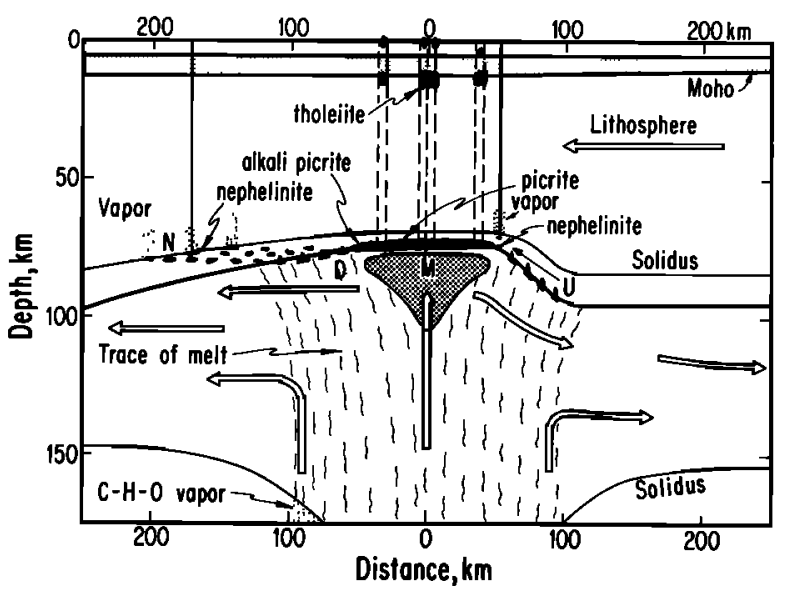

Fig. 43. Petrological structure of lithosphere and upper plume corresponding to Figure 42, with expanded vertical scale. Picritic magmas enter lithosphere from melting region $\mathbf{M}$. Volatile-charged magmas enter the lithosphere on either side of $\mathbf{M}$, with subsequent percolation retarded. As they approach the solidus, vapor is evolved (e.g., at N) enhancing the prospect of eruption directly through the lithosphere; paths followed by these magmas to the solidus differ according to their position on the upstream (U) or downstream (D) side of the plume. boundaries are static, fixed in position as long as the isotherms do not change. Material migrates through the framework, following flow lines represented by the arrows in Figures 42 and 43 . The positions of the phase boundaries in this structure becomes modified by energy changes associated with melting and the extraction of melts, but those plotted provide a guide as to what happens where, within the cross section.

If there are volatile components in the deep mantle, $\mathrm{H}_{2} \mathrm{O}$ is released from the hydrates as the plume material crosses the dehydration boundary in Figure 42 [Woermann and Rosenhauer, 1985], joining the carbon species [Deines, 1980]. Green et al. [1987] consider uprise of $\mathrm{CH}_{4}$ and $\mathrm{H}_{2}$. The mantle plume with volatiles rises until it reaches the solidus boundary, where the volatiles become dissolved in a trace of melt. In the central part of the plume, for the thermal structure in Figure 9, the hydrated peridotite melts directly without an interval for a separate vapor phase. Significant melting of the plume occurs in the shaded area $M$, which is situated above the volatile-free solidus (see $M$ in Figure 21). In the outer envelope of the plume, the entrained volatile-charged melt bypasses the region $M$, entering the lithosphere near the $1200^{\circ} \mathrm{C}$ isotherm. At this level the change in rheology would significantly retard the upward movement of the small percentage of interstitial melt.

Figure 43 shows in more detail what may happen in the lower lithosphere. The compositions of the magmas reaching the lithosphere are labelled according to the experimentally determined compositions of melts under the specified conditions (Figures 15b, 17, and 18). The picritic magmas enter the lithosphere and remain there in magma chambers [Maalge and Scheie, 1982; Ribe and Smooke, 1987] until suitable tectonic conditions permit their uprise through cracks to shallower magma chambers, where they differentiate to the tholeiites and alkali basalts erupted at the surface. The concentration of magmas in chambers at the base of the lithosphere may cause partial melting of the overlying lithosphere [Chen and Frey, 1985].

Figure 21 indicates that the solidus temperature for peridotite-C-H-O is increased with reduced oxygen fugacity, and D. H. Green (personal communication, 1987) now has experimental confirmation that this is so. If the oxygen fugacity in the mantle were known, then following the experimental data the deep solidus boundary below the major melting region $M$ in Figures 43 and 44 could be remapped at shallower depths, making a smaller envelope of mantle with a trace of volatile-charged melt.

The fate of the volatile-charged magma differs according to its position within the plume. The melt in the central region is incorporated into the much larger volume of picritic melt. The melt on either side of the region $\mathbf{M}$ reaches the lithosphere and then follows different routes according to its location on the upstream (U) or downstream (D) side of $M$. Depending upon the relative rates of mantle flow and melt percolation in the region $U$ (Figure 43), magma on the upstream side could percolate slowly through the lithosphere with decreasing temperature to the solidus, or percolate upward and downstream from $U$ along the asthenosphere-lithosphere boundary layer, and become incorporated into the hotter alkali picrite magma above the upstream margin of the melting region $M$. Melt entering the lithosphere on the downstream side, $D$, would be carried away from the plume along lithosphere flow lines as shown in Figure 43, remaining above the solidus of the peridotite-melt system as temperature decreased along DN. 
The distance downstream that it would reach the solidus depends on the relative rates of lithosphere movement and of migration of small bodies of magma through the lithosphere. When magma approaches the solidus $\mathbf{N}$, vapor is released, and this may enhance crack propagation and permit eruption of nephelinites or basanites directly from the asthenospherelithosphere boundary region to the surface. Fundamental questions to be addressed include the relative rates of movement of solid, vapor, and melt within the plume and in the lithosphere and the chemical consequences of differential flow rates.

\section{Magmatic Sequence}

If the Hawaiian Islands were generated over a thermal plume, the sequence of magmatic events should correspond to those illustrated in Figure 43. A specific surface area receives magmas in succession following the processes depicted in Figure $\mathbf{4 3}$ from right to left. The first event could be eruption of nephelinites (or basanites), followed by, or almost contemporaneous with, the eruption of alkali basalts. Then comes major eruption of tholeiites with no time break. The width of $M$ and the time interval for the eruption of tholeiites are extensive in comparison with the initial alkalic magma phase. The third phase is the eruption of alkali basalts generated at the downstream edge of the melting region $M$; if some of the alkali picrite becomes trapped in the lithosphere and is transported in the direction downstream before escaping to shallower levels, this stage could be somewhat extended in time and intermittent. The final stage occurs much later, when the small pockets of nephelinitic magma are erupted from N. By the time this occurs, the original volcanic pile, migrating with the plate above DN, has become deeply eroded. Thereafter, magmatic activity ceases until the lithosphere crosses some other thermal disturbance in the mantle capable of raising the geotherm to a level where it crosses the solidus. This sequence of events appears to satisfy the broad geological and petrological history of the Hawaiian Islands [Decker et al., 1987].

There have been many proposals to explain the geochemistry of the different lavas [Wright and Helz, 1987; Carlson, 1987; McCallum, 1987], but there is no consensus [Frey and Roden, 1987]. There are at least three distinct mantle reservoirs involved in the melting process. If the central plume material is assumed to rise from an undepleted lower mantle layer, or some other deep enriched mantle source such as a mesosphere or core-mantle boundary layer (Figure 4), the outer envelope of the plume may be derived from the upper mantle layer (depleted), and the lithosphere is further depleted and differentiated by removal of MORB constituents. The framework outlined in Figures 42 and 43 indicates that different deep source materials could be involved in the formation of the tholeiites and of the nephelinites, with a prospect that more than one deep source may provide material for the alkalic magmas near the margins of the melting zone. The lithosphere reservoir may contaminate nephelinites and alkali basalts on the upstream side of the plume, $U$, but this is less likely on the downstream side, where the thickening lithosphere is composed of plume material. The tholeiites from the deep mantle reservoir may be contaminated with the lithosphere to the extent that the hot picrite magmas can cause local melting in the lithosphere [Chen and Frey, 1985]. The scheme in Figures 42 and 43 is presented as a flexible framework that can be modified with new data.

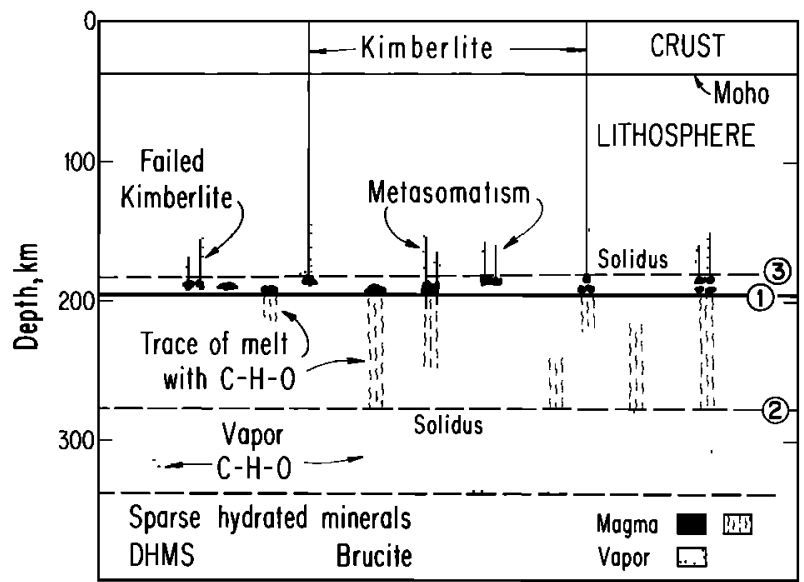

Fig. 44. Craton section corresponding to Figure 8, with phase boundaries transferred from Figure 20. Migration of deep volatile components, generation of melts in asthenosphere, and their entrapment in lower lithosphere. Escape of volatile components as magmas approach the solidus leads to metasomatism, crack propagation, and intrusion of kimberlites. Various stages of this process are illustrated covering a long tıme interval.

\section{Continental Plates}

Many varieties of magmas and petrographic associations are represented on continental plates. In this section we consider three groups, two of which are associated with volatile components from the mantle in cratonic or rift environments (kimberlites, nephelinites and carbonatites) and the third associated with a hot spot bringing basalt and heat into the crust and generating anorogenic granitoid rocks.

\section{Cratons and Kimberlites}

Kimberlites are interesting igneous rocks not only because they bring diamonds to the surface, but also because they bring rock specimens from as deep as $150-200 \mathrm{~km}$ within the lower lithosphere. All kinds of geochemical and geophysical information can be gleaned from these specimens including fossil geotherms for the time of eruption of the kimberlite (Figure 7). Approximately 25 million tons of rock were hauled out of the famous Kimberley mine, and this included about 3 tons of diamond. The ratio carbon/kimberlite is very small, but a 3-ton pile of diamonds would look rather impressive. In addition to diamond, many kimberlites contain carbonate, much of which precipitated at shallow levels from $\mathrm{CO}_{2}$ carried from greater depths. There is no doubt that carbon was present in the depth region from which kimberlite was erupted, and experimental petrologists so far know of no way to generate kimberlite magma from mantle peridotite without involving $\mathrm{CO}_{2}$ [Eggler, 1978; Wyllie, 1978c].

The question of oxygen fugacity in the mantle and its effect on speciation in $\mathrm{C}-\mathrm{H}-\mathrm{O}$ vapors and the consequences for melting temperatures and magmatic products remain controversial, and it has special significance for the origin of kimberlites. A relatively oxidized mantle associated with kimberlite genesis is preferred by Eggler and Baker [1982]. Wyllie [1980] presented an interpretation of kimberlites involving the uprise from below the asthenosphere of reduced gases in the system $\mathrm{C}-\mathrm{H}-\mathrm{O}$ which dissolved in melts in the asthenosphare, became oxidized during magmatic processes involving diapiric uprise into the lithosphere, and were released at shallower levels as $\mathrm{H}_{2} \mathrm{O}+\mathrm{CO}_{2}$. Several alternative models were suggested, one 


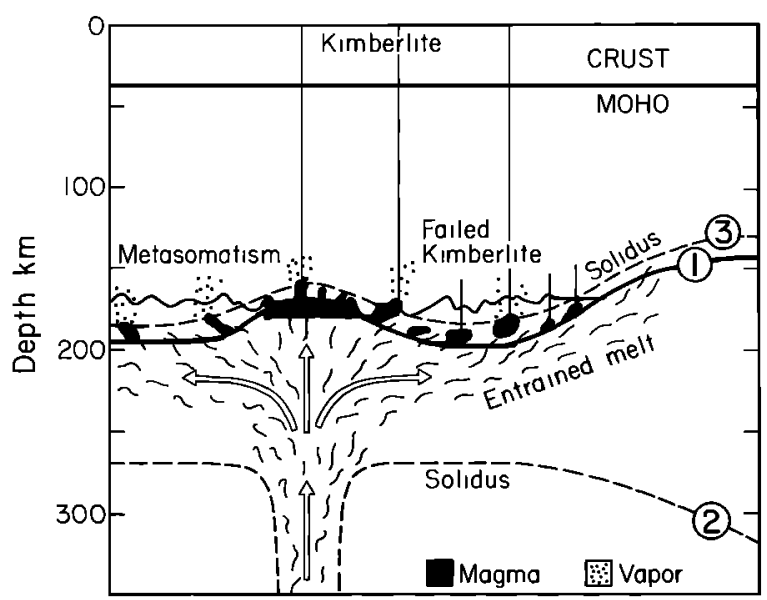

Fig. 45. Upper mantle section corresponding to Figure 10, with phase boundaries transferred from Figure 20 . The mantle plume (with volatile components) melts, with concentration of magma above the plume, and entrainment of melts in flowing lherzolite of the asthenosphere. Magma in the boundary layer of the lithosphere approaches the solidus, level 3, with consequences as illustrated in Figure 44.

of which involved the failure of geotherm and solidus to overlap at depth [Wyllie, 1980, p. 6905]: "A third possibility is that the components $\mathrm{C}-\mathrm{H}-\mathrm{O}$ may occur in the mantle peridotite without the occurrence of melting if reduced oxygen fugacity raises the solidus for the system peridotite-C-H-O, especially if the subcontinental geotherm is lower than that plotted. Partial melting would then occur only where temperatures were raised or oxygen fugacity was increased." Green et al. [1987], using the data of Taylor and Green [1987], have developed this idea in elegant detail, referring to the process as redox melting. The partial melting of peridotite in the presence of rising $\mathrm{CH}_{4}+\mathrm{H}_{2}$ is delayed until a more oxidized level in the lithosphere is reached where $\mathrm{CO}_{2}$ forms and fluxes melting; with the reduced gases the solidus is at temperatures above the geotherm, but with oxidation it is lowered to a temperature below the geotherm. It is obvious from Figure 20 that with the cool cratonic geotherm a small upward displacement of the solidus (Figure 21) would be sufficient to permit the passage of reduced volatile components through the depth interval (2-3) without partial melting, but note that the solidus displacement required to accomplish this with the inflected geotherm is considerably wider.

I have modified the 1980 diapiric model for one in which the mantle melt percolates into the base of the lithosphere where it stalls [Wyllie, 1987a]. Once the relationships among oxygen fugacity, water activity, experimentally determined solidus curves, and actual redox conditions in the mantle have been established, the appropriate solidus boundaries can be used with isotherms to produce petrological structures. In the present state of uncertainty, however, let us examine the diagrams that can be constructed for the limiting situation, where the solidus for peridotite-C-H-O is assumed to remain near that for peridotite- $\mathrm{CO}_{2}-\mathrm{H}_{2} \mathrm{O}$ (Figure 20). Subsequent change in the temperature of either solidus or geotherm will involve movement of the phase boundaries in the petrological structures.

Figure 44 represents a stable craton with uninflected geotherm, corresponding to Figure 8. Phase boundaries at the specified depths are drawn at intersections of the uninflected geotherm with the phase boundaries in Figure 20. Intersection of the geotherm with the solidus at levels 2 and 3 implies small degrees of melting between these two levels if volatile components are present. For simplicity, the two dehydration boundaries of Figures 20 and 21 were merged into a single dehydration boundary. Intermittent local disturbances could release vapors from the deep dissociation front [Woermann and Rosenhauer, 1985]. The volatile components would rise through mantle to the solidus at level 2 , where they would dissolve in melt. The trace of interstitial melt so developed would rise through the asthenosphere to the asthenospherelithosphere boundary at level 1 . The rate of percolation of magmas entering the depleted lithosphere would be reduced. Small magma chambers could form and remain sealed within the more rigid lithosphere, maintained at temperatures above the solidus for lherzolite-C-H-O. The magmas have little tendency to crystallize or to evolve vapors until they approach level $3,10-15 \mathrm{~km}$ above the asthenosphere-lithosphere boundary. Contact of the lherzolite-derived magma with harzburgite, however, should cause reaction and the precipitation of minerals through magma contamination. This slow process may cause the more or less isothermal growth of large minerals resembling the discrete nodules in some kimberlites. Those magmas managing to insinuate their way near to level 3 , the solidus, will evolve $\mathrm{H}_{2} \mathrm{O}$-rich vapors. $\mathrm{CO}_{2}$-rich vapors cannot exist in this part of the mantle [Eggler, 1978; Wyllie, 1978c]. The vapors may enhance crack propagation, permitting rapid uprise of the kimberlite magma. Many intrusions from this level will solidify through thermal death before rising far [Spera, 1984], but others will enter the crust as kimberlite intrusions [Artyushkov and Sobolev, 1984].

Figure 44 illustrates a series of events as they might have occurred at successive times. It does not represent a set of simultaneous events. The depleted, refractory base of the lithosphere, $150-200 \mathrm{~km}$ deep, has probably been invaded intermittently by small bodies and dikes of kimberlite or magmas of related composition through billions of years. Most of these aborted and gave off vapors. The combination of failed kimberlite intrusions and their vapors has contributed to the generation of a heterogeneous layer in this depth interval, characterized by many local volumes metasomatized in diverse ways at various times. The aqueous vapors may percolate upward through many kilometers to shallower levels, perhaps generating the sequence of metasomatized garnet peridotites described in detail by Erlank et al. [1987]. Schneider and Eggler [1986] suggested on the basis of their experimental data that aqueous vapors and solutions rising through the lithosphere would leach the mantle with minor precipitation until they reached a level of about $70 \mathrm{~km}$ where a "region of precipitation" is associated with the formation of amphibole and consequent change in vapor composition toward $\mathrm{CO}_{2}$.

If a thermal plume rises below the cratonic lithosphere (Figure 10), the petrological structure of Figure 44 becomes modified in the way illustrated in Figure 45. The depth of intersection of the geotherm with a dissociation reaction is displaced to greater depths, releasing vapor [Woermann and Rosenhauer, 1985]. Interstitial melt is generated at level 2 where the lherzolite is transported across the solidus curve. With continued convection, the geotherm rises to a higher, inflected position as depicted in Figure 20, and the depth 2 at which melting begins is increased considerably. The intersection points of geotherm with solidus and dissociation boundary could overlap, causing the hydrated solid to melt directly without the opportunity for a vapor phase to exist through a discrete depth interval (see Figure 45). As the plume diverges 
below the lithosphere, the melt becomes concentrated in layers or chambers in the boundary layer above the plume, as shown in Figure 45. Ribe and Smooke [1987] concluded from their analysis of a dynamic model for melt extraction from a mantle plume that layers of segregated melt are likely to form at the base of the lithosphere above a plume. Lateral divergence of the asthenosphere transports some of the entrained plume melt, and this penetrates the lithosphere, forming small dikes or magma chambers. Kimberlites may rise either from the early magma accumulating above the plume or from the lateral magma chambers in the lithosphere base. If the plate is moving across the plume, modifications are required as suggested by Figure 9 .

\section{Rift Valleys, Nephelinites, and Carbonatites}

There is evidence that beneath major rifts the lithosphere is thinned. The continued heat flux from a rising plume and the concentration of hotter magma at the asthenospherelithosphere boundary (see Figure 45) will promote further thinning of the lithosphere. Gliko et al. [1985] discussed the rates of thinning. Figure 46 depicts the petrological structure in a craton with rifting crust.

The magma near the boundary layer at levels 1-3 in Figure 45 will rise with the layer as the lithosphere thins, either percolating through the newly deformable rock matrix or rising as a series of diapirs with the amount of liquid increasing in amount as the diapirs extend further above the solidus for peridotite-C-H-O. This magma approaches the solidus ledge at level 4 in the depth range 90-70 km (Figure 20). Magma chambers may be formed as the magma solidifies (Figure 46), and vapors will be evolved causing metasomatism in the overlying mantle and facilitating intermittent crack propagation, which permits the escape of magmas through the lithosphere. The metasomatic vapors will be aqueous if released at depth greater than $\mathrm{Q}$ and $\mathrm{CO}_{2}$-rich if released at depths shallower than $Q$ (Figure 20;Wyllie [1980, Figure 8]), which is consistent with Haggerty's [1988] account of metasomes at these depths. Magmas passing Irom level 3 to level 4 will also have left metasomatic traces beneath former rift zones.

A variety of alkalic magmas may be generated at level 4 , depending sensitivity upon conditions. There are large changes in the compositions of melts and vapors in this region for small changes in pressure and temperature [Wyllie, 1978c; Wendlandt and Eggler, 1980; Wendlandt, 1984]. Magmas rising from this level may include the parents of olivine nephelinites, melilite-bearing lavas, and other igneous associations differentiating at shallower depths to carbonatites. The igneous sequence associated with the thinning of the lithosphere between the conditions in Figures 45 and 46 was discussed by Wendlandt and Morgan [1982]. For the formation of carbonatites in this environment, see Le Bas [1977] and Wyllie $[1987 a, 1988 b]$.

\section{Continental Flood Basalts}

Not all magmas are affected by the solidus ledge at level 4 in Figures 20 and 21. For those magmas that have already escaped from equilibrium with a peridotite host, the solidus ledge has no significance. For those diapirs or melts of higher temperature rising from greater depths, adiabatic paths would miss the solidus at $\mathrm{M}$ in Figure 20, and these might reach the solidus for volatile-free peridotite, at shallower levels. The magmatic product is basalt, generated from continental lithosphere as required by Allegre [1987].

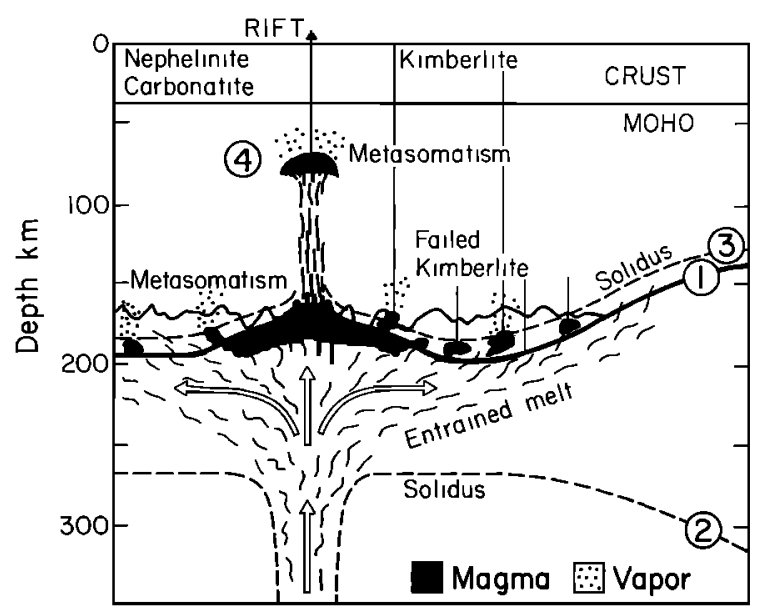

Fig. 46. An upper mantle section corresponding to conditions in Figures 10 and 45, followed by lithospheric thinning in Figure 11 . Thinning of the lithosphere above the plume permits upward migration of the magma to level 4, where magma chambers develop, and vapor is evolved with strong metasomatic effects. This level is the source of parent magmas for nephelinitic volcanism, and the associated carbonatites.

\section{Anorogenic Granites}

Granitoid batholiths are characteristic rocks of subduction zones and compressive plate boundaries, but there are many occurrences of granite intrusions within stable plates. The general depth-temperature relationships for these anorogenic granites are shown in Figures 31 and 32. Pore fluids in the deep continental crust are likely to be trivial in amount except in special environments such as in Figures $5 b$ and $5 c$. Some anorogenic granites may be produced by differentiation of basalt, but partial melting of crustal rocks with hydrous minerals such as muscovite, biotite, and amphibole under vaporabsent conditions is probably more likely for the generation of granitic magmas in stable continental crust ( $K$ in Figure 32).

Figure 27 shows the results of Rutter and $W y$ llie [1988a] on tonalite gneiss at $10 \mathrm{kbar}$, representing partial melting of the deep crust. The biotite-melting reaction produced $20 \%$ $\mathrm{H}_{2} \mathrm{O}$-undersaturated melt by $900^{\circ} \mathrm{C}$, and the hornblendemelting reaction produced $35 \%$ granodioritic melt with $2.3 \%$ $\mathrm{H}_{2} \mathrm{O}$ at $1000^{\circ} \mathrm{C}$. The partly molten rock can be mobilized only when the critical melt fraction is reached. According to recent estimates, the critical melt fraction for granitic melts is 30 $50 \%$. According to the results in Figure 27, temperatures between $950^{\circ} \mathrm{C}$ and $1000^{\circ} \mathrm{C}$ are required for segregation of a granodioritic melt from a tonalite gneiss source at the base of the crust through dehydration melting.

There is a problem of heat supply. The geotherm for stable continents (e.g., b or $\int$ in Figure 7) is too low for the continental crust to be partly melted to provide granitic magmas under normal circumstances. In a detailed review on the origin of silicic magma chambers and associated igneous rocks, $\mathrm{Hil}$ dreth [1981] presented strong evidence to support his thesis that granitoid magmas were the end product of a complex series of events initiated by flux of basalt into the crust and followed by a long history of partial melting of the crust and slow migration of magmas, with many opportunities for contamination of the magmas and for mingling of the various materials. There are now many examples of the intrusion of basic magma into a silicic magma chamber. Figure 32 indicates that temperatures of basalts from mantle are high 
enough to melt stable continental crust. The topics of contamination and mixing of basaltic and granitic magmas were discussed briefly in connection with Figure 37. The intrusion of basalt into continental crust appears to be a prerequisite for anorogenic granites.

\section{Metasomatism}

The study of mantle xenoliths has revealed two kinds of metasomatism. Infiltration (or patent or modal) metasomatism has introduced elements leading to the formation of new minerals such as phlogopite, ilmenite, rutile, sulfides, richterite, barium titanite, and carbonate, as well as changes in chemistry of preexisting minerals. The metasomatizing fluids cause enrichment in $\mathrm{Fe}, \mathrm{K}, \mathrm{Ti}, \mathrm{H}_{2} \mathrm{O}, \mathrm{S}, \mathrm{Nb}, \mathrm{Zr}, \mathrm{Hr}, \mathrm{Sr}, \mathrm{Cu}, \mathbf{R b}, \mathrm{Ba}, \mathrm{Na}$, $\mathrm{CO}_{2}$, and light rare earth elements, among others. Micas and amphiboles contain $\mathrm{F}, \mathrm{Cl}$, and $\mathrm{O}$ as well as $\mathrm{OH}$. Diffusion (or cryptic) metasomatism involves the formation of no new minerals, but the addition of elements such as light REE, $\mathrm{Ba}$, and Sr to clinopyroxene. These observations need to be correlated with the inferences from inverse interpretations of the geochemistry of basalts. Two recent books are informative [Nixon, 1987; Menzies and Hawkesworth, 1987].

The appeal to metasomatism to explain the geochemical idiosyncracies of basalt geochemistry, supported and illuminated by the observations of metasomatism in hand specimens of mantle xenoliths, is certainly reinforced by the proposals for widespread migration of vapors and volatile-charged melts illustrated in several of the preceding figures. We assume that most of these vapors and melts can percolate through rocks under some conditions, despite the warning signal from the recent research of Watson and Brenan [1987] on the wetting characteristics of $\mathrm{CO}_{2}-\mathrm{H}_{2} \mathrm{O}$ fluids suggesting that these fluids may be incapable of movement except by hydrofracture. The chemical consequences inferred and observed for mantle metasomatism were outlined above. There are very few experimental data to supplement the geochemical algebra.

Much effort has been devoted to determination of the compositions of liquids coexisting with mantle rocks at various pressures and with various volatile components, but much less is known about the solubilities of the solid components in vapor phases of various compositions under mantle conditions. Wyllie and Sekine [1982] reviewed briefly data applicable to conditions above subducted oceanic crust, and Schneider and Eggler [1984, 1986] reviewed existing data and presented new data on the compositions of solutes coexisting with peridotite at high pressures. The solubility of components is sensitive to the mineralogy of the host rocks as well as to depth and temperature. Metasomatic vapors rising from greater to lower depths commonly follow paths of decreasing temperature, but in subduction zones they may rise from lowertemperature subducted oceanic slab into higher temperature mantle wedge. Metasomatic vapors either scavenge peridotite for additional components or change its composition by exchange or precipitation of components. Schneider and Eggler [1986] demonstrated that addition of even small amounts of $\mathrm{CO}_{2}$ to a hydrous solution causes a significant decrease in solubilities of peridotite components.

It is easy to appeal to metasomatism by fluids. It is important to attempt to distinguish between metasomatism by vapors and by liquids. We can expect differences in the nature of the chemical changes caused by the passage of a vapor phase compared with the intrusion of a liquid, or magmatic phase. One distinction between these two processes of passage and addition of magma on the one hand and the passage of vapors or solutions on the other, is quantitative, involving mass of material added to the rock. The final stage of metasomatism by magmas is solidification of the magma with the resultant introduction of new material into the rock. Schneider and Eggler [1986], following their experimental studies on the solubility of peridotite components in $\mathrm{H}_{2} \mathrm{O}$ and $\mathrm{H}_{2} \mathrm{O}-\mathrm{CO}_{2}$ fluids at high pressures, calculated that high fluid/rock ratios would be required to effect signifciant changes in the chemistry of rocks with such fluids passing through them. They concluded that the fluids were not effective metasomatic agents and that most mantle metasomatism was accomplished by magmas. It is also established, however, that metasomatism of individual mantle samples has been accomplished both by the intrusions of magmas and by the infiltration of solutions emanating from the magmas during solidification of the melt [Wilshire, 1984]. In time we should be able to erect criteria to make the distinction even when the source rock is not in hand.

\section{CONCLUding Remarks}

The petrological cross sections shown in Figures 35, 42, 43, 44,45 , and 46 , derived by transferring phase boundaries onto assumed thermal structures, provide physical frameworks with specific boundaries for consideration of magmatic and metasomatic events. The boundary positions will change in response to the dynamics of mantle flow and the chemical differentiation caused by separation of melts and vapors from rocks. The fluid dynamics of rock-melt-vapor systems is of paramount importance in deciding what will actually happen to the phases in the phase fields depicted in these petrological cross sections [Marsh, 1987]. The physical frameworks may be adjusted to satisfy the geochemical constraints as the geochemical models are themselves adjusted [Carlson, 1987] and in order to satisfy the geophysical constraints. The frameworks appear to be robust enough to accommodate modifications, and it is precisely through such modifications arising from the interplay of geochemistry, geophysics, fluid dynamics, thermodynamics, and experimental petrology that understanding of the petrological consequences of volatile fluxes from the mantle may be advanced.

It is mantle convection that controls the motion of the plates, the geology of the continents, and the eruption of volcanoes. As we take an overview of the North American continent, we can see ourselves sitting in Vancouver surrounded by mountains and volcanic activity. The divergent plate boundary of the Juan de Fuca ridge off Vancouver and its more southern extension rifting Baja California from the main continent are the sites of basaltic eruptions and submarine hot springs. Subduction of the Pacific Plate beneath North America was responsible for Mount Garibaldi just up the road from this conference hall, for the Cascade volcanoes to the south, and for the Sierra Nevada batholith. Mount St. Helens, after its dramatic eruption of 1980 , still puffs out water and carbon dioxide laced with sulfur dioxide, the by-products of digesting the Pacific Ocean crust.

My favorite slide, the volcano Mount Fuji seen from Tokyo Bay with the sun setting behind it, summarizes the available energy sources. First, the sun represents our direct external source of energy. Second, the lava represents an uprise of the Earth's internal energy, and it heats groundwater providing geothermal energy. The magma brings to the surface increased concentrations of radioactive elements such as $T h$ and $U$, which may be redistributed by crustal waters, becoming con- 
centrated into uranium/thorium ore deposits. The volcanic gases contributed to the atmosphere and oceans when exposed to sunshine participate through the marvels of photosynthesis in chemical reactions involving the formation of organic materials from $\mathrm{CO}_{2}$ and $\mathrm{H}_{2} \mathrm{O}$. These molecules may become trapped into fossil fuels, coal and petroleum, and geological history dictates whether or not these materials are saved as fossil sunshine.

Magmas and volcanoes, the magmatic overflow valves, have clearly played a major role in Earth evolution and in the distribution of energy. The Earth's fluid envelopes interact with the magmatic rocks most vigorously at divergent plate boundaries where the ocean transforms fresh basalt and in subduction zones where most of the trapped ocean is expelled either as solutions or in magmas. The major problem of identifying the geochemical reservoirs in the Earth and relating these to mantle convection patterns [Allègre, 1987] cannot be solved without more information on the details and mass balance of interactions between the fluid envelopes and crust and mantle in these two plate tectonic environments.

Acknowledgments. This research was supported by the Earth Sciences section of the U.S. National Science Foundation, grants EAR84-16583 an EAR85-06857. For preprints and comments, I thank C. J. Allègre, D. L. Anderson, R. W. Clayton, B. H. Hager, and T. Tanimoto. California Institute of Technology Division of Geological and Planetary Sciences contribution $\mathbf{4 5 6 5 .}$

The Editor thanks J. Longhi for his assistance in evaluating this paper.

\section{REFERENCES}

Allègre, C. J., Isotope geodynamics, Earth Planet. Sci. Lett., 86, 175203, 1987.

Allègre, C. J., O. Brevart, B. Dupre, and J.-F. Minster, Isotopic and chemical effects produced in a continuously differentiating and convecting Earth mantle, Philos. Trans. R. Soc. London, Ser. A, 297, $447-477,1980$.

Allègre, C. J., T. Staudacher, and P. Sarda, Rare gas systematics: Formation of the atmosphere, evolution and structure of the Earth's mantle, Earth Planet. Sci. Lett., 8I, 127-150, 1987.

Anderson, D. L., The chemical composition and evolution of the mantle: Advances in Earth and planetary sciences, in High-Pressure Research in Geophysics, edited by S. Akimoto and M. H. Manghnani, pp. 301-318, D. Reidel, Hingham, Mass., 1982.

Anderson, D. L., Chemical composition of the mantle, J. Geophys. Res., 88, B41-B52, 1983.

Anderson, D. L., The Earth as a planet: Paradigms and paradoxes, Science, 223, 347-355, 1984.

Anderson, D. L., Global mapping of the upper mantle by surface wave tomography, in The Composition, Structure and Dynamics of the Lithosphere-Asthenosphere System Geodyn. Ser., vol. 16, edited by K. Fuchs and C. Froidevaux, pp. 89-97, AGU, Washington, D. C., 1987

Anderson, D. L., and J. D. Bass, Transition region of the Earth's upper mantle, Nature, 320, 321-328, 1986.

Anderson, R. N., S. E. De Long, and W. M. Schwartz, Thermal model for subduction with dehydration in the downgoing slab, J. Geol., $86,731-739,1978$.

Anderson, R. N., S. E. De Long, and W. M. Schwartz, Dehydration, asthenospheric convection and seismicity in subduction zones, $J$. Geol., 88, 445-451, 1980.

Armstrong, R. L., A model for $\mathrm{Sr}$ and $\mathrm{Pb}$ isotope evolution in a dynamic Earth, Rev. Geophys., 6, 175-199, 1968.

Artyushkov, I. V., and S. V. Sobolev, Physics of the kimberlite magmatism, in Kimberlites I: Kimberlites and Related Rocks, edited by J. Kornprobst, pp. 309-322, Elsevier, New York, 1984.

Bowen, N. L., The Evolution of the Igneous Rocks, Princeton University Press, Princeton, N. J., 1928. (Reprinted by Dover, Mineola, N. Y., 1954.)

Boyd, F. R., and J. J. Gurney, Diamonds and the African lithosphere, Science, 232, 472-477, 1986 .

Brey, G., W. R. Brice, D. J. Ellis, D. H. Green, K. L. Harris, and I. D.
Ryabchikov, Pyroxene-carbonate relations in the upper mantle, Earth Planet. Sci. Lett., 62, 63-74, 1983.

Brophy, J. G., and B. D. Marsh, On the origin of high-alumina arc basalt and the mechanics of melt extraction, J. Petrol., 27, 763-789, 1986.

Carlson, R. W., Geochemical evolution of the crust and mantle, Rev. Geophys., 25, 1011-1020, 1987.

Carmichael, I. S. E., F. J. Turner, and J. Verhoogen, Igneous Petrology, McGraw-Hill, New York, 1974.

Carroll, M. R., and P. J. Wyllie, Phase equilibria and liquid lines of descent in the system tonalite-peridotite- $\mathrm{H}_{2} \mathrm{O}$ at $15 \mathrm{~kb}$ (abstract), Eos Trans. $A G U, 68,451,1987$.

Chen, C.-Y., and F. A. Frey, Trace element and isotopic geochemistry of lavas from Haleakala volcano, East Maui, Hawaii: Implications for the origin of Hawaiian basalts, J. Geophys. Res., 90, 8743-8768, 1985.

Committee on Physics and Chemistry of Earth Materials, Earth Materials Research, National Academy Press, Washington, D. C. 1987.

Courtney, R. C., and R. S. White, Anomalous heat flow and geoid across the Cape Verde Rise: Evidence for dynamic support from a thermal plume in the mantle, Geophys. J. R. Astron. Soc., 87, 815$867,1986$.

Creager, K. C., and T. H. Jordan, Slab penetration into the lower mantle, J. Geophys. Res., 89, 3031-3049, 1984.

Davies, G. F., Earth's neodymium budget and structure and evolution of the mantle, Nature, 290, 208-213, 1981.

Davies, G. F., Geophysical and isotopic constraints on mantle convection: An interim synthesis, J. Geophys. Res., 89, 6017-6040, 1984.

Decker, R. W., T. L. Wright, and P. H. Stauffer, Volcanism in Hawaii 2 vols., U.S. Geol. Surv. Prof. Pap., 1350, 1987.

Deines, P., The carbon isotopic composition of diamonds: Relationship to diamond shape, color, occurrence and vapor compositions, Geochim. Cosmochim. Acta, 44, 943-961, 1980.

DePaolo, D. J., and G. J. Wasserburg, Inferences about mantle sources and mantle structure from variations of ${ }^{143} \mathrm{Nd} /{ }^{144} \mathrm{Nd}, G e o-$ phys. Res. Lett., 3, 743-746, 1976.

DePaolo, D. J., and G. J. Wasserburg, Petrogenetic mixing models and $\mathrm{Nd}-\mathrm{Sr}$ isotopic patterns, Geochim. Cosmochim. Acta, 43, 615627, 1979.

Dziewonski, A. M., Mapping the lower mantle: Determination of lateral heterogeneity in $P$ velocity up to degree and order $6, J$. Geophys. Res., 89, 5929-5952, 1984.

Eggler, D. $\mathrm{H}$., The effect of $\mathrm{CO}_{2}$ upon partial melting of peridotite in the system $\mathrm{Na}_{2} \mathrm{O}-\mathrm{CaO}-\mathrm{Al}_{2} \mathrm{O}_{3}-\mathrm{MgO}-\mathrm{SiO}_{2}-\mathrm{CO}_{2}$ to $35 \mathrm{~kb}$, with an analysis of melting in a peridotite- $\mathrm{H}_{2} \mathrm{O}-\mathrm{CO}_{2}$ system, $A m$. J. Sci., 278, 305-343, 1978.

Eggler, D. H., Discussion of recent papers on carbonated peridotite, bearing on mantle metasomatism and magmatism: An alternative, Earth Planet. Sci. Lett., 82, 398-400, 1987.

Eggler, D. H., and D. R. Baker, Reduced volatiles in the system C-O-H: Implications to mantle melting, fluid formation, and diamond genesis, in High Pressure Research in Geophysics, Adv. Earth Sci. 12, edited by S. Akimoto and M. H. Manghnani, pp. 237-250, D. Reidel, Hingham, Mass., 1982.

Ellis, D., and P. J. Wyllie, Hydration and melting reactions in the system $\mathrm{MgO}-\mathrm{SiO}_{2}-\mathrm{H}_{2} \mathrm{O}$ at pressures up to 100 kilobars, $\mathrm{Am}$. Mineral., 64, 41-48, 1979.

Erlank, A. J., F. G. Waters, C. J. Hawkesworth, S. E. Haggerty, H. L. Allsop, R. S. Rickard, and M. Menzies, Evidence for mantle metasomatism in peridotite nodules from the Kimberley pipes, South Africa, in Mantle Metasomatism, edited by $\mathbf{M}$. Menzies and C. J. Hawkesworth, pp. 221-311, Academic, San Diego, Calif., 1987.

Falloon, T. J., and D. H. Green, Anhydrous partial melting of MORB pyrolite and other peridotite compositions at $10 \mathrm{kbar}$ : Implications for the origin of primitive MORB glasses, Mineral. Petrol., 37, 181219, 1987.

Frey, F. A., and M. F. Roden, The mantle source for the Hawaiian Islands: Constraints from the lavas and ultramafic inclusions, in Mantle Metasomatism, edited by M. Menzies and C. J. Hawkesworth, pp. 423-463, Academic, San Diego, Calif., 1987.

Gill, J., Orogenic Andesites and Plate Tectonics, Springer-Verlag, New York, 1981.

Gliko, A. L., A. F. Grachev, and V. S. Magnitsky, Thermal model for lithospheric thinning and associated uplift in the neotectonic phase of intraplate orogenic activity and continental rifts, J. Geodyn. Res., $3,137-138,1985$. 
Green, D. H., Experimental testing of "equilibrium" partial melting of peridotite under water-saturated, high-pressure conditions, $C a n$. Mineral., 14, 255-268, 1976.

Green, D. H., T. J. Falloon, and W. R. Taylor, Mantle-derived magmas-Roles of variable source peridotite and variable $\mathrm{C}-\mathrm{H}-\mathrm{O}$ fluid compositions, in Magmatic Processes: Physicochemical Princıples, Geochem. Soc. Spec. Publ. 1, edited by B. O. Mysen, pp. 139-154, Pergamon, New York, 1987.

Griggs, D. T., The sinking lithosphere and the focal mechanism of deep earthquakes, in The Nature of the Solid Earth, edited by E. C. Robertson, pp. 361-384, McGraw-Hill, New York, 1972.

Grove, T. L., and R. J. Kinzler, Petrogenesis of andesites, Annu. Rev. Earth Planet. Scl., 14, 417--454, 1986.

Hager, B. H., Subducted slabs and the geoid: Constraints on mantle rheology and flow, J. Geophys. Res., 89, 6003-6016, 1984.

Hager, B. H., and R. W. Clayton, Constraints on the structure of mantle convection using seismic observations, flow models, and the geoid, in Mantle Convection, edited by W. R. Peltier, Gordon and Breach, New York, in press, 1987.

Hager, B. H., R. W. Clayton, M. A. Richards, R. P. Cramer, and A. M. Dziewonskı, Lower mantle heterogeneity, dynamic topography and the geoid, Nature, 313, 541-545, 1985.

Haggerty, S. E., Diamond genesis in a multiply constrained model, Nature, 320, 34-38, 1986.

Haggerty, S. E., Source regions for oxides, sulfides and metals in the upper mantle: Clues to the stability of diamonds, and the genesis of kimberlites, lamproites and carbonatites, in Proceedings of the 45th International Kimberlite Conference, Australian Geological Society, in press, 1988.

Hammarstrom, J. M., and E. Zen, Aluminum in hornblende: An empirical igneous geobarometer, Am. Mineral., 71, 1297-1313, 1986.

Heinz, D. L., and R. Jeanloz, Measurement of the melting curve of $\mathrm{Mg}_{0.9} \mathrm{Fe}_{0} \mathrm{SiO}_{3}$ at lower mantle conditions and its geophysical implications, J. Geophys. Res., 92, 11,437-11,444, 1987.

Hildreth, W., Gradients in silicic magma chambers: Implications for lithospheric magmatism, J. Geophys. Res., 86, 10,153-10,192, 1981.

Hofmann, A. W., and W. M. White, Mantle plumes from ancient oceanic crust, Earth Planet. Sci. Lett., 57, 421-436, 1982.

Hollister, L. S., G. C. Grissom, E. K. Peters, H. H. Stowell, and V. B. Gisson, Confirmation of the empirical correlation of $\mathrm{Al}$ in hornblende with pressure of solidification of calc-alkaline plutons, $A \mathbf{m}$. Mineral., 72, 231-239, 1987.

Huang, W. L., and P. J. Wyllie, Phase relationships of $S$-type granite with $\mathrm{H}_{2} \mathrm{O}$ to $35 \mathrm{kbar}$ : Muscovite granite from Harney Peak, South Dakota, J. Geophys. Res., 86, 1015-1029, 1981.

Huang, W. L., and P. J. Wyllie, Phase relationships of gabbrotonalite-granite-water at 15 kilobar with applications to differentiation and anatexis, Am. Mineral., 71, 301-316, 1986.

Huang, W. L., P. J. Wyllie, and C. E. Nehru, Subsolidus and liquidus phase relationships in the system $\mathrm{CaO}-\mathrm{SiO}_{2}-\mathrm{CO}_{2}$ to $30 \mathrm{kbar}$ with geological applications, Am. Mineral., 65, 285-301, 1980.

Jacobsen, S. B., and G. J. Wasserburg, Transport models for crust and mantle evolution, Tectonophysics, 75, 163-179, 1981.

Jaques, A. L., and D. H. Green, Anhydrous melting of peridotite at $0-15 \mathrm{~kb}$ pressure and the genesis of tholeiitic basalts, Contrib. $\mathrm{Min}$ eral. Petrol., 73, 287-310, 1980.

Jeanloz, R., and F. M. Richter, Convection, composition, and the thermal state of the lower mantle, J. Geophys. Res., 84, 5497-5504, 1979.

Johnston, A. D., Anhydrous P-T relations of near-primary highalumina-basalt from the South Sandwich Islands: Implications for the origin of island arcs and tonalite-trondhjemite series rocks, Contrib. Mineral. Petrol., 92, 368-382, 1986.

Johnston, A. D., and P. J. Wyllie, Interaction of slab-derived melts with mantle peridotite: Experimental constraints at $\mathbf{3 0}$ kbar with $\mathrm{H}_{2} \mathrm{O}$ (abstract), Eos Trans. $A G U, 67,405,1986 a$.

Johnston, A. D., and P. J. Wyllie, Simulated $\mathrm{H}_{2} \mathrm{O}$-undersaturated two-layer magma chambers: Rhyolite above basalt, 10-30 kbar (abstract), in Abstracts With Programs 1986 Cordilleran Section, p. 122, Geological Society of America, Boulder, Colo., $1986 b$.

Johnston, A. D., and P. J. Wyllie, Interaction of granite and basic magmas: Experimental observations on contamination processes at 10 kbar with $\mathrm{H}_{2} \mathrm{O}$, Contrib. Mineral. Petrol., 98, 352-362, 1988.

Kushiro, I., Y. Syono, and S. Akimoto, Melting of a peridotite nodule at high pressures and high water pressures, J. Geophys. Res., 73, 6023-6029, 1968.

Maaløe, S., Magma accumulation in the ascending mantle, J. Geol. Soc. London, 138, 223-236, 1981
Maaløe, S., and T. S. Petersen, Petrogenesis of oceanic andesites, $J$. Geophys. Res., 86, 10,273-10,286, 1981.

Maaløe, S., and A. Scheie, The permeability controlled accumulation of primary magma, Contrib. Mineral. Petrol., 81, 350-357, 1982.

Marsh, B. D., Island-arc volcanism, Am. J. Sci., 67, 161-172, 1979.

Marsh, B. D., Magmatic processes, Rev. Geophys., 25, 1043-1053, 1987.

McCallum, I. S., Petrology of the igneous rocks, Rev. Geophys., 25, 1021-1042, 1987.

McKenzie, D. P., The generation and compaction of partial melts, $J$. Petrol., 25, 713-765, 1984.

Menzies, M., and C. J. Hawkesworth (Ed.), Mantle Metasomatism Academic, San Diego, Calif., 1987.

Mysen, B. O., and I. Kushiro, Compositional variations of coexisting phases with degree of melting of peridotite in the upper mantle, $A m$. Mineral., 62, 843-856, 1977

Navon, O., and E. Stolper, Geochemical consequences of melt percolation: The upper mantle as a chromatographic column, J. Geol., 95, 285-397, 1987.

Nehru, C. E., and P. J. Wyllie, Compositions of glasses from St. Paul's peridotite partially melted at 20 kilobars, $J$. Geol., 83, 455-471, 1975

Nicholls, I. A., and A. E. Ringwood, Effect of water on olivine stability in tholeiites and production of silica-saturated magmas in the island arc environment, J. Geol., 81, 285-300, 1973.

Nickel, K. G., and D. H. Green, Empirical geothermobarometry for garnet peridotites and implications for the nature of the lithosphere, kimberlites and diamonds, Earth Planet. Sci. Lett., 73, 158$170,1985$.

Nisbet, E. G., and D. Walker, Komatiites and the structure of the Archean mantle, Earth Planet. Sci. Lett., 60, 105-113, 1982.

Nixon, P. H. (Ed.), Mantle Xenoliths, John Wiley, New York, 1987

Ohtani, E., The primordial terrestrial magma ocean and its implication for stratification of the mantle, Phys. Earth Planet. Inter., 38 70-80, 1985.

Olafsson, M., and D. H. Eggler, Phase relations of amphibolecarbonate, and phlogopite-carbonate peridotite: Petrologic constraints on the asthenosphere, Earth Planet. Sci. Lett., 64, 305-315, 1983.

Presnall, D. C., and C. E. Helsley, Diapirism of depleted peridotiteA model for the origin of hot spots, Phys. Earth Planet. Inter., 29, 148-160, 1982.

Presnall, D. C., J. R. Dixon, T. H. O'Donell, and S. A. Dixon, Generation of mid-ocean ridge tholeiites, J. Petrol., 20, 3-35, 1979.

Ribe, N. M., and M. D. Smooke, A stagnation point flow model for melt extraction from a mantle plume, J. Geophys. Res., 92, 64376443, 1987.

Richter, F. M., and D. P. McKenzie, On some consequences and possible causes of layered mantle convection, J. Geophys. Res., 86, 6133-6142, 1981.

Rigden, S. M., T. J. Ahrens, and E. M. Stolper, Densities of liquid silicates at high pressures, Science, 226, 1071-1074, 1984.

Ringwood, A. E., Composition and Petrology of the Earth's Mantle, McGraw-Hill, New York, 1975.

Ringwood, A. E., Phase transformation and differentiation in subducted lithosphere: Implications for mantle dynamics, basalt petrogenesis, and crustal evolution, J. Geol., 90, 611-643, 1982.

Rutter, M. J., and P. J. Wyllie, Experimental evidence for the chemical effects of interaction between hydrous silicic melts and hornblendegabbro at upper crustal pressures (abstract), Eos Trans. AGU, 67, 1279,1986

Rutter, M. J., and P. J. Wyllie, Melting of vapour-absent tonalite at 10 kbar to simulate dehydration-melting in the deep crust, Nature, $331,159-160,1988 a$.

Rutter, M. J., and P. J. Wyllie, Experimental calibration of hornblende as a proposed empirical geobarometer, Eos. Trans. $A G U$, $69,86-87,1988 b$.

Ryabchikov, I. D., D. H. Green, W. J. Wall, and G. P. Brey, The oxidation state of carbon in the reduced-velocity zone, Geochem. Int. 1981, 148-158, 1981.

Schneider, M. E., and D. H. Eggler, Compositions of fluids in equilibrium with peridotite: Implications for alkaline magmatismmetasomatism, in Kimberlites I: Kimberlites and Related Rocks, edited by J. Kornprobst, pp. 383-394, Elsevier, New York, 1984.

Schneider, M. E., and D. H. Eggler, Fluids in equilibrium with peridotite minerals: Implications for mantle metasomatism, Geochim. Cosmochim. Acta, 50, 711-724, 1986.

Schreyer, W., H.-J. Massonne, and C. Chopin, Continental crust sub- 
ducted to depths near $100 \mathrm{~km}$ : Implications for magma and fluid genesis in collision zones, in Magmatic Processes: Physicochemical Principles, Geochem. Soc. Spec. Publ. 1, edited by B. O. Mysen, pp. 155-163, Pergamon, New York, 1987.

Scott, D. R., and D. J. Stevenson, Magma ascent by porous flow, $J$. Geophys. Res., 91, 9283-9296, 1986.

Sekine, T., and P. J. Wyllie, The system granite-peridotite- $\mathrm{H}_{2} \mathrm{O}$ at 30 kbar, with applications to hybridization in subduction zone magmatism, Contrib. Mineral. Petrol., 81, 190-202, 1982.

Sekine, T., and P. J. Wyllie, Experimental simulation of mantle hybridization in subduction zones, J. Geol., 91, 511-528, 1983.

Sekine, T., P. J. Wyllie, and D. R. Baker, Phase relationships at 30 kbar for quartz eclogite composition in $\mathrm{CaO}-\mathrm{MgO}$ $\mathrm{Al}_{2} \mathrm{O}_{3}-\mathrm{SiO}_{2}-\mathrm{H}_{2} \mathrm{O}$ with implications for subduction zone magmas, Am. Mineral., 66, 938-950, 1981.

Sparks, R. S. J., and L. A. Marshall, Thermal and mechanical constraints on mixing between mafic and silicic magmas, J. Volcanol. Geotherm. Res., 29, 99-124, 1986.

Spera, F. J., Carbon dioxide in petrogenesis III: Role of volatiles in the ascent of alkaline magma with special reference to xenolithbearing mafic lavas, Contrib. Mineral. Petrol., 88, 217-232, 1984.

Stern, C. R., and P. J. Wyllie, Phase compositions through crystallization intervals in basalt-andesite- $\mathrm{H}_{2} \mathrm{O}$ at $30 \mathrm{kbar}$ with implications for subduction zone magmas, Am. Mineral., 63, 641-663, 1978.

Stern, C. R., and P. J. Wyllie, Phase relationships of I-type granite with $\mathrm{H}_{2} \mathrm{O}$ to $35 \mathrm{kbar}$ : The Dinkey Lakes biotite granite from the Sierra Nevada batholith, J. Geophys. Res., 86, 10,412-10,422, 1981.

Stern, C. R., W. L. Huang, and P. J. Wyllie, Basaltandesite-rhyolite- $\mathrm{H}_{2} \mathrm{O}$ : Crystallization intervals with excess $\mathrm{H}_{2} \mathrm{O}$ and $\mathrm{H}_{2} \mathrm{O}$-undersaturated liquidus surfaces to 35 kilobars with implications for magma genesis, Earth Planet. Sci. Lett., 28, 189-196, 1975.

Stolper, E., and D. Walker, Melt density and the average composition of basalt, Contrib. Mineral. Petrol., 74, 7-12, 1980.

Sullivan, W., Continents in Motion, McGraw-Hill, New York, 1974.

Takahashi, E., Melting of dry peridotite KLB-1 up to 14 GPa: Implications on the origin of peridotitic upper mantle, J. Geophys. Res., 91, 9367-9382, 1986.

Takahashi, E., and I. Kushiro, Melting of dry peridotite at high pressures and basalt magma genesis, Am. Mineral., 68, 859-879, 1983.

Tanimoto, T., Three dimensional reconstruction of Pangaea, Geophys. Res. Lett., 14, 235-238, 1987.

Taylor, W. R., and D. H. Green, The petrogenetic role of methane: Effect on liquidus phase relations and the solubility mechanism of reduced C-H volatiles, in Magmatic Processes: Physicochemical Principles, Geochem. Soc. Spec. Publ. 1, edited by B. O. Mysen, pp. 121-138, Pergamon, New York, 1987.

Toksöz, N. M., and A. T. Hsui, Numerical studies of back-arc convection and the formation of marginal basins, Tectonophysics, 50, 177$196,1978$.

Wasserburg, G. J., Isotopic abundances: Inferences on solar system and planetary evolution, Earth Planet. Sci. Lett., 86, 129-173, 1987.

Watson, E. B., Diflusion in magmas at depth in the Earth: The effects of pressure and dissolved $\mathrm{H}_{2} \mathrm{O}$, Earth Planet. Sci. Lett., 52, 291-301, 1981.

Watson, E. B., Basalt contamination by continental crust: Some experiments and models, Contrib. Mineral. Petrol., 80, 73-87, 1982.

Watson, E. B., and J. B. Brenan, Fluids in the lithosphere, 1, Experimentally determined wetting characteristics of $\mathrm{CO}_{2}-\mathrm{H}_{2} \mathrm{O}$ fluids and their implications for fluid transport, host-rock physical properties, and fluid inclusion formation, Earth Planet. Sci. Lett., 85, 497-515, 1987.

Watson, E. B., and S. R. Jurewicz, Behavior of alkalis during diffusive interaction of granitic xenoliths with basaltic magma, J. Geol., 92, 121-131, 1984.

Wendlandt, R. F., An experimental and theoretical analysis of partial melting in the system $\mathrm{KAlSiO}_{4}-\mathrm{CaO}-\mathrm{MgO}-\mathrm{SiO}_{2}-\mathrm{CO}_{2}$ and applications to the genesis of potassic magmas, carbonatites and kimberlites, in Kimberlites I: Kimberlites and Related Rocks, edited by J. Kornprobst, pp. 359-369, Elsevier, New York, 1984.

Wendlandt, R. F., and D. H. Eggler, The origins of potassic magmas, 2, Stability of phlogopite in natural spinel lherzolite and in the system $\mathrm{KAlSiO}$ - $-\mathrm{MgO}-\mathrm{SiO}_{2}-\mathrm{H}_{2} \mathrm{O}-\mathrm{CO}_{2}$ at high pressures and high temperatures, Am. J. Sci., 280, 421-458, 1980.
Wendlandt, R. F., and P. Morgan, Lithospheric thinning associated with rifting in East Africa, Nature, 298, 734-736, 1982.

Wickham, S. M., and H. P. Taylor, Jr., Stable isotope constraints on the origin and depth of penetration of hydrothermal fluids associated with Hercynian regional metamorphism and crustal anatexis in the Pyrenees, Contrib. Mineral. Petrol., 95, 255-268, 1987.

Williams, Q., R. Jeanloz, J. Bass, B. Svendsen, and T. J. Ahrens, The melting curve of iron to 250 gigapascals: A constraint on the temperature at Earth's center, Science, 236, 181-182, 1987.

Wilshire, H. G., Mantle metasomatism: The REE story, Geology, 12, 395-398, 1984.

Woermann, E., and M. Rosenhauer, Fluid phases and the redox state of the Earth's mantle: Extrapolations based on experimental, phase-theoretical and petrological data, Fortschr. Mineral., 63, 263$349,1985$.

Woodhouse, J. H., and A. M. Dziewonski, Mapping the upper mantle: Three-dimensional modeling of Earth structure by inversion of seismic wave forms, J. Geophys. Res., 89, 5953-5986, 1984.

Wright, T. L., and R. T. Helz, Recent advances in Hawaiian petrology and geochemistry, Volcanism in Hawaii, vol. 1., edited by R. W. Decker, T. L. Wright, and P. H. Stauffer, U.S. Geol. Surv. Prof. Pap., 1350, 625-640, 1987.

Wyllie, P. J., The Dynamic Earth, John Wiley, New York, 1971

Wyllie, P. J., Crustal anatexis: An experimental review, Tectonophysics, 13, 41-71, 1977.

Wyllie, P. J., Water and magma generation at subduction zones, Bull. Volcanol., 41-4, 360-377, 1978a.

Wyllie, P. J., Peridotite- $\mathrm{CO}_{2}-\mathrm{H}_{2} \mathrm{O}$ and the low-velocity zone, Bull. Volcanol., 41-4, 670-683, $1978 b$.

Wyllie, P. J., Mantle fluid compositions buffered in peridotite- $\mathrm{CO}_{2}-\mathrm{H}_{2} \mathrm{O}$ by carbonates, amphibole, and phlogopite, $J$. Geol., 86, 687-813, 1978c.

Wyllie, P. J., Magmas and volatile components, Am. Mineral., 64, 469-500, 1979.

Wyllie, P. J., The origin of kimberlites, J. Geophys. Res., 85, 6902$6910,1980$.

Wyllie, P. J., Plate tectonics and magma genesis, Geol. Rundsch., 70, 128-153, 1981.

Wyllie, P. J., Constraints imposed by experimental petrology on possible and impossible magma sources and products, Philos. Trans. R. Soc. London, Ser. A, 310, 439-456, 1984.

Wyllie, P. J., Transfer of subcratonic carbon into kimberlites and rare earth carbonatites, in Magmatic processes: Physicochemical Principles, Geochem. Soc. Spec. Publ. 1, edited by B. O. Mysen, pp. 107-119, Pergamon, New York, 1987a.

Wyllie, P. J., Discussion of recent papers on carbonated peridotite, bearing on mantle metasomatism and magmatism, Earth Planet. Sci. Lett., 82, 391-397, 1987b.

Wyllie, P. J., Response, Earth Planet. Sci. Lett., 82, 401-402, 1987c.

Wyllie, P. J., Solidus curves, mantle plumes, and magma generation beneath Hawaii, J. Geophys. Res., 93, 4171-4181, 1988a.

Wyllie, P. J., Origin of carbonatites-Evidence from phase equilibrium studies, in Carbonatites-Genesis and Evolution, edited by $\mathrm{K}$. Bell, Allen and Unwin, London, in press, $1988 b$.

Wyllie, P. J., and M. J. Rutter, Experimental data on the solidus for peridotite- $\mathrm{CO}_{2}$, with applications to alkaline magmatism and mantle metasomatism (abstract), Eos Trans. AGU, 67, 390, 1986.

Wyllie, P. J., and T. Sekine, The formation of mantle phlogopite in subduction zone hybridization, Contrib. Mineral. Petrol., 79, 375380, 1982.

Wyllie, P. J., C. J. Donaldson, A. J. Irving, S. E. Kesson, R. B. Merrill, D. C. Presnall, E. M. Stolper, T. M. Usselman, and D. Walker, Experimental petrology of basalts and their source rocks, in $B a$ saltic Volcanism on the Terrestrial Planets, Basaltic Volcanism Study Project, pp. 492-630, Pergamon, New York, 1981.

Wyllie, P. J., W. L. Huang, J. Otto, and A. P. Byrnes, Carbonation of peridotites and decarbonation of siliceous dolomites represented in the system CaO-MgO-SiO ${ }_{2}-\mathrm{CO}_{2}$ to $30 \mathrm{kbar}$, Tectonophysics, 100 , 359-388, 1983.

P. J. Wyllie, Division of Geological and Planetary Sciences, California Institute of Technology, 170-25, Pasadena, CA 91125.

(Received December 9, 1987; accepted March 17, 1988.) 